\title{
MHD Integrated Topping Cycle Project
}

\section{Seventeenth Quarterly Technical Progress Report}

\section{Report No. MHD-ITC-92-126}

\author{
Date Submitted: July 1992 \\ Period Covered: $\quad$ August 1991 through Ostober 1991
Reporting Organization: Applied Technology Division TRW Space and Technology Group One Space Park \\ Redondo Beach, Califomia 90278 \\ Sponsoring Organization: U.S. Deparment of Energy \\ Pitusburgh Energy Technology Center \\ Contract Number: \\ DE-ACC22-87PC90274
}


TABLE OF CONTENTS

Executive Summary

Page

1. INTRODUCTION

ix

2. PROJECT DESCRIPTION

3. SYSTEMS ENGINEERING (TASK 1)

3.1 SYSTEM/SUBSYSTEM DOCUMENTATION

3.1.1 Interface Documentation

3.1.2 Channel Requirements Document

3.1.3 Channel Dry-Out Requirements

3.1.4 Integrated Schedule Review

4. COMBUSTION SUBSYSTEM DESIGN AND FABRICATION (TASK 2)

4.1 COMBUSTION SUBSYSTEM DESIGN ACTIVITIES (SUBTASK 2.1.3)

4.1.1 Combustor Installation

4.1.2 L.PCS Water Electrical Isolator

4.1.3 Panel Coolant Channel Cleaning

4.1.4 Second Stage Brazing Development

4.2 COMBUSTION SUBSYSTEM MANUFACTURING (SUBTASK 2.2.1)

4.2.1 Prototypical Combustor Manufacturing

4.2.2 Low Pressure Cooling Subsy'stem (L.PCS) Procurement

5. PROTOTYPICAL CHANNEL DESIGN

5.1 CHANNEL DESIGN STATUS (TASK 3)

5.1.1 Tungsten-Copper Base Sidewall Tube Cracking Investigation 5-1

\subsubsection{Background}

5.1.1.2 Design

5.1.1.3 Root Cause Investigation

5.1.1.4 Corrective Action

5.1.2 1A4 Sidewall Design and Manufacturing Decisions $\quad 5.5$

5.2 CHANNEL FABRICATION STATUS (TASK 3)

5.2 .1 Schedule $5-5$

5.2.2 Cathode Wall 5-5

5.2 .3 Sidewalls $5-5$

5.2.4 Anode Wall 5-5

5.2.5 Manifolding and Supporring Brackets $\quad 5.9$

5.3 DIFFUSER DESIGN (TASK 4)

5.3.1 Surnmary $5-9$

5.3.2 Mechanical Design $\quad 5-9$ 


\section{TABLE OF CONTENTS (Continued)}

5.3.3 Cooling Water Design

5.3.4 Diffuser Status

6. CURRENT CONSOLIDATION SUBSYSTEM DESIGN AND FABRICA'TION (TASK 5)

6.1 CURRENT CONSOLIDATION DIODE STACK 6-1

6.1.1 Diode Stack Overview and Principle of Operation 6-1

6.1.2 Diode Stack Construction $6-7$

6.1.3 Diode Stack Connections 6.7

6.1.3.1 Connection to 115 VAC $6-7$

6.1.3.2 Connection wo Inverter Negative Bus 6-7

6.1.3.3 Connection from SCR Cathode to MSE Resistors or Dioule Anodes $6-7$

6.1.3.4 Connection to Anodes and Cathodes of Diodes 6-7

6.1.3.5 Connection to Anode Local Control $6-9$

6.1.4 Westinghouse Pre-Operation Tests $6-9$

6.2 POWER CABINET CONSTRUCTION 6-9

7. CDIF TESTING $7-1$

7.1 WORKHORSE POWER TRAIN TESTTNG AT THE CDIF (SUBTASK 6.3) 7-1

7.1.1 Objectives of Workhorse Test Program 7-1

$\begin{array}{ll}7.1 .2 & \text { Approach } \\ 7.1 .3 & 7.2\end{array}$

$\begin{array}{lll}7.1 .3 & \text { Test Summaries } & 7-2\end{array}$

7.2 CDIF HARDWARE ACTIVITIES

7.2.1 Combustion Subsystem Activities - Rectangular Second Stage Installation 7-2

$\begin{array}{ll}7.2 .2 & \text { Channel Subsystem Activities } \\ 7.2 .3 & 7-2\end{array}$

$\begin{array}{ll}7.2 .3 \text { Slag Rejector Activities } & 7-4\end{array}$

$\begin{array}{ll}7.3 \text { CDIF SYSTEM ACTVTTIES } & 7-7\end{array}$

7.3.1 Primary Cooling Water System (PCW)

$\begin{array}{ll}\text { 7.3.2. Iron Oxide System } & \text { 7-7 }\end{array}$

7.3.3 Coal System - Coal Mass Flow Meter Calibration 7.8

$\begin{array}{lll}7.3 .4 & \text { Seed System } & 7-9\end{array}$

$\begin{array}{lll}7.3 .5 & \text { Magnet } & 7.9\end{array}$

$\begin{array}{lll}\text { 7.3.6 Oxygen System Upgrade } & 7-10\end{array}$

$\begin{array}{ll}\text { 7.3.7 Westinghouse Current Consolidation Cabinet Installation } & 7-10\end{array}$

7.3.8 Data Acquisition System (DAS) Installation and Checkout $\quad 7-10$

$\begin{array}{ll}\text { 7.3.9 High Voltage Room Modifications } & 7-10\end{array}$

$\begin{array}{ll}\text { 7.3.10 Stack Emissions Compliance } & 7-11\end{array}$ 
TABLE OF CONTENTS (Continued)

\subsection{TEST PLANS}

Page

7.4.1 Baseline Power Takeoff Tests

$7-11$

7.4.2 Anode Sidebar-to-Anode Middle Bar Shorting

$7-11$

7.4.3 Electrical Test

$7-11$

$7-13$

8. MODELING AND PERFORMANCE ANALYSIS ACTIVITIES (SUBTASK 1.3)

8-1

9. TTIRC AND POC INTEGRATION 'TASK FORCE ACTIVITIES (TASK 8)

9-1

10. PLANNED ACTIVITIES

$10-1$

11. SUMMARY

$11-1$

12. QUARTERLY REPORT DISTRIBUTION LIST

$12-1$

APPENDIX A. NOMENCLATURE

A-1 


\section{LIST OF FIGURES}

Figure

4-1 Combustor Support System

4-2 Overall Combustor Installation

4-3 Water Electrical Isolator

4.4 Isolator Details

4-5 Isolator Instrumentation/Diagnostics

4-6 Prototypical Combustor Pressure Shell Components

4-7 Combustor Pressure Shell Fit Check Assembly

4-8 Cooling Panels with RTV88 Bonded to the Backside

4-9 Endplate Assembly

4-10 Precombustor Internal Components 4-10

4-11 Baffle Plate with Covers Welded in Place (Prior to Heat Treatment) 4-11

4-12 Simplified LPCS Schematic 4-12

4-13 LPCS Equipment Layout (Plan View) 4-14

4-14 LPCS Equipment Layout (Elevation View)

4-15 LPCS Component Assembly: A. Main Pump No. 1; B. "Night-Jockey" Circulation Pump 4-16

4-16 LPCS Component Assembly: A. Plate Heat Exchanger, B. Coolant Purification System 4-17

5-1 1 A4 Channel Sidewall Gas-Side Material Zone Layout

5-2 1A4 Sidewall Z-Bar Elements

5-3 Water Tube Crack Investigation Logic $5-4$

5-4 Channel and Diffuser Fabrication Schedule 5-6

5-5 Channel and Diffuser Fabrication Schedule (Continued) 5-7

5-6 Channel and Diffuser Fabrication Schedule (Continued) $\quad 5-8$

5-7 Cathode Wall Wiring $5-9$

5-8 Cathode Wall Wiring Panel $\quad$ 5-10

5-9 Sidewall Water Tube Brazing 5-11

5-10 Partially Assembled Sidewall $\quad$ 5-12

5-11 Anode Cap Subassembly Fixturing 5-13

5-12 Anode Cap Subassembly Ultrasourd Inspection Records 5-13

5-13 Water Manifolds and Brackets - End View 5-14

5-14 Water Manifolds and Brackets - Top View 5-14

5-15(a) Diffuser Comparisons: CDIF 1A1

5-15(b) Diffuser Comparisons: CDIF 1A4 5-15

5-16 Typical Hosing Scheme for 1A4 Aft Diffuser Sections $5-16$

6-1 Connection to the 1A1 Anode $6-2$

6-2. Diode Stack Right Side View 6-3 


\section{LIST OF FIGURES (Continued)}

Figure

Page

6-3

Diode Stack Intemal View

$6-4$

6-4 Diodes on individual Heat Sinks

6-5

6-5 Diode Stack SCR Switch

$6-6$

6-6 Diode Stack Assembly Drawing

$6-8$

6-7 Installation of Shelving for Switch Modules

$6-10$

7-1 CFC Second Stage Configuration - CDIF - 50SS - 910829

$7-3$

7-2 Location of 1A4 Test Coupons in 1A1 Right Forwand Sidewall

$7-5$

7-3 Location of 1A.4 Test Coupons in 1A1 Left Forward Sidewall

$7-5$

7-4 Slag Rejection System Schematic

7.6

7-5 Slag Removal Schematic

$7-7$

7-6 Iron Oxide Flow Circuit Instrumentation.

7.8 


\section{LIST OF TABLES}

Table

Page

2-1 MHD ITC Task Objectives $\quad$ 2-2

4-1 LPCS Water Electrical Isolator Design Requirements

4-2 LPCS Water Electrical Isolator Design Parameters $4-5$

5-1 Cooling Water Requirements $\quad$ 5-17

7-1 CDIF 18th Quarter Test Plans $\quad$ 7-12 


\section{EXECUTIVE SUMMARY}

This seventeenth quarterly technical progress report of the MHD Integrated Topping Cycle Project presents the accomplishments during the period August 1, 1991 to October 31, 1991. A summary of the work completed during this reporting period is presented in this Executive Summary.

\section{SYSTEMS ENGINEERING (SECTION 3)}

The Interface Document was sent out for final review prior to CADM release.

The High Voltage Room requirements for the prototypical power train were reviewed in conjunction with the Channel Requirements Document.

The initial release of the channel dry-out requirements was sent to MSE for review.

The overall integrated schedule for MSE, TRW, TDS, and Westinghouse was reviewed.

\section{COMBUSTION SUBSYSTEM DESIGN AND FABRICATION (SECTION 4)}

Manufacturing of the prototypical combustor pressure shell has been completed including leak, proof, and assembly fit checking. Manufacturing of forty-five cooling panels was also completed including leak, proof, and flow testing.

All precombustor internal components (combustion can, baffle and swirl box) were received and checked, and integration of the components was initiated.

Manufacturing of all other lead items is well in progress including the LPCS.

Design of the servicing platforms and LPCS/combustor connecting piping was completed.

\section{PROTOTYPICAL CHANNEL DESIGN (SECTION 5)}

A decision was made regarding the primary and backup designs for the 1A4 channel. As a result of coupon manufacturing and design confirmation testing, it became evident that the tungsten-copper base designs had not matured sufficiently to be carried forward as the primary design without affecting the overall delivery of the 1A4 channel. Therefore, a decision was made to go forward with the copper base designs as the primary design and to utilize the tungsten-copper base elements as the backup design. This approach provides the capability of immediately proceeding with the $1 \mathrm{~A} 4$ sidewall manufacturing while, at the same time, carrying to completion the manufacturing development and confirmation testing of the tungsten-copper base elements. Both primary and backup design elements will be included in the initial channel build for DVT testing.

The assembly of the channel related prototypical hardware continued. The cathode wall electrical wiring is now complete. Sidewall assembly is well underway, with completion dates of February and March 1992 expected for the two sidewalls. Anode cap subassemblies are presently undergoing braze attachment of the platinum top caps to the tungsten substrates. Cooling water manifolds and their supporting brackets have been designed and ordered.

The mechanical design of the diffuser has been completed. The forward supersonic diffuser section in the 1 A4 channel is a new design and it features electrical segmentation to minimize current circulation. The three remaining diffuser sections (i.e., aft supersonic, forward subsonic, and aft subsonic) will be the standard copper design. They will be constructed by modifying the existing $1 \mathrm{~B} 2$ diffuser, thus eliminating the costly process of gun-drilling cooling water passages in new walls.

\section{CURRENT CONSOLIDATION SUBSYSTEM DESIGN AND FABRICATION (SECTION 6)}

Construction of the diode stack was completed this quarter. It was delivered to the CDIF site in September where it will be installed to support the fall test series. Construction of the power cabinets continues with installation of shelving for the switch modules. 


\section{CDIF TESTING (SECTION 7)}

Activities at the CDIF this quarter were focus :d on the installation of new power train components and on facility upgrades to support long duration testing. No testing of the power train was conducted during this reporting period.

The primary power train hardware activities performed at the CDIF during this reporting period included:

1) Installation of the rectangular cross-section, prototypical combustor second stage assembly.

2) Installation of new and refurbished prototypical channel elements in the workhorse $1 \mathrm{~A} 1$ channel.

The key facility projects completed or nearing completion included:

1) Installation of the new Data Acquisition System (DAS)

2) Installation of expanded oxygen system storage capacity

3) Installation of the facility slag removal equipment

4) Repair and checkout of the magnet.

Workhorse power train testing is current'y scheduled to begin in late November 1991 and will continue through January 1992. This will be the last workhorse power train test series conducted prior to the installation of the prototypical hardware. The total number of test hours (thermal) during this test series will be restricted in order to comply with an emission ceiling on carbon monoxide production ( $250 \mathrm{tons} /$ year) at the CDIF.

\section{MODELING AND PERFORMANCE ANALYSIS ACTIVITIES (SECTION 8)}

Power train modeling and perfornance analysis activities were focused on the following areas: analysis of seed utilization tests conducted in May 1991; evaluation of the combustor slag rejection requirement; improved modeling of the combustor slag rejection process; evaluation of coal and slag sampling procedures at the CDIF; and general test planning support for the fall 1991 test series at the CDIF.

\section{TTIRC (SECTION 9)}

The Power Management Working Group (an ad-hoc committee of the POC Task Force responsible for the integration of the subsystems which comprise channel power management) met at TRW on 1 August and 12 October to re-evaluate the PTO configurations as a result of two new system level requirements:

- Protection of the consolidation circuity against reverse voltage.

- Distribution of excess current into the indirectly controlled electrode(s) resulting from high speed load current fluctuations.

As a result, a modified indirectly controlled electrode concept and additional PTO circuitry have been proposed.

\section{SCHEDULE}

The overall schedule for the ITC project is shown on the following pages. 


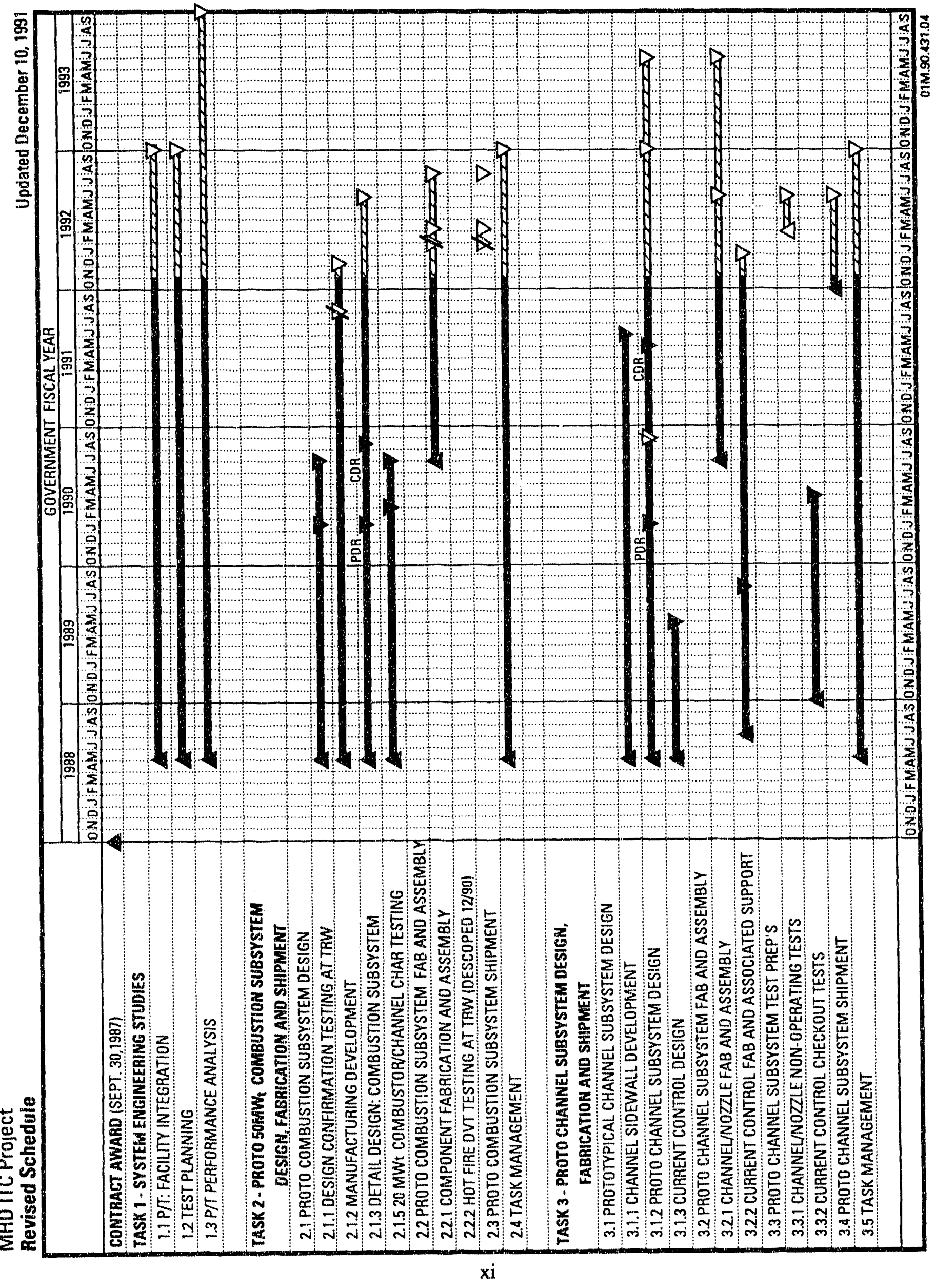




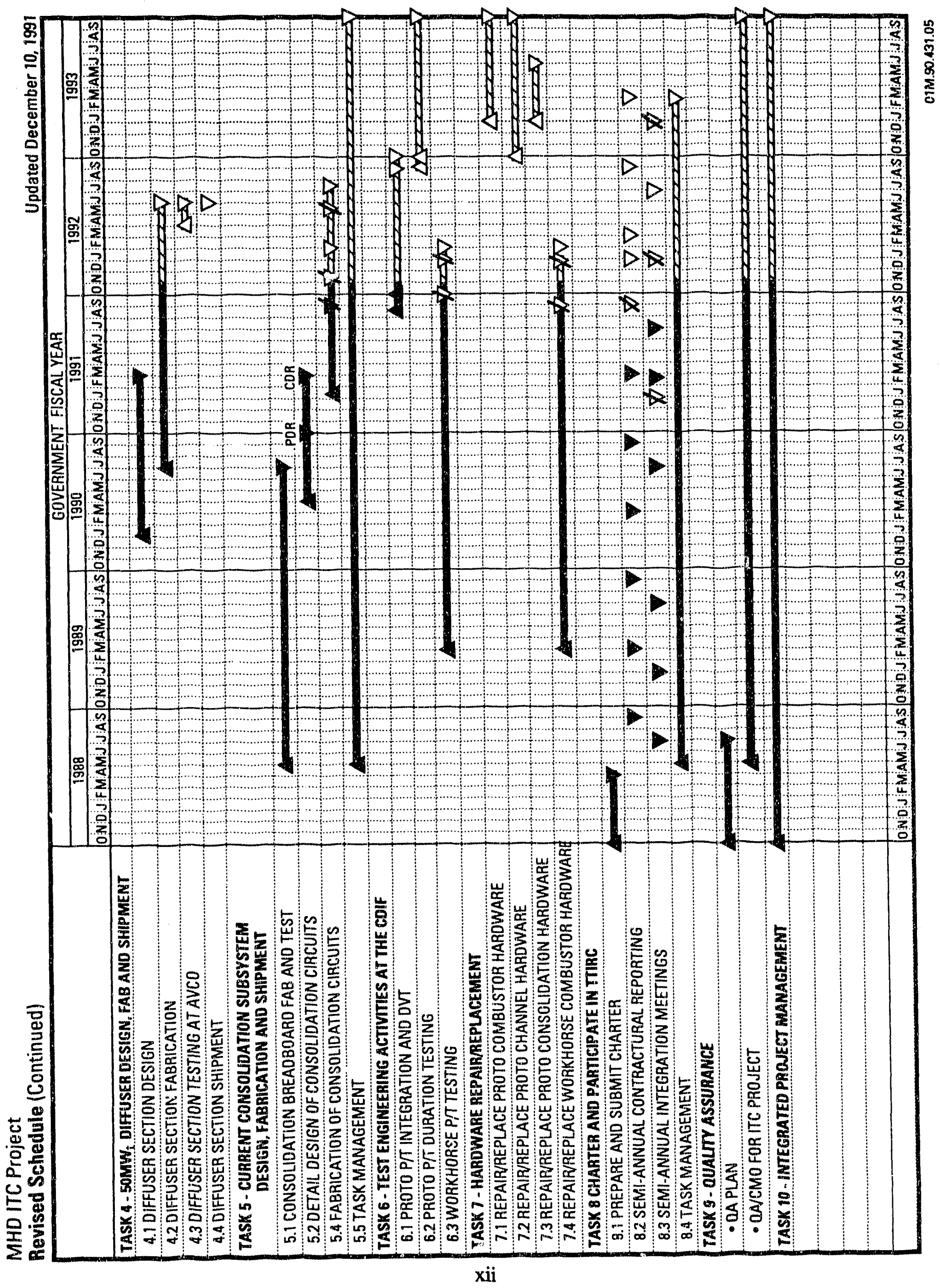




\section{INTRODUCTION}

The Magnetohydrodynamics (MHD) Integrated Topping Cycle (ITC) Project represents the culmination of the proof-of-concept (POC) development stage in the U.S. Department of Energy (DOE) program to advance MHD technology to early commercial development stage utility power applications. The project is a joint effort, combining the skills of three topping cycle component developers: TRW, TDS, and Westinghouse. TRW, the prime contractor and system integrator, is responsible for the 50 thermal megawatt ( $50 \mathrm{MW}_{\mathrm{D}}$ ) slagging coal combustion subsystem. TDS is re ponsible for the MHD channel subsystem (nozzle, channel, diffuser, and power conditioning circuits), and Westinghouse is responsible for the current consolidation subsystem.

The ITC Project will advance the state-of-the-art in MHD power systems with the design, construction, and integrated testing of $50 \mathrm{MW}$ power train components which are prototypical of the equipment that will be used in an early commercial scale MHD utility retrofit. Long duration testing of the integrated power train at the Component Development and Integration Facility (CDIF) in Butte, Montana will be performed, so that by the early 1990 's, an engineering data base on the reliability, availability, maintainability and performance of the system will be available to allow scaleup of the prototypical designs to the next development level.

Ten tasks comprise the ITC Project.

Task 1 - Systems Engineering Studies

Task 2 - $50 \mathrm{MW}_{\mathrm{t}}$ Combustor Design, Fabrication, and Shipment

Task 3 - $50 \mathrm{MW}_{\mathrm{t}}$ Channel Design, Fabrication, and Shipment

Task 4 - Diffuser Design, Fabrication, and Shipment

Task 5 - Power Conditioning Design, Fabrication, and Shipment

Task 6 - Test Engineering Activities at the CDIF

Task 7 - Hardware Repair/Replacement

Task 8 - MHD Technology Transfer/Integration

Task 9 - Quality Assurance

Task 10 - Integrated Project Management

This Seventeenth Quarterly Technical Progress Report covers the period August. 1, 1991 to October 31, 1991. The report is organized into sections which roughly follow the above task structure. The first section is this introduction. Section 2 contains a concise description of the contract tasks to be performed and their objectives. Section 3 summarizes the systems engineering activities in Subtask 1.1. Sections 4 through 7 summarize progress on the combustion subsystem (Task 2), channel subsystem (Tasks 3 and 4), and current consolidation subsystem (Task 5) for this reporting period, and discuss testing at the CDIF (Subtasks 1.2 and 6.3). Section 8 reporis the results of ongoing power train performance analyses which are part of Subtask 1.3. Activities of the Technology Transfer, Integration and Review Committee (TTIRC) are reported in Section 9. Planned activities during the next reporting period are summarized in Section 10. Section 11 is a brief summary of the work performed during the quarter, and Section 12 is the distribution list for this report. 


\section{PROJECT DESCRIPTION}

The overall objective of the project is to design and constnuct prototypical handware for an integrated MHD topping cycle, and conduct long duration proof-of-concept tests of the integrated systern at the U.S. DOE Component Development and Integration Facility (CDIF) in Butte, Montana. The results of the long duration tests will augment the existing engintering design data base on MHD power train reliability, availability, maintainability, and performance, and will serve as a basis for scaling up the topping cycle design to the next level of development, an early commercial scale power plant natrofit.

The components of the MHD power train to be designed, fabricated, and tested include:

- A slagging coal combustor with a rated capacity of $50 \mathrm{MW}$ thermal inpul. capable of operation with an Eastem (Tllinois No. 6) or Wesiem (Montana Rusebud) coal,

- A segmented supersonic rozzic,

- A supersonic MHD channel capable of generating at least 1.5 MW of electrical power,

- A segmented supersonic diffuser section to interface the channel with existing facility quench and exhaust systems,

- A complete set of current contml circuits for local diagonal current control along the channel, and

- A set of current consolidation circuits to interface the channel with the existing facility inverter.

Specific objectives of the i s contract tasks are shown in Table 2-1. The overall approach to meeting these objectives is to: 1) utilize the design and operational experience gained from workhorse hardware to design and construst prototypical hardware, 2) conduct design verification tests on the prototypical hardware, and 3) integrate and operate the components for 1000 hours as a complete power train at the CDIF. At the current stage of the project, the techrical approach is focusing on item (1) above. Fabrication of prototypical hardware for the combustion, channel, and current consolidation subsystems continued this quarter. The critical design review for the low pressure cooling system was held and fabrication was initiated. Systems engineering disciplines are ensuring compatibility of each of the prototypical subsystems with the overall topping cycle system as well as with the CDIF where they eventually will te integrated. Finally, the TTIRC is disseminating information on the POC program and airing the major integration issues involved in retrofitting an existing power plant so as to permit utilities, the potential future users of the technology, to assume an active role in the U.S. MHD program. 
TABLE 2-1. MHD ITC TASK OBJECTIVES

\begin{tabular}{|c|c|}
\hline $\begin{array}{l}\text { SYSTEMS ENGINEERING STUDIES } \\
(\text { TASK } \|\end{array}$ & $\begin{array}{l}\text { Perform power trainffacility integration activities to ensure } \\
\text { compatibility of topping cycle componants with the existing } \\
\text { test bay at the CDIf } \\
\text { Define aystem level requirements and specifications for the } \\
\text { integrated topping eycle power train } \\
\text { Provide test planning and performance data analysis } \\
\text { support for CDIF power train testing }\end{array}$ \\
\hline $\begin{array}{l}\text { PROTOTYPICAL } 50 \mathrm{MW} \text {, COMBUSTOR } \\
\text { DESIGN, FABRICATION, AND SHIPMENT } \\
\text { (TASK 2) }\end{array}$ & $\begin{array}{l}\text { Design, fabricate and deliver to the CDIF a prototypical } \\
\text { coal-fired combuator for the integrated topping cycle power } \\
\text { train } \\
\text { Conduct testing in support of the protolypical design effort } \\
\text { or to evaluate the risks and benefits of proceeding to the } \\
\text { development of an early commercial scale retrofit MHD } \\
\text { power plent }\end{array}$ \\
\hline $\begin{array}{l}\text { PROTOTYPICAL } 50 \text { MW } \text { CHANNEL } \\
\text { (TASK 3) }\end{array}$ & $\begin{array}{l}\text { Design, fabricate and deliver to the CDIF a prototypical } \\
\text { MHD channel (including the inlet nozzle and diagonal } \\
\text { current controls) for the integrated topping cycle power } \\
\text { train } \\
\text { Conduct testing in support of the prototypical design affort } \\
\text { or to evsiuate the risks and benefits of proceeding to the } \\
\text { development of an early commercial scale retrofit MHD } \\
\text { power plant }\end{array}$ \\
\hline DIFFUSER (TASK 4 ) & $\begin{array}{l}\text { Design, fabricate and deliver to the CDIF a diffuser section } \\
\text { for the integrated topping cycle power train }\end{array}$ \\
\hline $\begin{array}{l}\text { POWER CONDITIONING AND INVERTER } \\
\text { (TASK 5) }\end{array}$ & $\begin{array}{l}\text { Design, fabricate and deliver to the CDIF current } \\
\text { consolidation eircuits for the prototypical channel }\end{array}$ \\
\hline $\begin{array}{l}\text { TEST ENGINEERING ACTIVITIES AT } \\
\text { THE CDIF (TASK 6) }\end{array}$ & $\begin{array}{l}\text { Provide to CDIF personnal technical direction and guidance } \\
\text { for the installation, checkout and testing of CDIF MHD } \\
\text { power train components and appropriate auxiliary } \\
\text { equipment }\end{array}$ \\
\hline $\begin{array}{l}\text { HAADWARE REPAIR/REPLACEMENT } \\
\text { (TASK } 7)\end{array}$ & $\begin{array}{l}\text { Provide for the repair or replacement of power train } \\
\text { components that show excessive wear, are damaged, or } \\
\text { fail as a result of operations and testing at the CDif }\end{array}$ \\
\hline $\begin{array}{l}\text { CHARTER AND PARTICIPATE IN AN MHD } \\
\text { TECHNOLOGY TRANSFER, INTEGRATION } \\
\text { AND REVIEW COMMITTEE (TASK B) }\end{array}$ & $\begin{array}{l}\text { Organize, charter and co-chair a committee that will permit } \\
\text { potential users of MHD technology in the private sector to } \\
\text { assurne an active role in the MHD Program }\end{array}$ \\
\hline & $\begin{array}{l}\text { Roview and integrate POC program schedules and } \\
\text { integration iseues and provide for technology trangfor to } \\
\text { potential future users }\end{array}$ \\
\hline OUALITY ASSURANCE (TASK 9) & $\begin{array}{l}\text { Prepare and implernent a plan to assure that prototypical } \\
\text { power train components are manufactured per the } \\
\text { approved design }\end{array}$ \\
\hline $\begin{array}{l}\text { INTEGRATED PROJECT MANAGEMENT } \\
(T A S K 10)\end{array}$ & $\begin{array}{l}\text { Provide for overall technical, programmatic and } \\
\text { subcontract management for the project }\end{array}$ \\
\hline
\end{tabular}




\section{SYSTEMS ENGINEERING (TASK 1)}

Systems engineering activities related to the power train integration and testing at the CDIF are discussed in this section. These activities comprise Subtask 1.1 of the ITC Project.

A principal objective of the systems engineering task is to focus the program's technical effort so that the subsystems designed and built for the topping cycle not only perform well by themseives, but also perform well when interconnected and integrated into the $50 \mathrm{MW} l$ power train at the CDIF. The integrated topping cycle system must be prototypical, and it must be designed to operate at conditions which closely approximate the operating state of a $250 \mathrm{MW}$ retrofit power plant.

To attain these objectives, systems engineering studies are being performed on specific issues as they arise, and systems engineering documentation is being developed and maintained current to provide a consistent basis for the design, fabrication and testing of the prototypical power train. The status of the systems engineering documentation for the project is reported below.

\subsection{SYSTEM/SUBSYSTEM DOCUMENTATION}

Requirements, technical criteria, specifications and interfaces for the power train hardware are being documented to insure that Statement of Work requirements are met and that the subsystems designed and built for the power train are compatible with each other and with the test facility at the CDIF.

\subsubsection{Interface Documentation}

During this quarter, the interface document was updated based on the latest neview and design information. The interface listing, instrumentation lists, process flow diagram, cooling water flow diagram, and both instrumentation diagrams were updated.

The updated document was sent out for intenal TRW review as well as to TDS, Westinghouse, and MSE for their review. At the completion of the review cycle, signatures will be obtained and the document will be released through the TRW Configuration and Data Management (CADM) system. This document, after its release from CADM, will become part of the configuration management of this program.

\subsubsection{Channel Requirements Document}

A draft version of Revision A of the Channel Requirements Docurnent which pulls together, under one cover, all of the requirements that the channel subsystem will place on the CDIF was issued to MSE for their review and cornments this quarter. The final version is scheduled to be released early next quarter.

This revision contained clarifications to the forward and aft PTO arrangements showing how the nozzle and diffuser segments will be used as "spreading" elements for the current transients and the required connections. The number of required measurements, both for panel meters and DAS inputs, was refined. Alarn and abort points were added for critical process pararneters. The anode and cathode imn oxide connections were clarified and arnbiguities in the individual flowrates corrected.

\subsubsection{Channel Dry-Out Requirements}

TDS released the initial requirements for channel dry-out between tests. These requirements included a warm air purge through the channel as well as water circulation in the cooling passages. In the event that water circulation could not be accomplished or maintained, the requirements for purging the cooling passages were included.

TDS and MSE are currently iterating on requirements in order to minimize facility impact. This process will continue into the next quarter. When TDS and MSE have reached an agreement on the dry-out requirements, they will be included in the next revision to the Channel Requirements Document. 


\subsubsection{Integrated Schedule Review}

During this quarter, a detailed look was taken at the schedules for all of the parties involved in the POC testing: 1) MSE, to understand the facility modifications and available test time; 2) TRW, to look at the manufacturing and delivery schedules for the combustion subsystem and the L.PCS; 3) TDS, to look at the channel manufacturing and delivery schedule; and 4) Westinghouse, for the current consolidation manufacturing and delivery schedule. The testing requested by the component developers was also included in the schedule neview. These schedules were integrated to assess the status of the entire program. The main focus this quarter was the impact of the anode current consolidation late delivery (due to fiscal constraints) on the program. Several work-around plans were investigated for the near term fall testing and for the longer term installation and testing with the $1 \mathrm{~A} 4$ channel. The schedule will be reviewed as part of the CDIF Facility Status meeting that will be held in mid-November.

The schedule issues will continue to be addressed in the coming months to ensure that these schedules do not impact the baseline scheduled start of the duration testing. A weekly telecon between TRW and MSE has been established to allow continual conversation between the component developers and MSE to ensure that all issues are addressed as they surface, to provide the maximum amount of time to prepare workarounds, and to ensure that these issues do not become problems which could jeopardize the schedule. 


\section{COMBUSTION SUBSYSTEM DESIGN AND FABRICATION (TASK 2)}

Task 2 combustion subsystem design support engineering and prototypical design activities are discussed in this section. Three subtasks comprise Task 2 of the ITC project: Subtask 2.1, prototypical combustor design; Subtask 2.2, prototypical combustor fabrication and assembly; and Subtask 2.3, prototypical combustor shipment.

During this quarterly reporting period, the efforts were concentrated on Subtasks 2.1 and 2.2. The 2.1 subtask encompasses design support engineering and testing, as well as the actual design of prototypical combustor hardware, and procurement specification development for the low pressure cooling subsystem (L.PCS). The 2.2 subtask encompasses the combustor and LPCS fabrication and assembly.

Subtask 2.1 was originally comprised of five elements:

- Subtask 2.1.1, Design confirmation testing at TRW. This subtask has been completed and the results have been reported.

- Subtask 2.1.2, Wall construction evaluations. Also completed and the results reported.

- Subtask 2.1.3, Design of prototypical combustor.

- Subtask 2.1.4, Low pressure oxidant second stage testing and design. This subtask was deleted from the program.

- Subtask 2.1.5, 20 MWt combustor/channel characterization. Also completed and the results reported.

Subtask 2.2 includes the following elements:

- Subtask 2.2.1, Component fabrication and assembly.

- Subtask 2.2.2, Hot fire DVT testing at TRW. This subtask was deleted from the program.

Section 4.1 titled Combustion Subsystem Design Activities includes elements of Subtask 2.1.3. Section 4.2 titled Combustion Subsystem Manufacturing includes elements of Subtask 2.2.1.

\subsection{COMBUSTION SUBSYSTEM DESIGN ACTIVITIES (SUBTASK 2.1.3)}

As a part of the combustion subsystem design development, the following activities occurred during this reporting period:

- A drawing of the combustor installation at the CDIF has been prepared. In addition to the slagging stage support, the drawing also incorporates the precombustor, second stage, and OFV supports.

- Interconnecting piping between the combustor and LPCS skid was finalized including the design of water electrical isolators.

- Detailed design of the combustor servicing platforms was completed.

- Optimization of the second stage brazing is in progress.

- Development of a process for cleaning the panel cooling channels was initiated.

\subsubsection{Combustor Installation}

The combustor subsystem installation at CDIF was finalized. It is shown in Figure 4-1. The slagging stage, the precombustor, the second stage, and OFV are all supported from the same support stand. The slagging stage is attached rigidly to the stand whereas the other components are mounted via the spring isolators. Each spring isolator will be adjusted in such a way that an appropriate load is taken by the spring support. The springs will also compensate for possible thermal mismatches of the components. The headend plate, exit endplate, and the precombustor endplate servicing platforms were designed. The platforms will be bolted to the support stand. They are not shown in Figure 4-1 for clarity purposes. An 


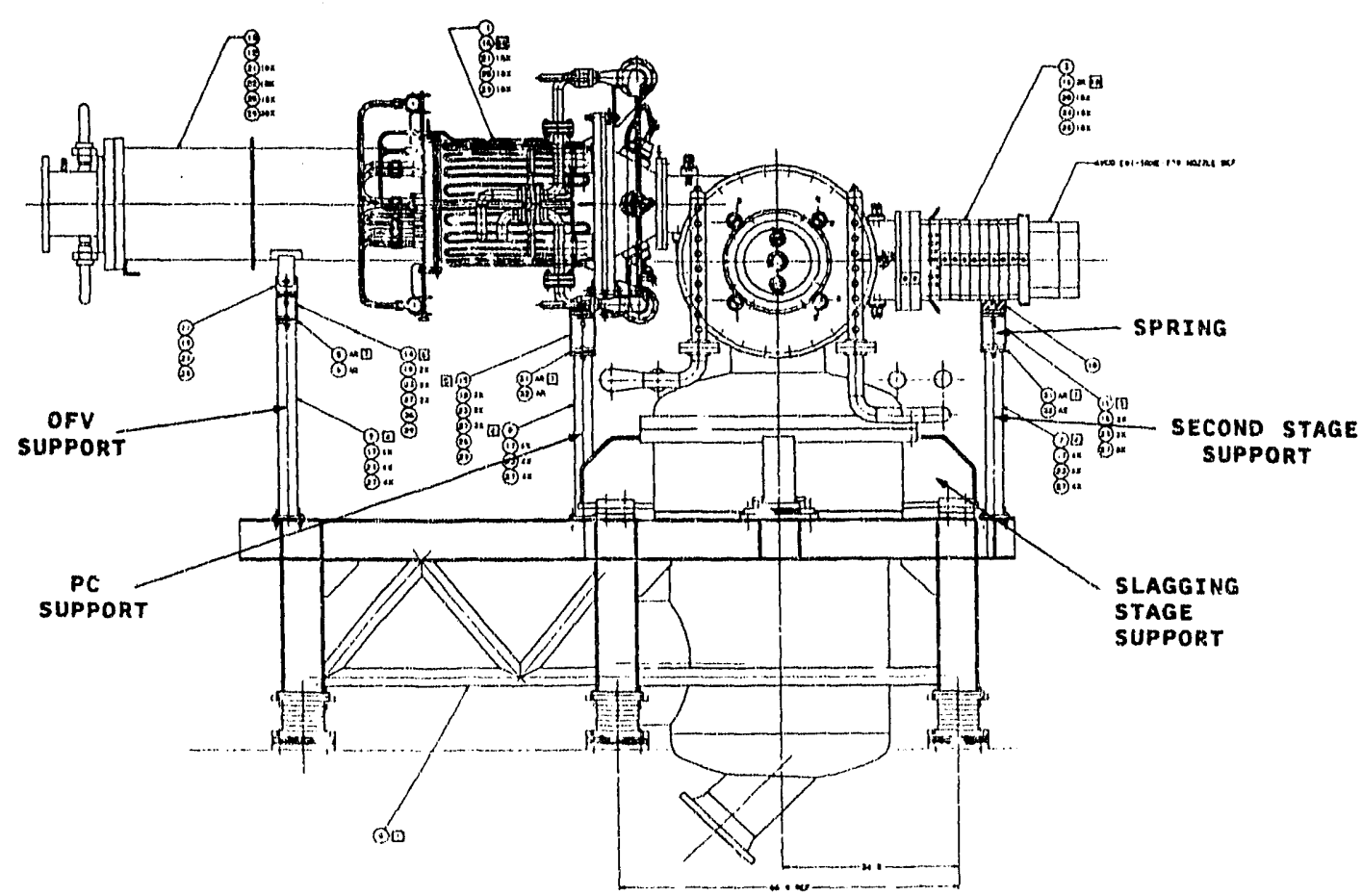

Figure 4-1. Combustor Support System

overall combustor subsystem arrangement which includes the combustor, LPCS, the interconnecting piping, the water electrical isolators, and servicing platforms is shown in Figure 4-2. The water electrical isolator is bolted on one side to the LPCS piping and on the other side to the combustor 8-inch header. During non-power tests, the isolator can be replaced with a pipe spool.

\subsubsection{LPCS Water Electrical Isolator}

The LPCS water electrical isolator design requirements are summarized in Table 4-1. The isolator design (Figures 4-3 and 4-4) consists of two stacks of six 1-inch thick 316L stainless steel plates, each separated by 0.125 -inch thick Teflon insulating plates. The plates are clamped between a $316 \mathrm{~L} 6$-inch 300 lb flange in the center and 8-inch $\times 6$-inch $300 \mathrm{lb}$ reducing flanges on either end. The flanges and isolating plates are sized to match a 6 -inch schedule 40 pipe I.D. (6.07 inches).

As shown in Figure 4-4 the assemblies are clamped together using 12 bolts (3/4-inch diameter), with CRES Belleville washers used to maintain the preload. Thick carton steel flat washers are used for load distribution. The bolts are insulated from the plates using 1-inch O.D. Teflon sleeves and G10 fiberglass insulators under the nuts and springs. Viton $O$-rings are used for sealing and are staggered in the CRES plates. The Gi0 nut isolators are potted in place with R'TV to prevent dirt migration and possible shorting.

An electrical connection (for instrumentation) is provided on the O.D. of every flange, including the reducers and central connecting flanges. The outside of the assembly will be coated with "Silguard" to prevent arcing. At $10 \mathrm{kV}$, the predicted current leakage is $75 \mathrm{~mA}$ (per isolator), assuming $1.0 \mathrm{Mohm}-\mathrm{cm}$ water resistivity. Using the minimum LPCS water resistivity of $0.5 \mathrm{Mohm}-\mathrm{cm}$ and the nominal Hall voltage of $6 \mathrm{kV}$, the predicted current leakage would be $90 \mathrm{~mA}$. 


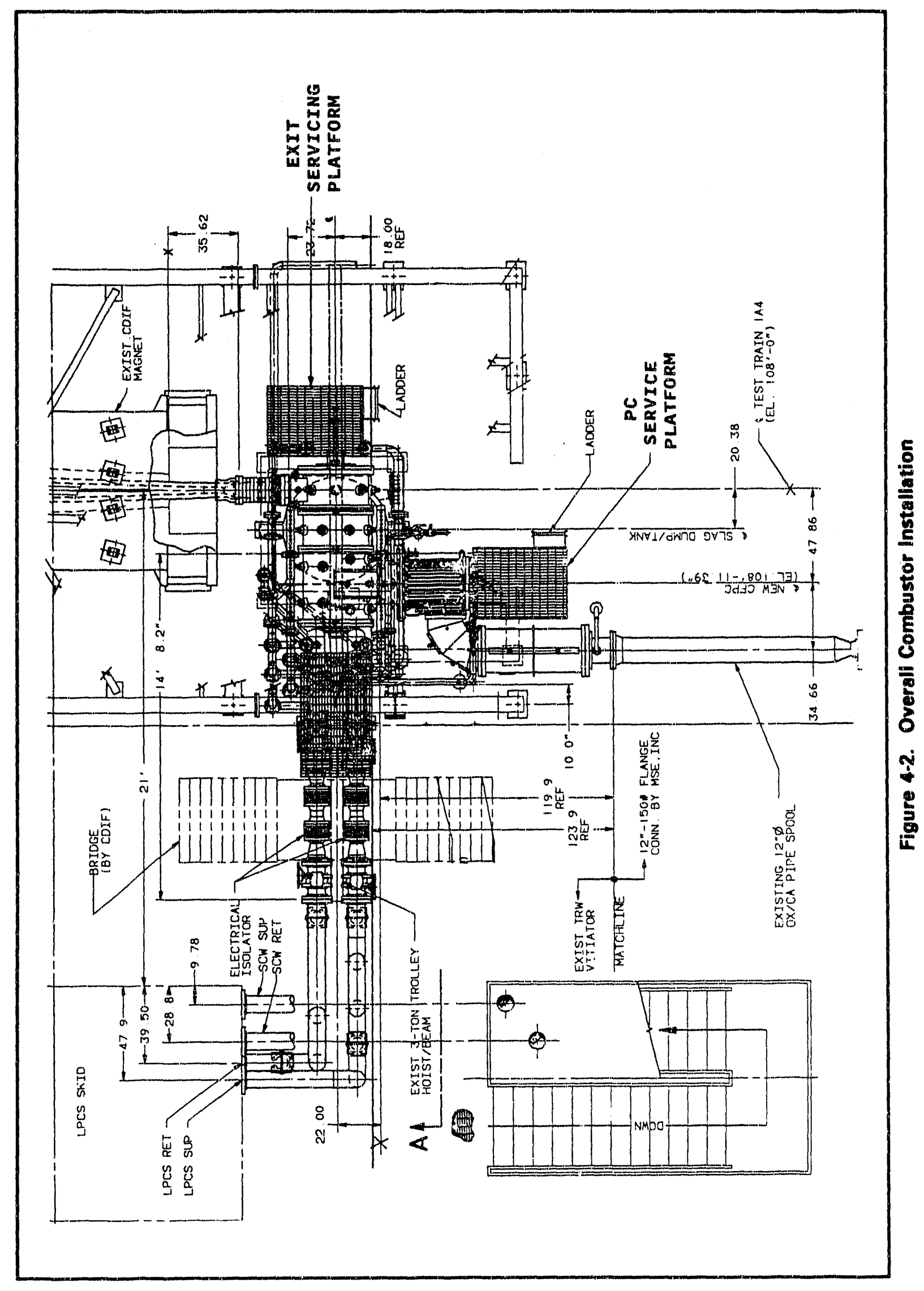


TABLE 4-1. LPCS WATER ELECTRICAL ISOLATOR DESIGN REQUIREMENTS

\begin{tabular}{|l|l|l|}
\hline \multicolumn{1}{|c|}{ Parameter } & \multicolumn{1}{c|}{ Requirement } & \multicolumn{1}{c|}{ Source } \\
\hline Maximum Water Pressure & $300 \mathrm{PSIA}$ & LPCS \\
\hline Maximum Water Temperature & $140^{\circ} \mathrm{F}$ & LPCS \\
\hline Water Flow Rate & $1250 \mathrm{GPM}$ & LPCS \\
\hline Design Voltage & $10,000 \mathrm{Vdc}$ & Maximum Channel Voltage \\
\hline Proof Voltage & $15,000 \mathrm{Vdc}$ & C.DIF \\
\hline Operating Voltage & $6,000 \mathrm{Vdc}$ & Typical Operating Voltage \\
\hline Maximum Current Leakage & $100 \mathrm{~mA} @ 10 \mathrm{kV}$ and 1 Mohm-cm & TRW Leakage Allocation \\
\hline Codes & $\begin{array}{l}\text { B31.1, Power Piping (No Stamp) } \\
\text { NEMA }\end{array}$ & $\begin{array}{l}\text { TRW } \\
\text { TRW/CDIF }\end{array}$ \\
\hline Interface & 8 IPS Class 300 RF Flange & LPCS \\
\hline Design Life & 2000 Hours; 500 Start/Stops & LPCS \\
\hline
\end{tabular}

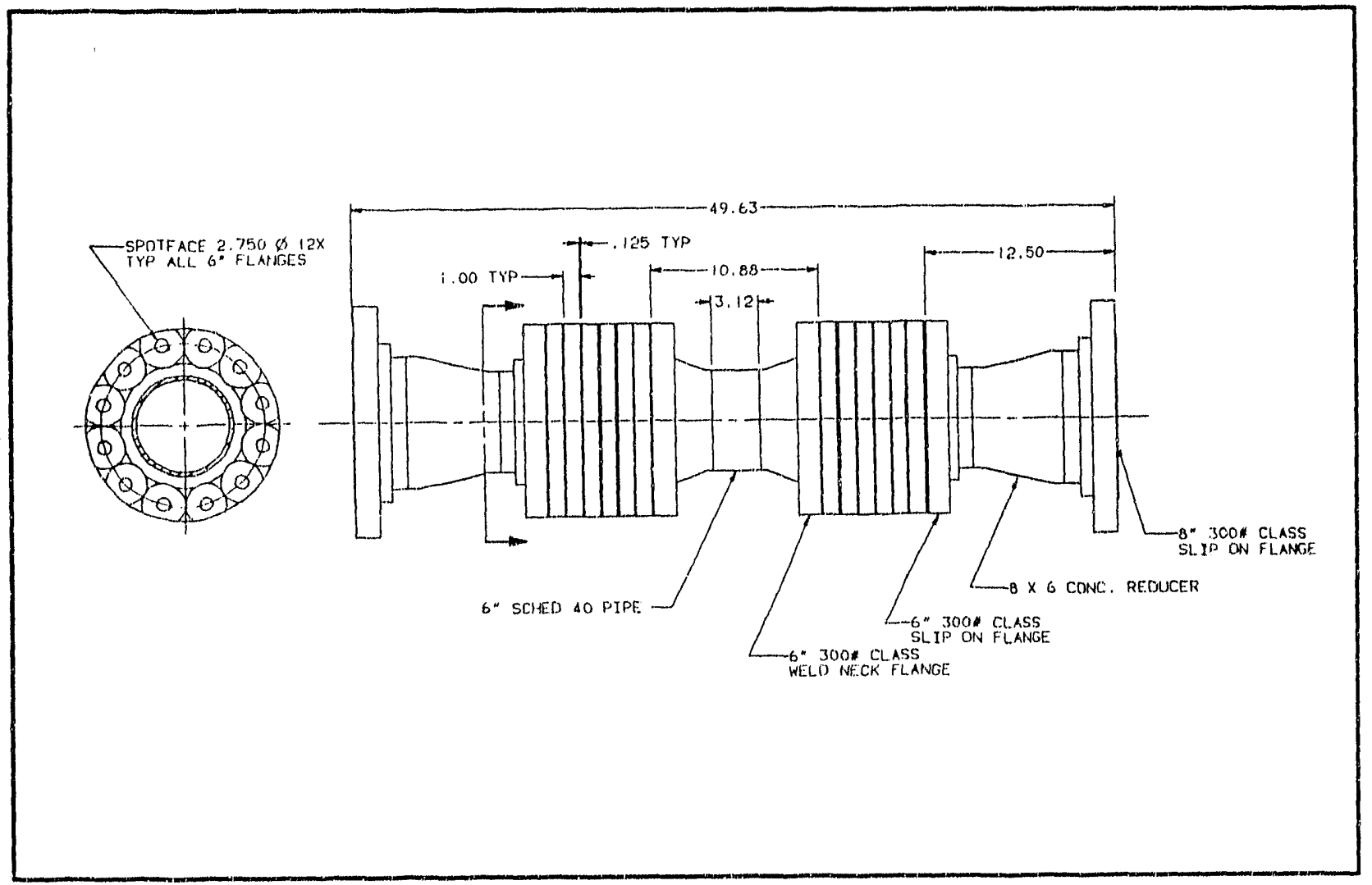

Figure 4-3. Water Electrical isolator

Design parameters for the isolator are as summarized in Table 4-2. The nominal gap voltage of $429 \mathrm{~V}$ at $6 \mathrm{kV}$ is conservative since gap voltages as high as $1100 \mathrm{~V}$ were routinely sustained during the high temperature isolator tests. The water pressure loss of 3 psi assumes the loss of 2 dynamic heads across the isolator. Differential thermal growth of the stacks is insignificant over the temperature range encountered.

A simplified isolator instrumentation diagram is shown in Figure 4-5. Selected individual plate voltages (5 per isolator) will be monitored to give an indication of possible problems on individual insulating plates. 


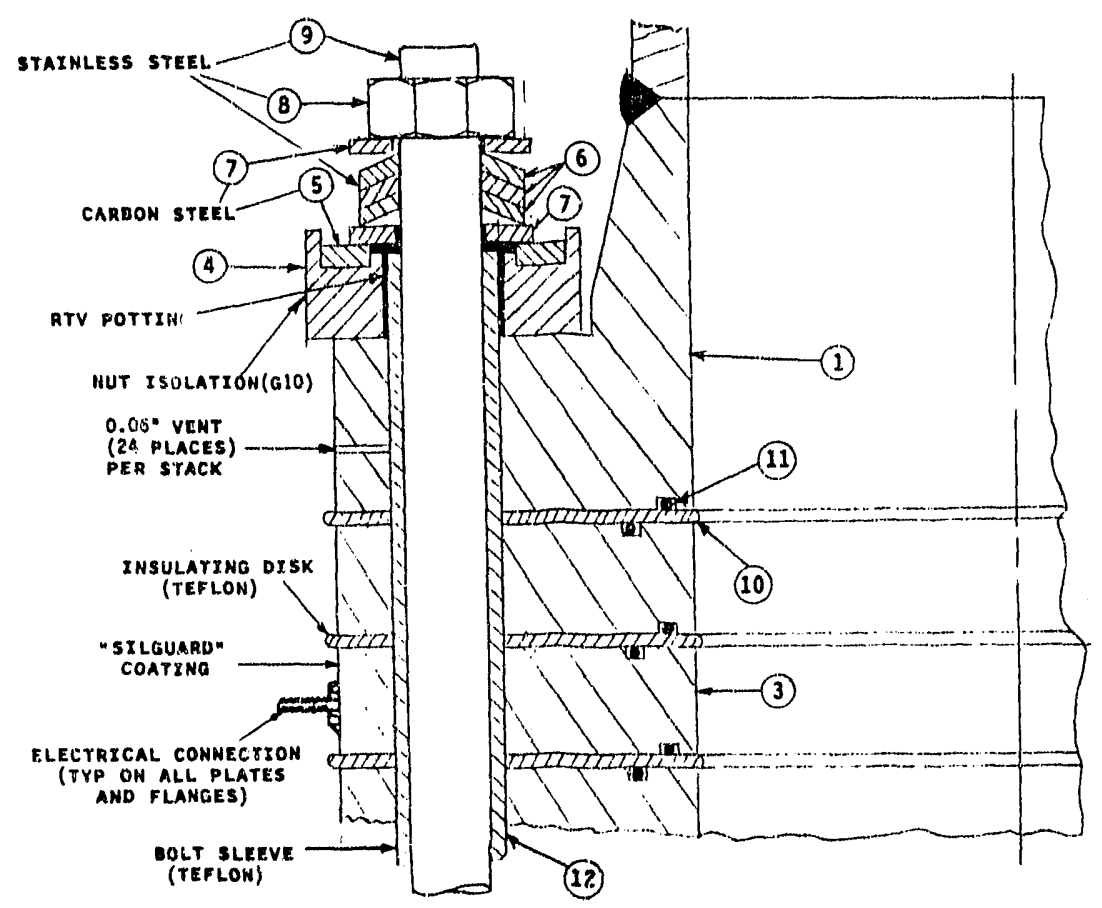

Figure 4-4. Isolator Details

TABLE 4-2. LPCS WATER ELECTRICAL ISOLATOR DESIGN PARAMETERS

\begin{tabular}{|l|l|}
\hline \multicolumn{1}{|c|}{ Parameter } & Raquirement \\
\hline Voltage/Gap @ 6000 Vdc & $429 \mathrm{~V}$ \\
Estimated Leakage Current @ 1 Mohm-cm and & $75 \mathrm{~mA}$ \\
10,000 Vdc & $14 \mathrm{ft} / \mathrm{sec}$ \\
Water Velocity & $3 \mathrm{PSI}$ \\
Pressure Drop & $0.003 \mathrm{inch}$ \\
Differential Thermal Growth Per Stack (60-140 $\mathrm{F})$ & $2500 \mathrm{lbs}$ \\
Bolt Preload & $8000 \mathrm{PSI}$ \\
Maximum Boit Stress & $18,700 \mathrm{PSI}$ \\
Allowable Stress & $40 \mathrm{ft}-\mathrm{lbs}$ \\
Required Torque & \\
Teflon Insulating Disks & $385 \mathrm{PSI}$ \\
Maximum Stress & $0.6 \%$ \\
Maximum Strain & $1.4 \%$ \\
Creep @ 140 F and 100 Hours and 500 PSI & \\
Nut Insulators & $845 \mathrm{PSI}$ \\
Maximum Stress & $0.05 \%$ \\
Maximum Strain (G10) & \\
\hline
\end{tabular}




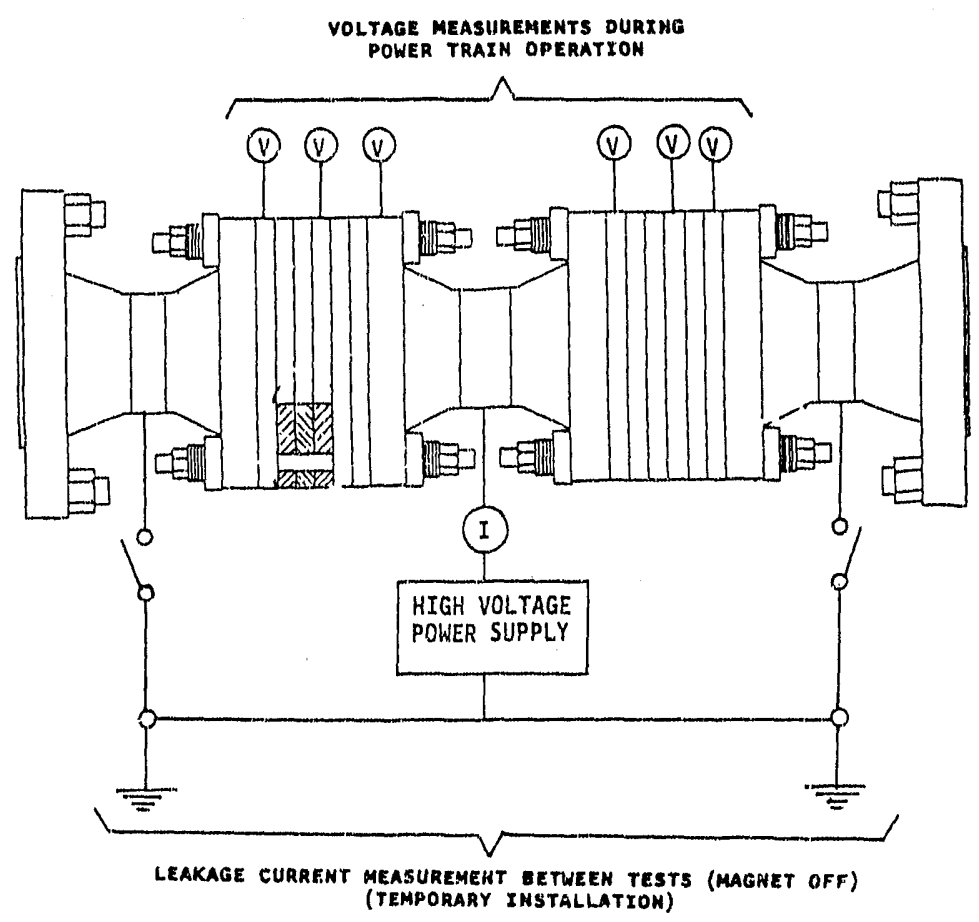

Figure 4-5. Isolator Instrumentation/Diagnostics

The measurements will indicate problems such as uneven voltage distribution due to I.D. surface contamination or shorting of individual insulating plates. The shutdown criterion will be set at a maximum of $1000 \mathrm{~V}$ per gap.

In addition, a high voltage power supply ( $15 \mathrm{kV})$ will be used periodically between tests to measure current leakage across the individual stacks. These measurements will be used to assess the relative "health" of the isolator over time.

\subsubsection{Panel Coolant Channel Cleaning}

Accumulation of rust in the thermal panel coolant channels is a real concern. Rust accumulation might be caused by a manufacturing process or be developed during the combustor downtime. A two-step coolant channel corrosion protection procedure was incorporated in the combustor assembly/manufacturing cycle. It includes a preclean/prefilm step sufficient to protect the panel for at least 30 days and then filming with a rust inhibiting lubricant for long term storage. (Details of the steps are described in Section 4.1.4.1 of the 15th Quarterly Technical Progress Report, February through April 1991.) What remains unclear is how a small amount of rust left in the coolant channel will affect the water electrical conductivity and how the residual nust can be removed in-situ if necessary. To answer the above questions a test program was initiated. A number of potential vendors involved in industrial cleaning were contacted and they were given material samples. In parallel, bench scale tests were initiated. A small (5 GPM) flow cart will be used to simulate the LPCS/combustor closed water loop by preserving the surface to volume ratio; a nitrogen blanket will also be provided. The main objective of the tests is to assess the impact of coolant channel rusting on water electrical conductivity and to establish an in-situ rust removal procedure if necessary. 


\subsubsection{Second Stage Brazing Development}

The second stage brazing problems were reported in Section 4.2.1 of the 16th Quarterly Technical Progress Report, May through July 1991. Many frames had random unacceptable voids between the stainless steel (446) liners and the base copper material and had to go through repair operations. It was theorized that the braze temperature was not optimal for the Nioro (BAu-4) alloy. Variations in braze parameters were then used, but did not seem to resolve the void problem. Cleanliness and joint contamination were issues, but were ruled out after review of braze preparation and cross-sectioning of the braze samples.

Metallurgical inspections revealed large amounts of braze alloy diffusing into the grain boundaries of the copper. An approach to reduce the diffusibility of the braze alloy into the copper by the use of a nickel plating (as a barrier) is being examined. Two copper bars were nickel plated, one bar completely plated on all surfaces and the other plated on one surface. These bars were then put through a Nioro (BAu-4) braze temperature cycle. Inspections revealed no signs of blistering, pitting, or porosity (things that would detrimentally affect the braze process).

After verifying the nickel plating process, eight coupons simulating two second stage frames were prepared. Four of them were made with nickel plated copper bars and another four, for comparis on, were made w hout nickel plating. These braze test coupons will utilize the Nioro (BAu-4) alloy. Additional coupons will be brazed using Cusil (BAg-8) alloy. An assessment of the nickel plated copper braze coupons will then be made.

It was also apparent that the stainless "teel (446) liners ground down to a 0.075-inch thickness were noticeably out of flatness, exceeding the drawing (E441332) call out. A dye contact test using the non-flat liners revealed large non-contact areas suspected to cause braze voids. An investigation to provide a method of achieving flat liners has been initiated. It is planned to pre-grind the entire sheet material down to a 0.100 -inch thickness, cut into slightly oversized strips, stress relieve (furnace bake), machine to size, then grind down to a 0.075 -inch thickness.

\subsection{COMBUSTION SUBSYSTEM MANUFACTURING (SUBTASK 2.2.1)}

The prototypical combustor manufacturing activities are summarized in Section 4.2.1, and the status of low pressure cooling system procurement is provided in Section 4.2.2.

\subsubsection{Prototypical Combustor Manufacturing}

During this period all cornbustor pressure shell components including precombustor, slagging stage, slag tank support, and respective endplates were received at the TRW facility. Some of these components are shown in Figure 4-6. Prior to delivery, all components were successfully leak and proof tested at the supplier's facility while monitored by a TRW Project Office representative. A fit check assembly of the pressure shells and endplates has been performed at TRW as shown in Figure 4-7 and no problems were found. A support/shipping stand used for the fit check simulates one-to-one the prototypical combustor/support stand interfaces.

Installation of the precombustor cylindrical shell water coolant tubing was cornpleted, and it has been sent to a vendor for refractory installation. The precombustor headend plate was also fitted with cooling tubes and copper plasma over-sprayed to enhance heat transfer to the tubes. After refractory installation, the precombustor cylindrical shell coolant tubes will be also plasma sprayed with copper.

By the end of October, a total of forty-five cooling panels were delivered by vendors and subjected to pre-installation processes including leak, proof and flow calibration testing and a corrosion inhibiting procedure for both flow passages and outer surfaces. A typical cooling panel backside (after being protected with RTV88) is shown in Figure 4-8. The balance of the panel assemblies have progressed through the major machining manufacturing operations, including gun drilling and surface grooving. It is 


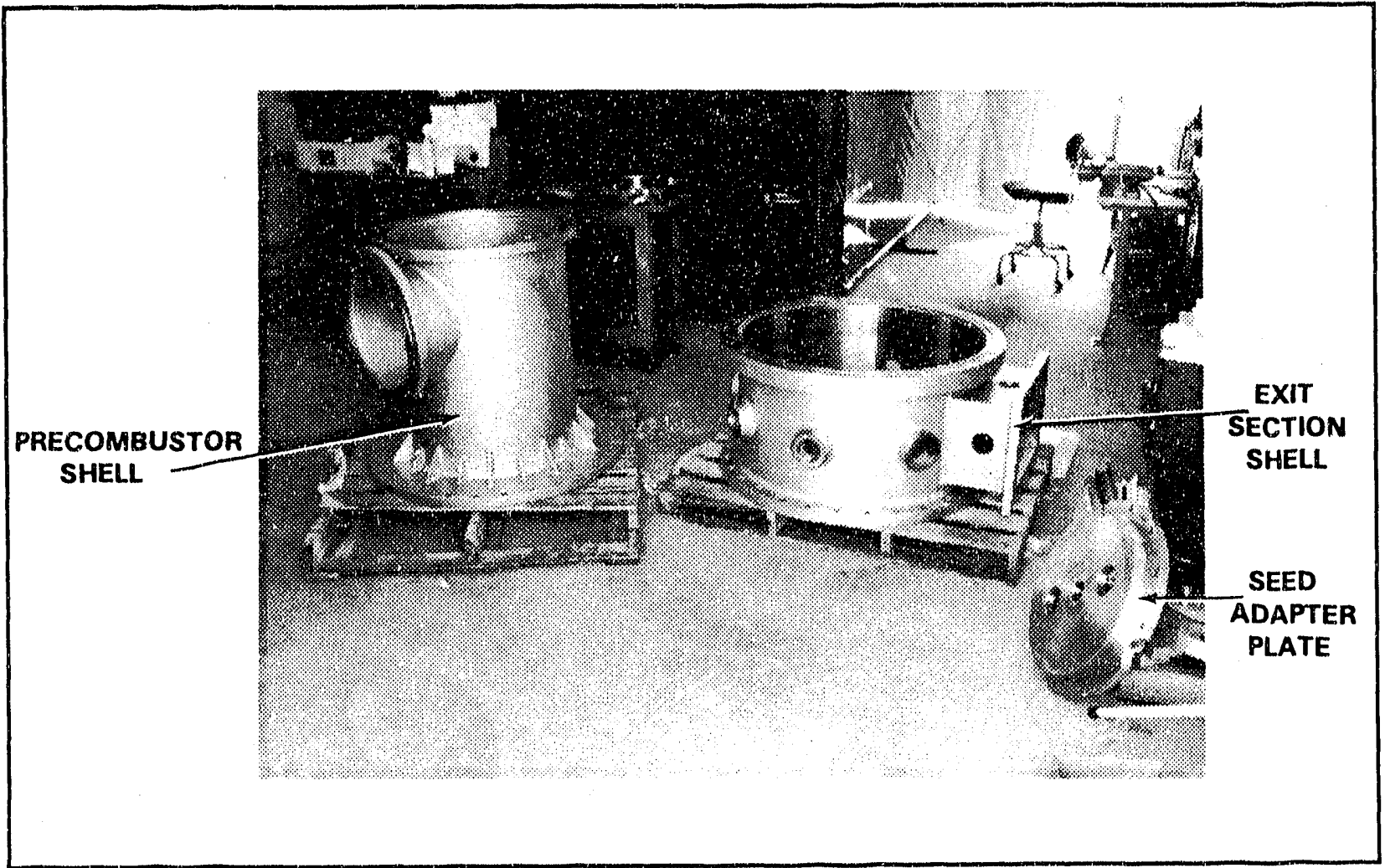

Figure 4-6. Prototypical Combustor Pressure Shell Components

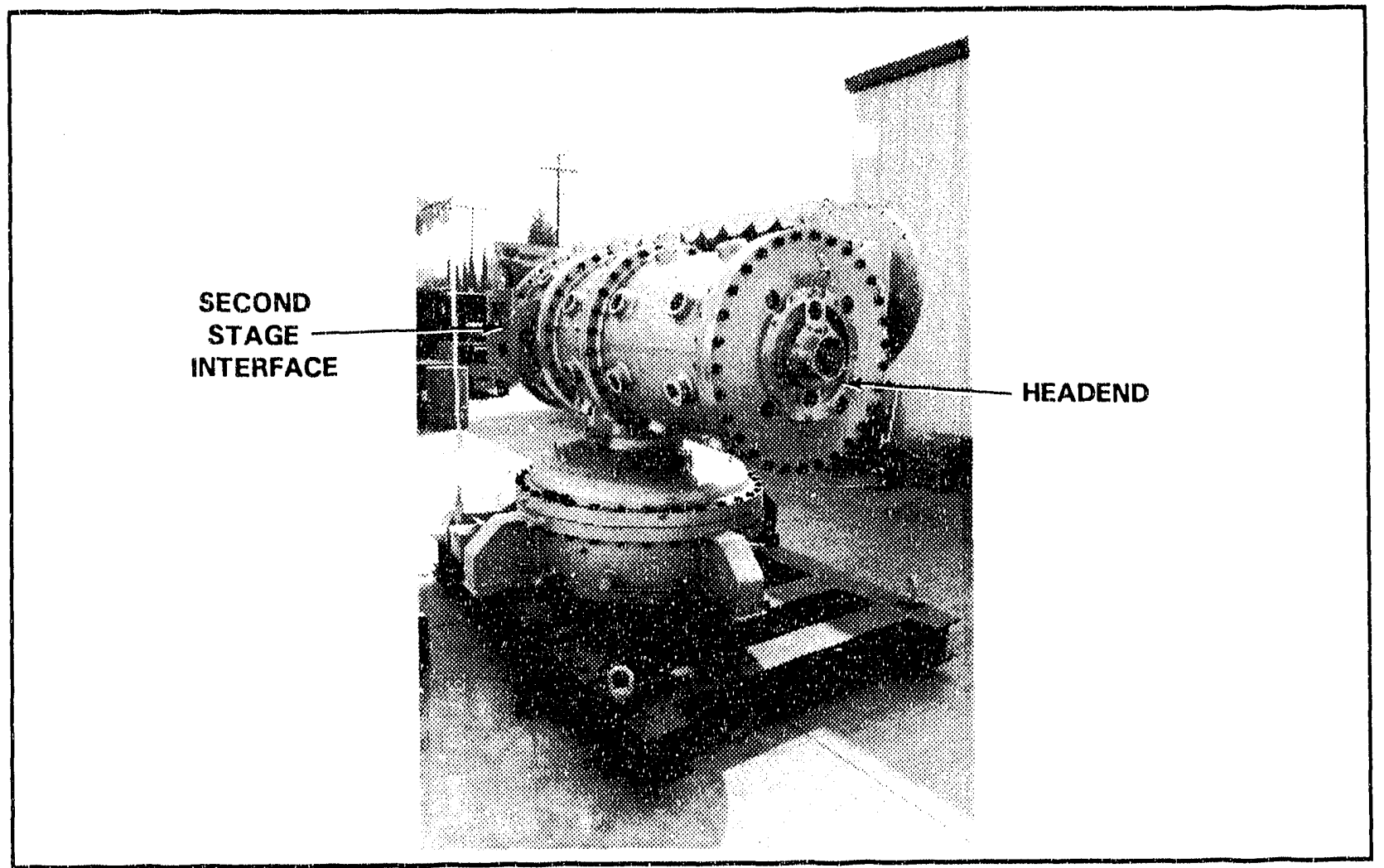

Figure 4-7. Combustor Pressure Shell Fit Check Assembly 


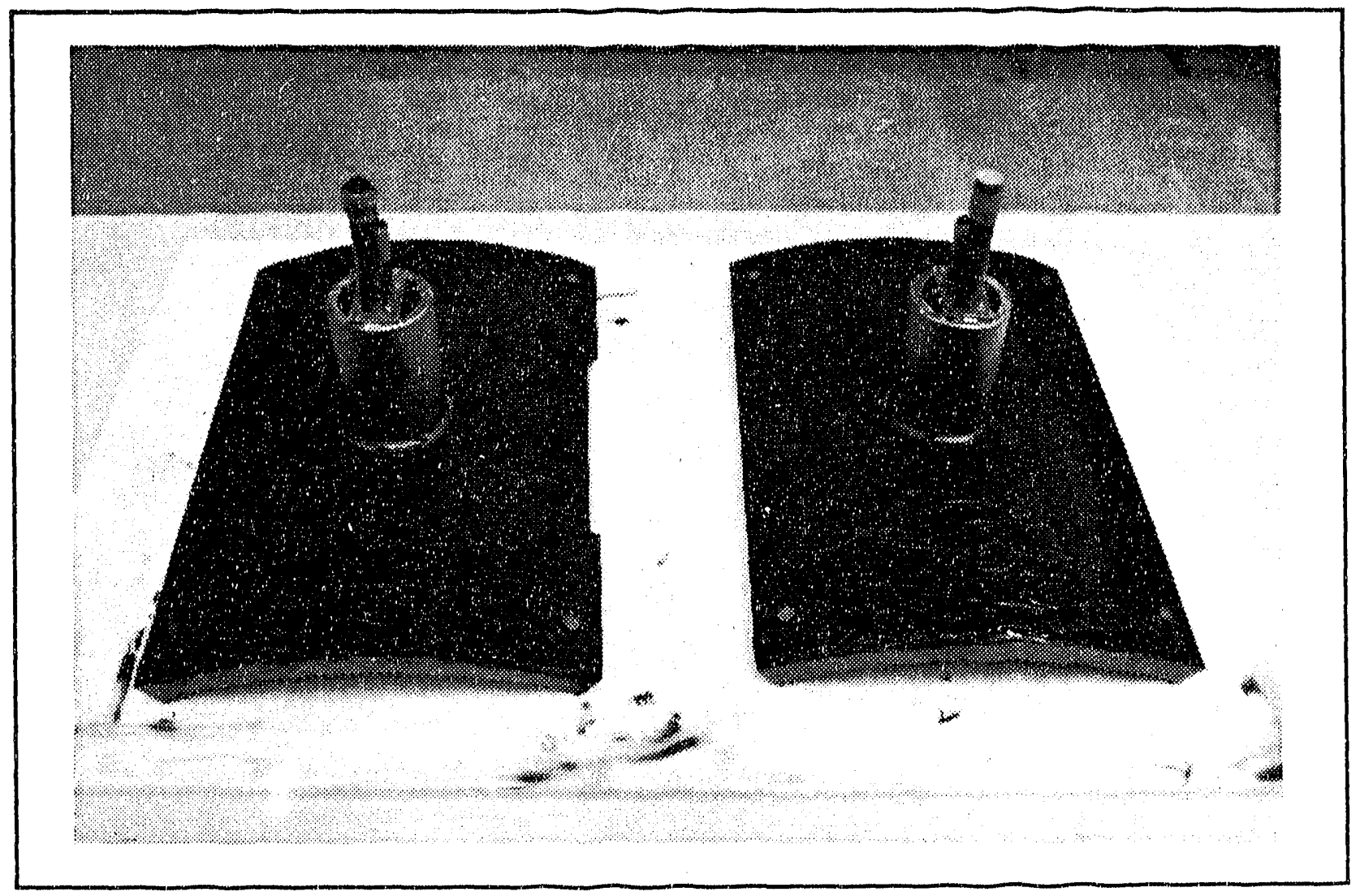

Figure 4-8. Cooling Panels with RTV88 Bonded to the Backside

expected that these remaining panels will be received by the third week in November. A fit check of the exit section panels and the endplate cooling panels with their respective mating parts has been performed successfully. During the endplate/endplate cooling panels assembly check, a verification RTV pour test was also performed (see Figure 4-9).

The components for the precombustor internal assembly have been received including the combustion can, baffle assembly and swirl box assembly (see Figure 4-10). All preassembly testing including leak, proof and flow calibration were completed and integration of the components was initiated.

Fabrication of the precombustor transition ring has progressed through the complete milling of all water passages and the machining and fitting of all flow passage covers. Welding of the flow passage covers has been initiated with completion expected by the end of November.

The combustor baffle has also progressed through the milling of all water passages and fabrication of the passage covers. Welding of the first slagging stage baffle plate has been completed (see Figure 4-11). It was dye-penetrant tested and is ready for heat treatment. The welding process has taken longer than expected due to the required procedures necessary to prevent unacceptable baffie distortion. The use of additional tooling and a slower welding rate has been effective in controlling this problem.

All water supply and retum manifolds and support brackets have been completed and delivered to TRW. The manifolds have also been leak and proof tested. During a fit check with the pressure shell assembly, several bracket interference problems were uncovered. As a result, some brackets will be retumed to the vendors for minor modifications. This will be accomplished while other assembly work is proceeding. It will not impact the assembly process. 


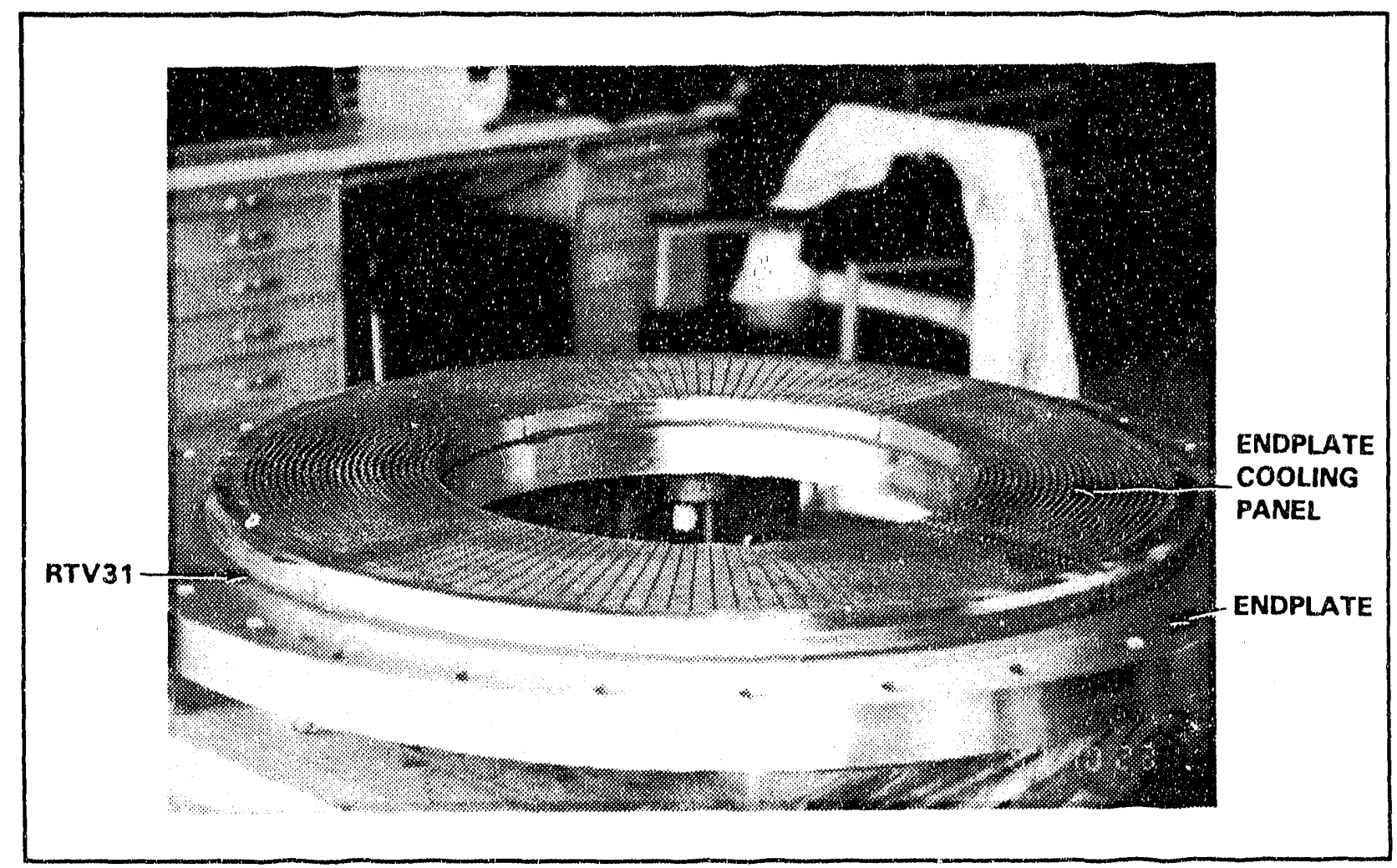

Figure 4-9. Endplate Assembly

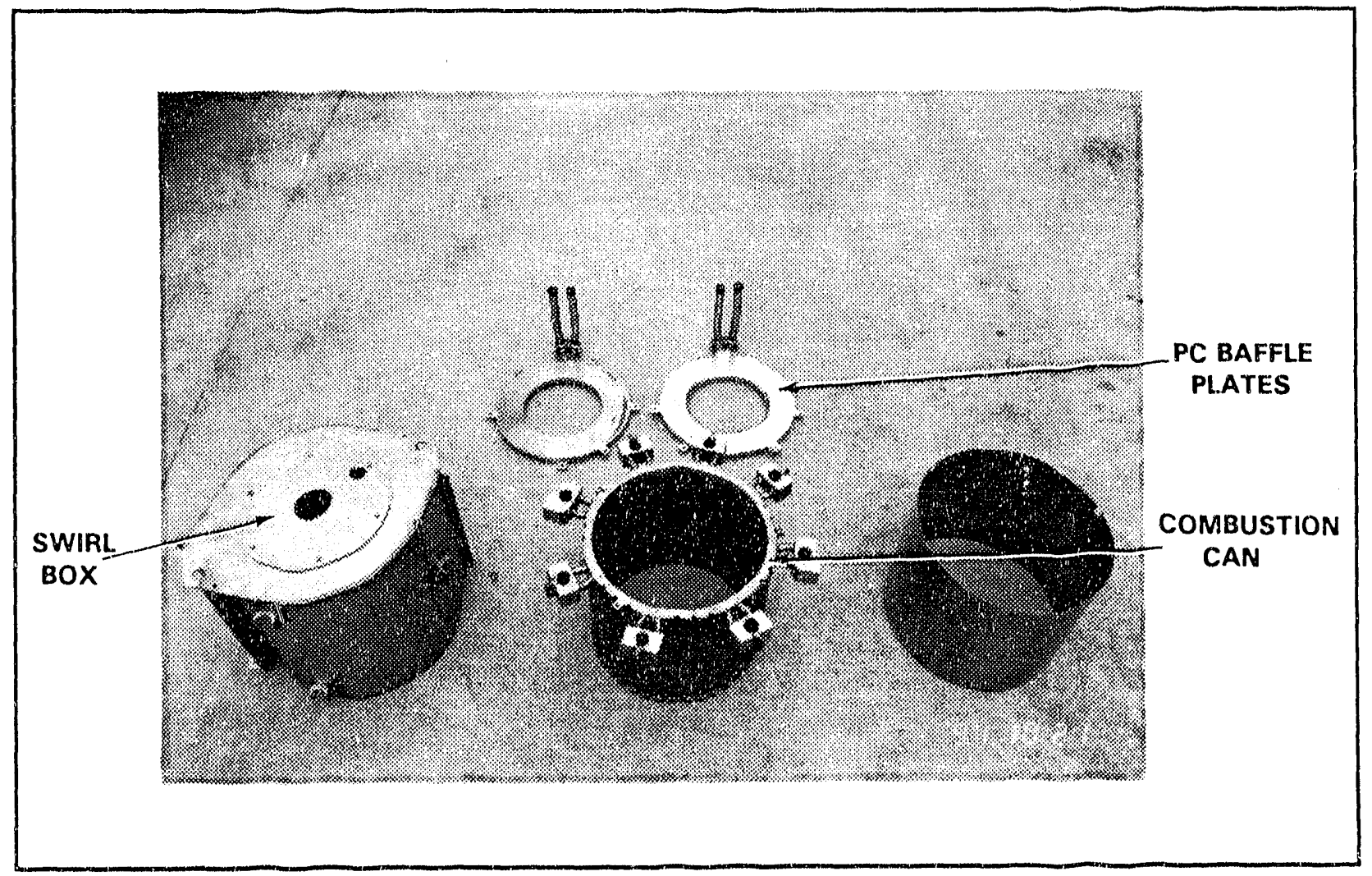

Figure 4-10. Precombustor Internal Components 


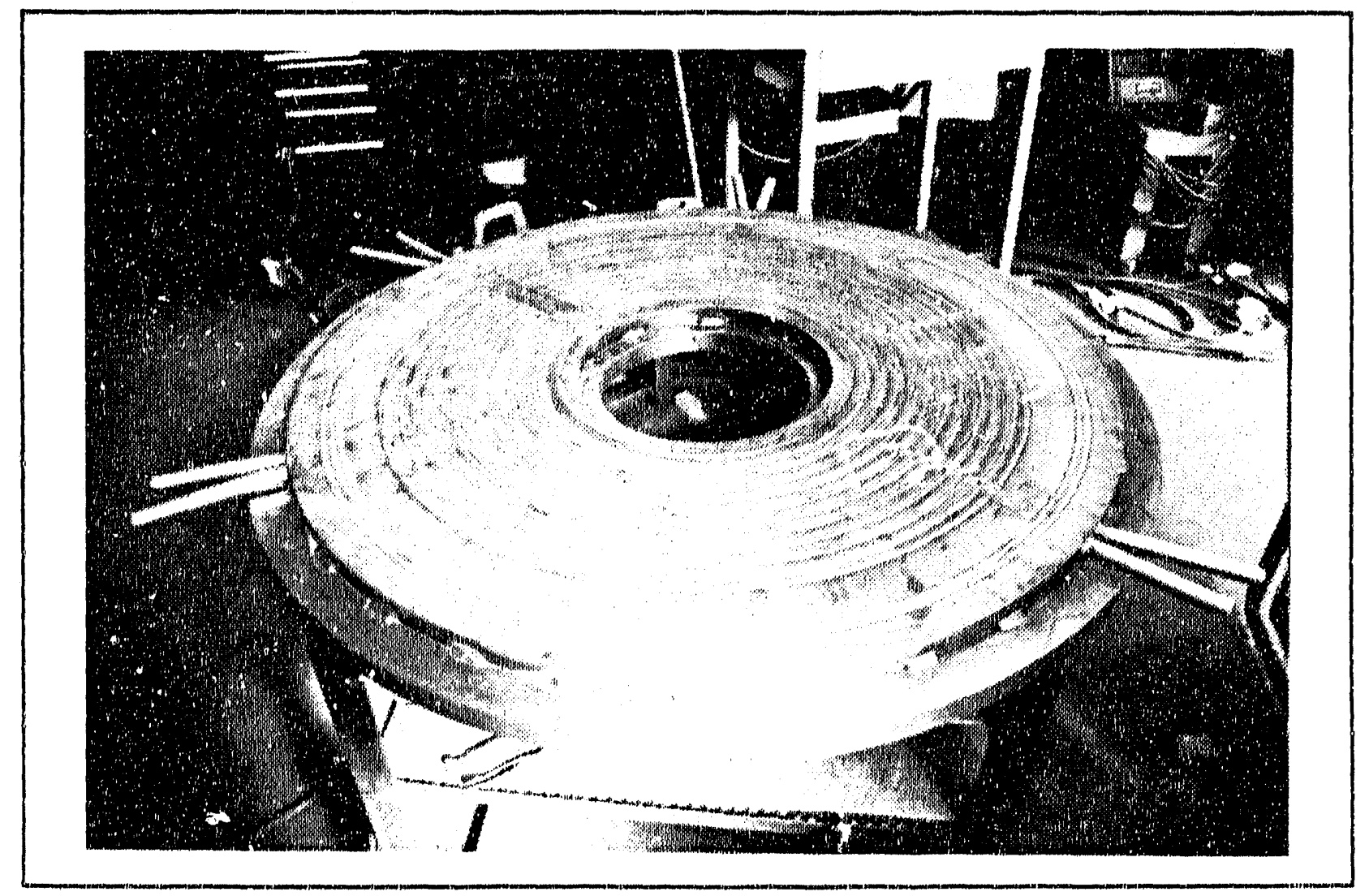

Figure 4.11. Baffle Plate with Covers Wolded in Place (Prior to Heat Treatment)

The eight-inch supply and retum headers are currently being fabricated and will be completed well before needed.

Purchase onders for the remaining major components having short fabrication cycles will be placed in November. These include the precombustor and slagging stage coal injectors, the seed injector, the cooling water electrical isolation assemblies and the combustion subsystem support stand ard platforms. All other assembly hardware except for the eight-inch coolant water isolation valves and six-inch recirculation valves have becr received.

\subsubsection{Low Pressure Cooling Subsystem (LPCS) Procurement}

The Low Pressure Cooling Water System (LPCS) provides conditioned cooling water (collant) to the prototypical combustion subsystem. The Ellis and Watts Model LTL-1500) (see simplified schematic Figure 4-12) is a self contained liquid-to-liquid heat exchange, coolant purification, filtration and temperatute control unit designed in provide continuous coolant conditioning and heat dissipation. The system is designed to provide nominally $1500 \mathrm{GPM}$ of deionized, low oxygen, neutral pH water at 310 psig and 110 degnes Faltrenteit. There are two $2(0) \mathrm{HP}$ main circulation pumps for operation during MHD lesting, and one $7.5 \mathrm{HP}$ circulation pump (150 GPM) for use when the main pumps are not operating. A self contained liquid.to-liquid plate type heat exchanger is included to provide continuous coolant heat dissipation at a rate of 17.8 million BTU/Hr. The cooling water provided to the heat exchanger (CDIF Secondary Cooling Water (SCW) system at $65^{\circ} \mathrm{F}$ maximum) will be controlled via a temperature control valve to ensure that the LPCS supply temperature to the combustion subsystem is maintained at $110^{\circ} \mathrm{F}$ : Makeup water for the L.PCS is supplied by the CDIF Primary Cooling Water (PCW) system. The skid is also supplied with connections for CDIF nitrogen for pressure control, service and instrument air for 


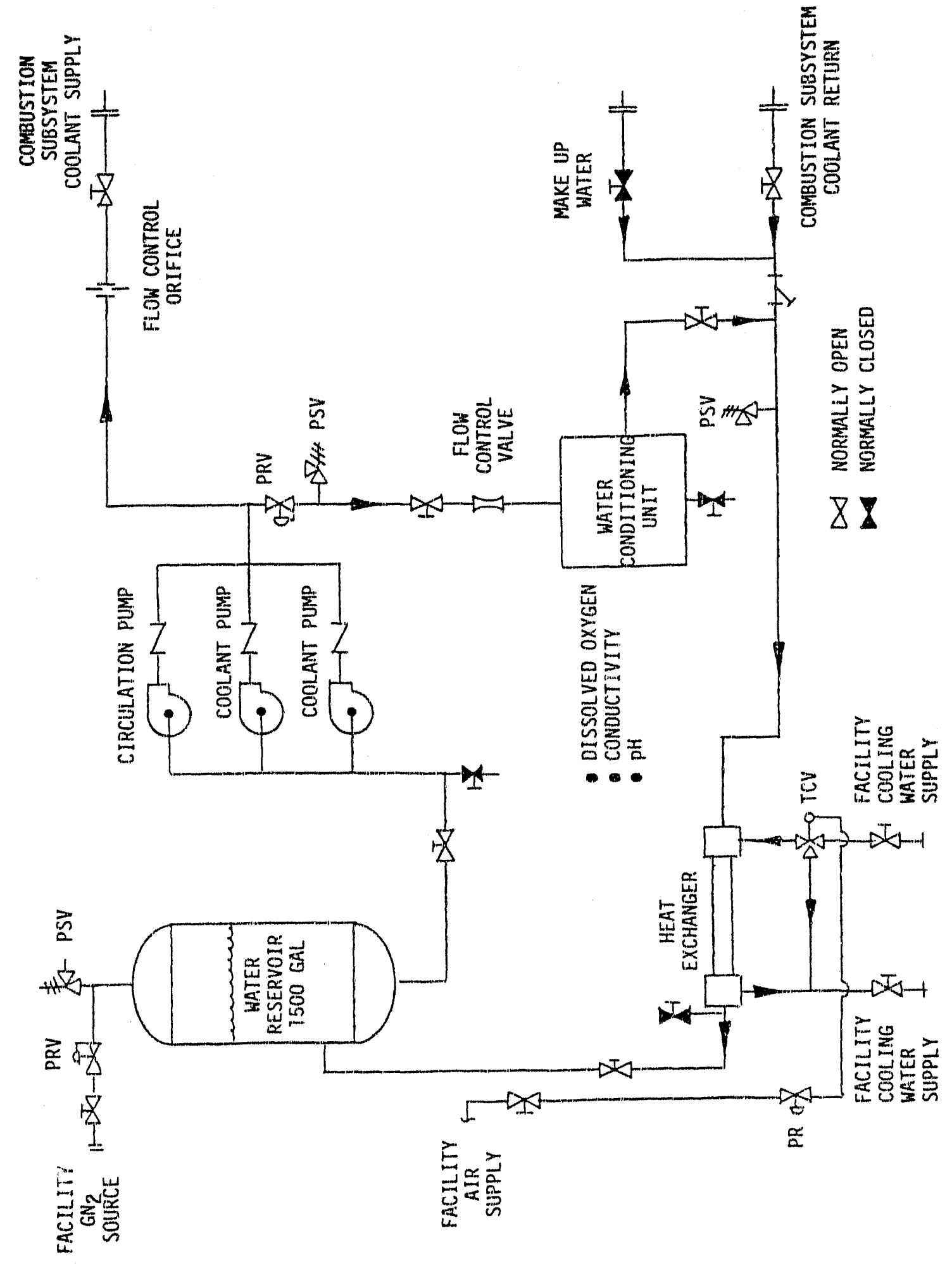


valve actuation, connection to the DAS and instrument recorders, and electrical power. A preliminary equipment layout plan and elevation is shown in Figures 4-13 and 4-14.

During previous reporting periods, the following tasks were completed as part of the Low Pressure Cooling Subsystem (LPCS) procurement:

- The L.PCS vendor, Ellis \& Wats, was placed under subcontract on 14 May 1991.

- A Conceptual Design Review of the LPCS design was held at Ellis \& Watts on 29 May 1991.

- The LPCS equipment specification was modified to eliminate the 2000F dryout capability.

- Work on the L.PCS detailed design continued, with a Final Design Review scheduled for 13 August 1991.

- TRW approved the purchase of several long lead items to ensure adherence to the LPCS delivery schedule.

During this reporting period, the following tasks were completed:

- A Final Design Review was held 13 August 1991.

- The LPCS equipment specification and Statement of Work were modified to correct errors.

- Cost incentives were initiated to maintain schedule.

The Final Design Review (FDR) held at the Ellis and Watts facility on 13 August 1991 was attended by TRW and MSE personnel. Drawings that were reviewed included the P\&ID, the interface control drawing, the electrical schematic, the overall layout, and the electrical box. The main design features described above were maintained. One area that changed from the Conceptual Design Review was the measurement of dissolved oxygen (DO) and $\mathrm{pH}$. The only sensors available requine a working pressure that is lower than the system pressure. The final resolution to the problem was the location of the $\mathrm{pH}$ and DO sensors on a separate leg of the L.PCS which will operate at lower pressune. The water from this separate leg will not be recirculated into the main LPCS. In order to minimize the amount of treated water lost through this separate leg. controls were added to the design to provide readings of $\mathrm{DO}$ and $\mathrm{pH}$ on a timed interval as well as on an "as-required" basis.

The delivery schedule presented at the FDR was one month after the need date, due to slippage by the suppliers as well as longer time required for assembly and fabrication by Ellis and Watts. This was unacceptable; therefore, TRW initiated graduated cost incentives for Ellis \& Wats and their suppliers in order to provide shipment of the LPCS skid prior to 15 January 1992.

All actions from the FDR have been resolved, and fabrication and installation of the components is almost complete. Figures 4-15 and 4-16 show selected components as they are assembled into the skid. Any interface problems with the CDIF have been resolved as soon as they were identified. 


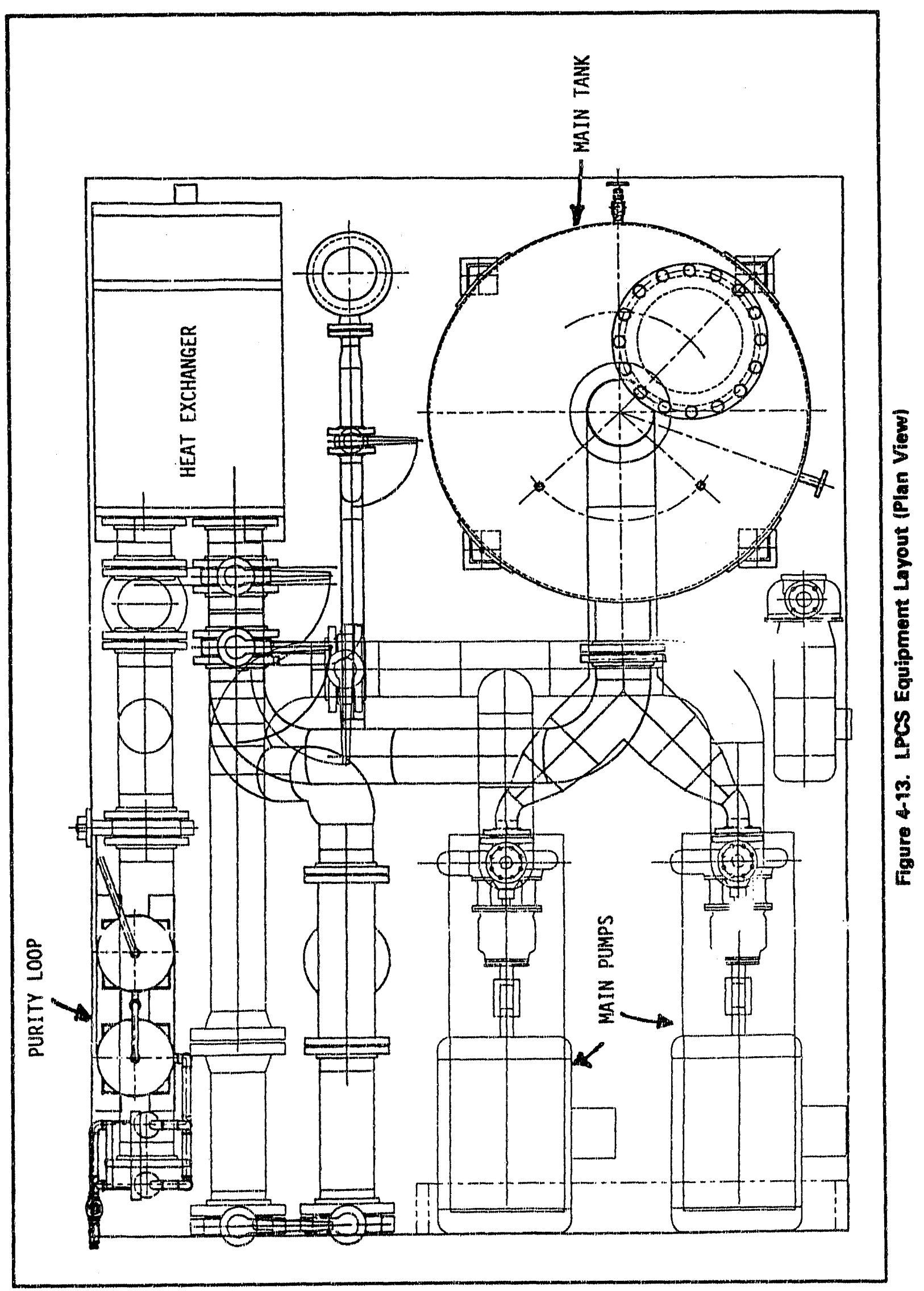




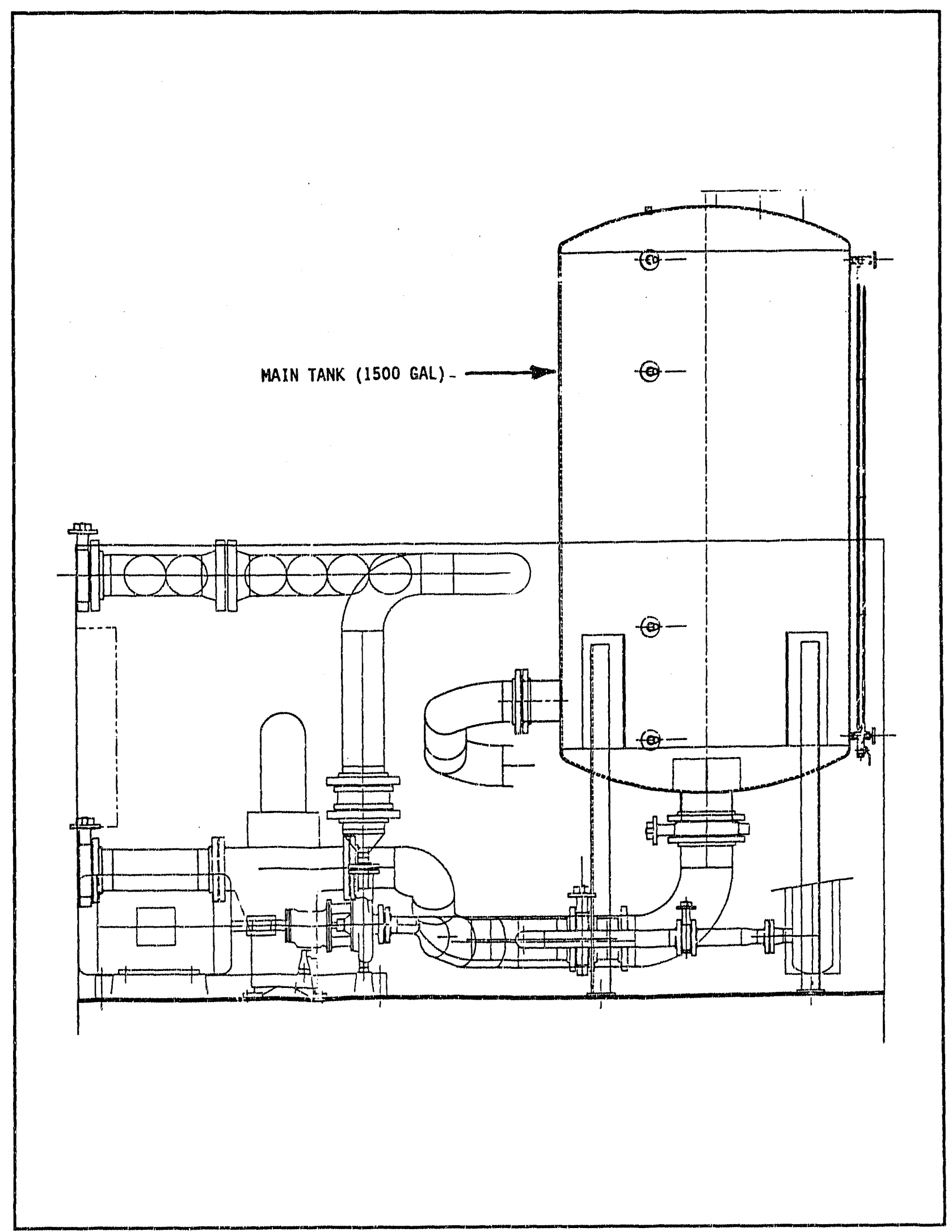

Figure 4-14. LPCS Equipment Layout (Elevation View) 


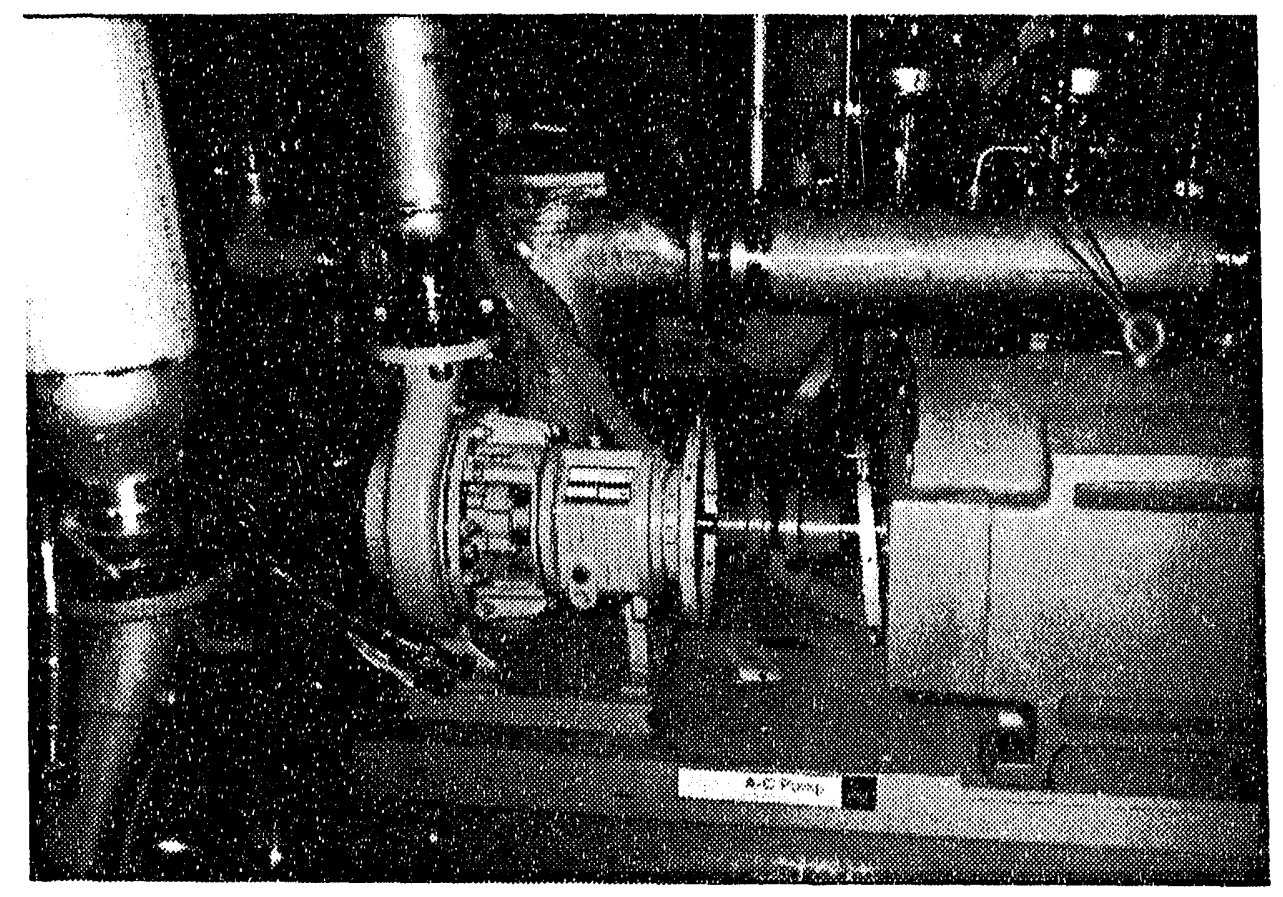

A. Main Pump No. 1

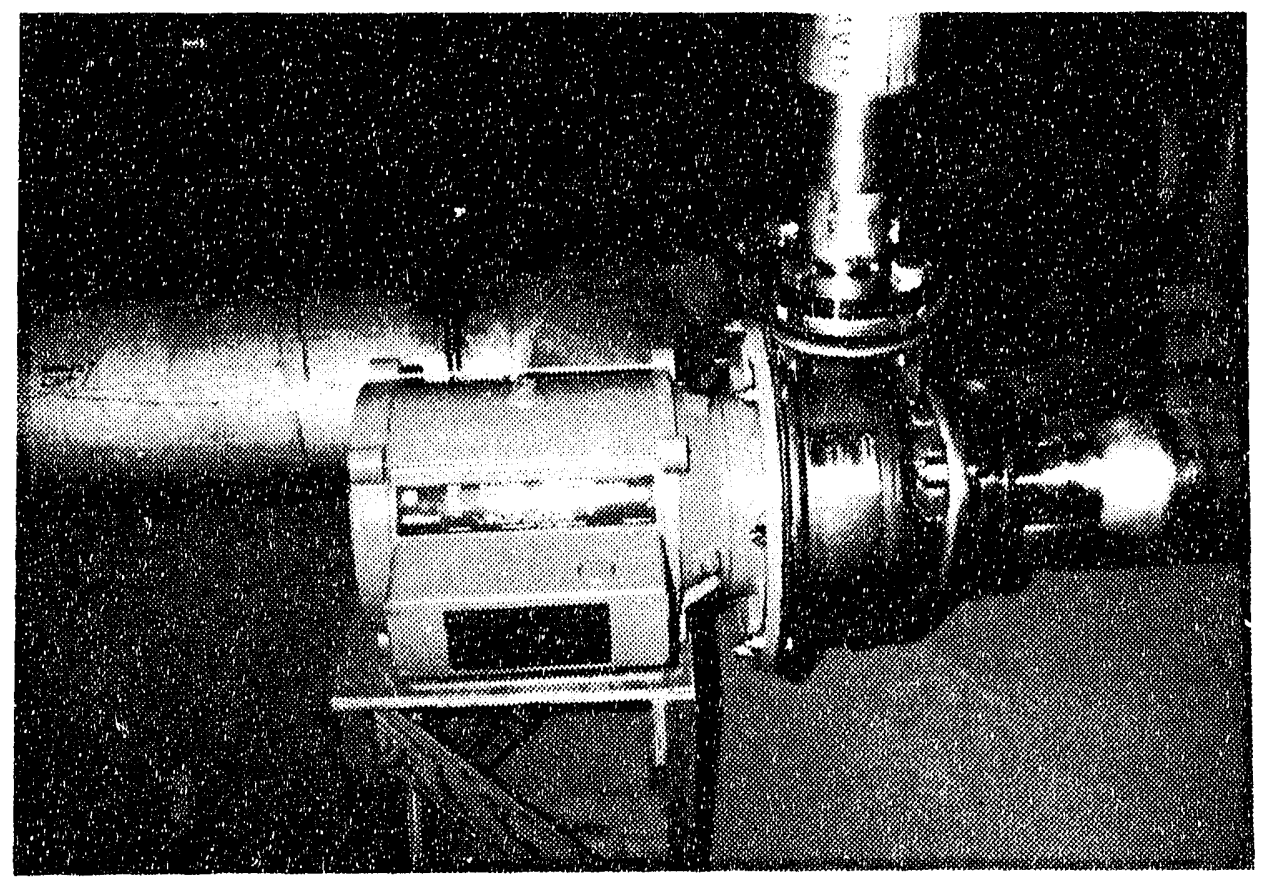

B. "Night-Jockey" Circulation Punp

Figure 4-15. LPCS Component Assembly 


\section{PROTOTYPICAL CHANNEL DESIGN}

During this reporting period, a decision was made regarding the primary and backup element designs for the 1A4 channel. As a result of coupon manufacturing and design confirmation testing, it became evident that the tungsten -copper base designs had not matured sufficiently to be carried forward as the prirnary design without affecting the overall delivery of the 1A4 channel. Therefore, a decision was made to go forward with the copper base designs as the primary design and to utilize the tungsten-copper base elements as the backup design.

This approach provides the capability of immediately proceeding with the 1A4 sidewall manufacturing while, at the same time, carrying to completion the manufacturing development and confirmation testing of the tungsten-copper base elements. The tungsten-copper base elements will continued to be carried forward in order to address concems with potential "undercutting" (arc erosion) of the gas-side capping in the presence of cathode wall voltage nonuniformities. Both primary and backup design elements will be included in the initial channel build for DVT testing. The channel design status including the sidewall tube cracking investigation and design decisions is described in Section 5.1.

During this reporting period, the assembly of the channel related prototypical hardware continued. The cathode wall electrical wiring is now complete. Sidewall assembly is well underway, with completion dates of February and March 1992 expected for the two sidewalls. Anode cap subassemblies are presently undergoing braze attachment of the platinum top caps to the tungsten substrates. A summary of the ongoing channel fabrication activities is presented in Section 5.2.

The mechanical design of the diffuser has been completed. The forward supersonic diffuser section in the $1 \mathrm{~A} 4$ channel is a new design and it features electrical segmentation to minimize current circulation. The three remaining diffuser sections (i.e., aft supersonic, forward subsonic, and aft subsonic) will be the standard copper design. They will be constructed by modifying the existing $1 \mathrm{~B} 2$ diffuser, thus eliminating the costly process of gun-drilling cooling water passages in new walls. Diffuser design activities are described in Section 5.3.

\subsection{CHANNEL DESIGN STATUS (TASK 3)}

During this reporting period, some manufacturing development issues related to the tungsten-copper base designs were identified. These issues and their resolutions are described in Section 5.1.1. As a result of these manufacturing development issues, a decision was made regarding the primary and backup designs for the 1A4 channel. Specifically, the copper base designs were designated as the primary design and the tungsten-copper base designs will be utilized as the backup design. Additional details on this decision are provided in Section 5.1.2.

\subsubsection{Tungsten-Copper Base Sidewall Tube Cracking Investigation}

\subsubsection{Background}

Several of the 1A4-style tungsten-copper base sidewall elements that were installed and tested in the 1 A1 channel developed cracks in the water tube. These cracks occurred in the brass tube just above the braze fillet. Both tungsten capped tungsten-copper and solid tungsten-copper designs experienced water tube cracking. Preliminary analysis suggests the cracks are stress corrosion related, resulting from the stresses imposed on the braze joint during brazing and subsequent attack by fluoride in the braze flux. Thus, proceeding with the fabrication of the Zone 1 and Zone 3 sidewall elements for the 1A4 requires both an understanding of the problem root cause and the successful implementation of a corrective action. The activities undertaken are outlined in the following sections.

\subsubsection{Design}

A layout of the $1 \mathrm{~A} 4$ sidewall at the time of coupon manufacture is shown in Figure 5-1. The Zone 1 elements were comprised of a 3/8-inch thick tungsten cap vacuum brazed onto a tungsten-copper (press- 


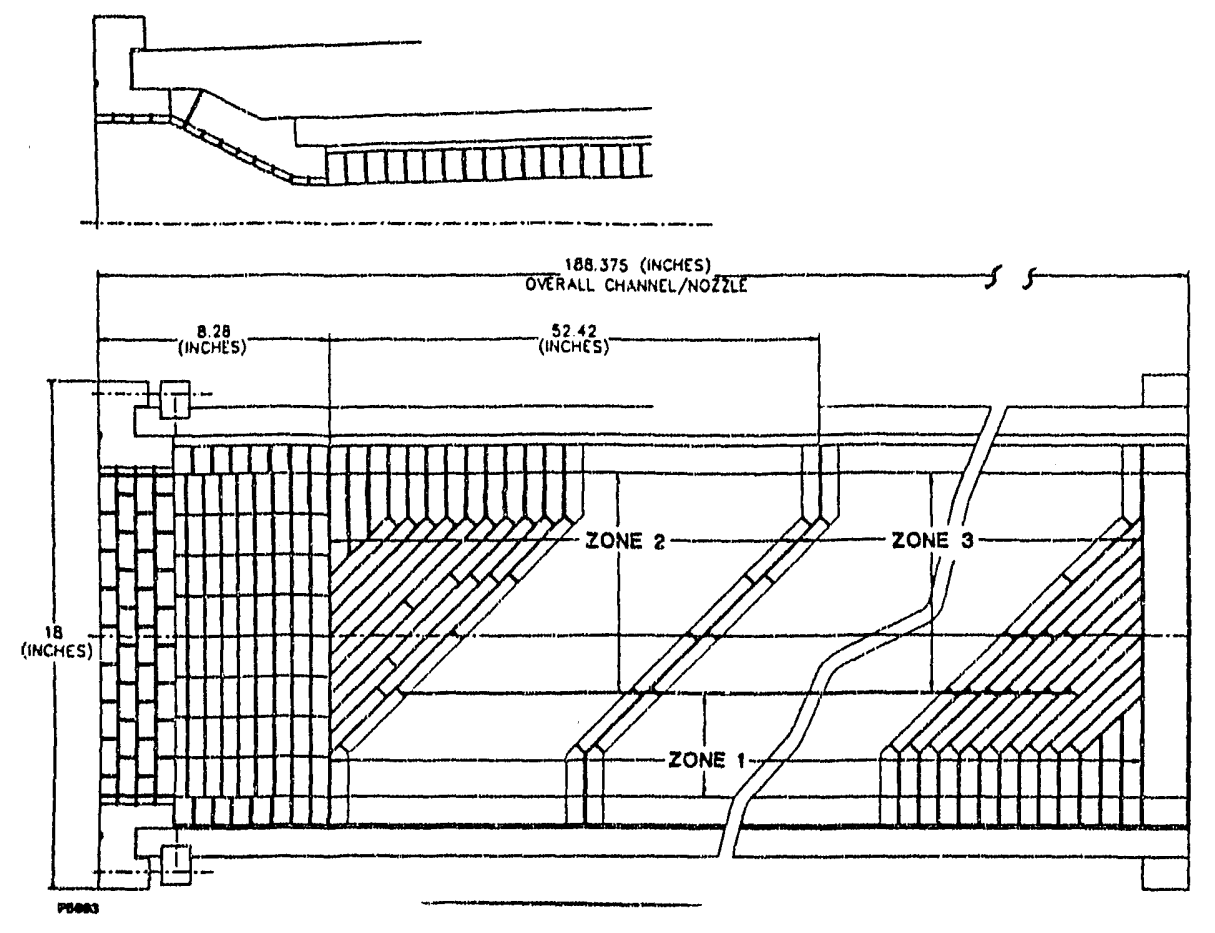

Figure 5-1. IA4 Channel Sidewall Gas-Side Material Zone Layout

sintered, $75 \%$ tungsten - $25 \%$ copper by weight) base. Lead free naval brass water tubes were torched brazed to the tungsten-copper base. The Zone 3 elements were comprised of a solid tungsten-copper piece with lead free naval brass water tubes. In both cases, the water tubes were torch brazed using B505 braze alloy and B-1 flux. The Zone 2 elements were comprised of tungsten capped copper. A cross-section of the sidewall designs, corresponding to the sidewall map is illustrated in Figure 5-2.

Tungsten-copper is utilized as the base material in Zone 1 because interelement arcing below the primary gas-side capping can occur when cathode wall high voltage gaps are present. Tungsten-copper being far more resistant to the material wastage process than copper is the preferred material. Downstream of the high heat flux region of the sidewalls, the remaining four bars of a diagonal row (designated Zone 3) are sufficiently removed from the high voltage breakdowns associated with the cathode wall slag polarization that they do not require tungsten capping. Gas-side lifetime projections indicate that tungsten-copper will provide the requisite lifetime of greater than 2000 hours. These elements are fabricated from solid tungstencopper to eliminate brazing of the gas-side capping, thereby, enhancing channel reliability.

\subsubsection{Root Cause Investigation}

Close examination of the 1A4-style tungsten-copper base sidewall elements installed in the CDIF 1A1 channel showed development of circumferential cracks in the water tube. The cracking initiates on the inside diameter of the tube and propagates outward resulting in a water leak. The cracks occurred in the brass water tube approximately $1 / 32$ to $1 / 16$ inch above the braze fillet. Both tungsten capped tungstencopper and solid tungsten-copper designs experienced cracking. No such cracking was observed in the tungsten on copper designs (Zone 2 of Figure 5-1) and, in addition, no cracks were observed in either the 1A4-style cathodes or anodes, which are comprised of tungsten caps or platinum/tungsten caps on copper bases, respectively. These observations suggested the cracking was specific to the designs incorporating 


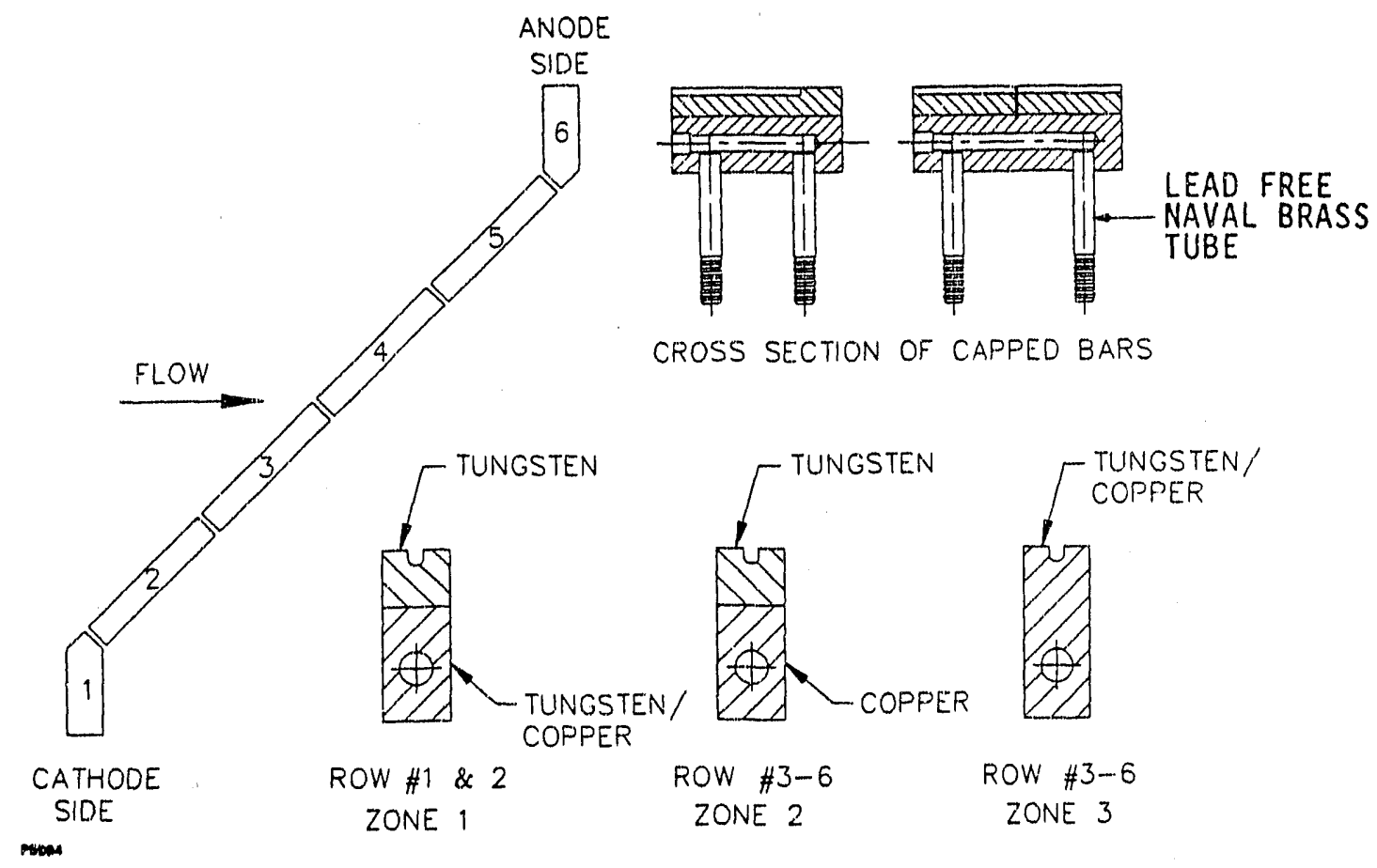

Figure 5-2. 1A4 Sidewall Z-Bar Elements

naval brass water tubes and tungsten-copper bases. Preliminary analysis suggested the cracks result from a brittle fracture condition which occurs as a result of stress corrosion cracking of the tube material in the heat affected zone adjacent to the braze fillet. The stress corrosion cracking of the water tube was caused by the different themal expansion coefficients between the tungsten-copper and brass materials which induce stresses on the braze joint during the brazing process. These stresses coupled with attack by the fluoride present in the braze flux cause the tube to crack. Careful post-test and fabrication inspections coupled with metallographic examinations were conducted which support these findings. Discussions with outside specialists confirmed that naval brass with a high zinc content (40\%) is very susceptible to stress corrosion cracking and is not the preferred tube material.

\subsubsection{Corrective Action}

In addition to the investigations conducted to determine the cause of the tube cracking, action was also taken to evaluate alternate solutions and/or design approaches. Of the several options evaluated, two approaches emerged as the most promising:

- Reduce the stress at the braze joint by selecting a copper base (which also does not require a braze flux containing fluoride).

- Change the tube material to a material not susceptible to stress corrosion cracking.

Plans have been made to evaluate tungsten-copper base sidebars fabricated with a bronze tube at the CDIF (see Section 7.2.2 for details). In addition, rigorous in-process manufacturing inspections and postmanufacturing evaluations including metallographic examinations are planned on candidate designs. The copper base design is available should design confirmation results impact channel delivery schedules. A logic network for these activities is depicted in Figure 5-3. 


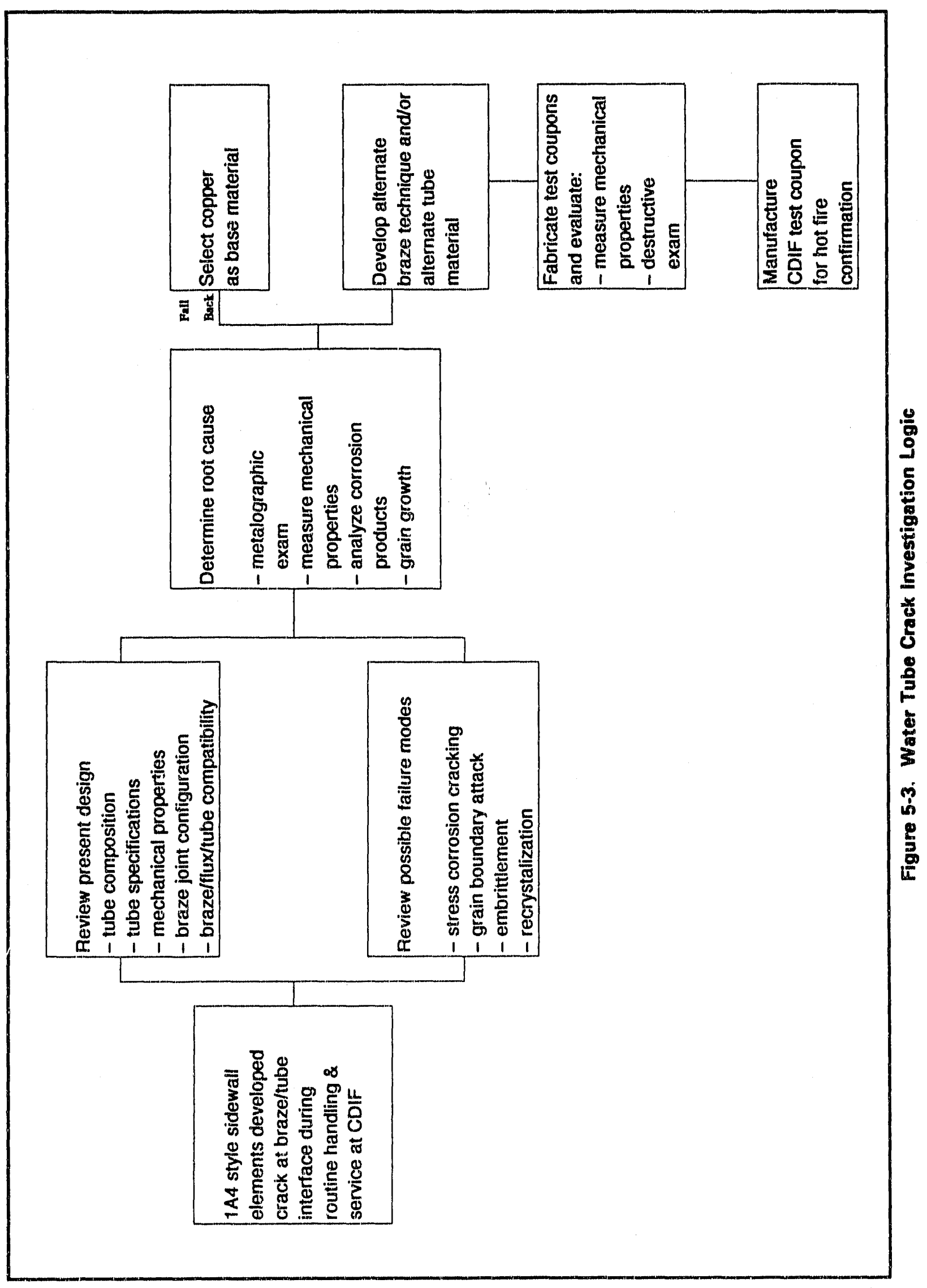




\subsubsection{A4 Sidewall Design and Manufacturing Decisions}

At the channel CDR, two designs for the 1A4 sidewalls, designated primary and backup, were carried forward into the manufacturing phase. As illustrated in Figure 5-1, the primary design consisted of tungsten capped tungsten-copper in Zone 1, tungsten capped copper in Zone 2 and solid tungsten-copper in Zone 3. The backup featured the same gas-side protection but with a copper base in Zones 1 and 3 .

As a result of coupon manufacturing and $1 \mathrm{~A} 1$ design confirmation testing, the CDR backup sidewall fabrication plan, incorporating all copper base sidebars, has been selected to be the new primary design. It is evident that the tungsten-copper base designs have not matured sufficiently to be carried forward as the primary design without affecting the overall delivery of the $1 \mathrm{~A} 4$ channel. The primary reasons for this decision are as follows:

- Water-side corrosion of the tungsten-copper in the absence of adequate $\mathrm{pH}$ control.

- Delays in obtaining CDIF coal-fired confirmation results for the upgraded sidewall designs reflecting changes in the tungsten cap design and water tube material.

The tungsten-copper base sidebars will continue to be carried forward as the backup design in order to address the concerns with potential undercutting of the gas-side capping in the presence of cathode wall voltage nonuniformities. In order to gain additional experience and experimental data regarding undercutting, a specific wiring configuration simulating high intercathode gaps on the workhorse $1 \mathrm{~A} 1$ channel is planned for the next quarter as described in Section 7.4.3.

The gas-side materials for DVT testing are unchanged from those originally agreed to at the channel subsystem CDR. In addition approximately fifty (50) rows of the DVT channel will incorporate the tungsten-copper base design. This approach provides sufficient confirmation testing ( 50 hours electrical) should their use be necessary during POC testing.

Sufficient hardware will be fabricated to enable the complete assembly of the channel without using any of the backup design elements. In addition, sufficient tungsten-copper base designs will be fabricated to enable replacement of all primary designs (copper base) in the rows adjacent to the cathode wall (rows 1,2 and some of row 3).

\subsection{CHANNEL FABRICATION STATUS (TASK 3)}

\subsubsection{Schedule}

The 1A4 nozzle, channel and diffuser fabrication status are shown in Figures 5-4 through 5-6. Completed activities are shown in black and ongoing activities in gray. Delivery of the 1A4 hardware to the DOE test facility remains scheduled for May 1992.

\subsubsection{Cathode Wall}

Assembly of the cathode wall is now complete. Figure 5-7 shows the underside of the cathode wall. Specially designed brackets confine the electrical wires in an orderly fashion. The "fin" that protrudes from the wiring hamesses will sit in the mid-channel support. The cathode wiring teminations at the channel wiring panel are shown in Figure 5-8.

\subsubsection{Sidewalls}

Sidebar brazing and sidewall assembly are underway. Figure 5-9 shows the brazing of the cooling water tubes onto sidewall elements. A partially assembled Z-bar sidewall appears in Figure 5-10. One of the sidewalls is scheduled for completion in February 1992 and the other is scheduled one month later.

\subsubsection{Anode Wall}

Anode cap brazing activities are underway. Figure 5-11 shows the fixturing of pieces for the oven braze of the platinum-clad tungsten top cap subassemblies. After these components are brazed, they must undergo a rigorous ultrasonic imaging inspection process. Typical anode cap subassembly ultrasound 


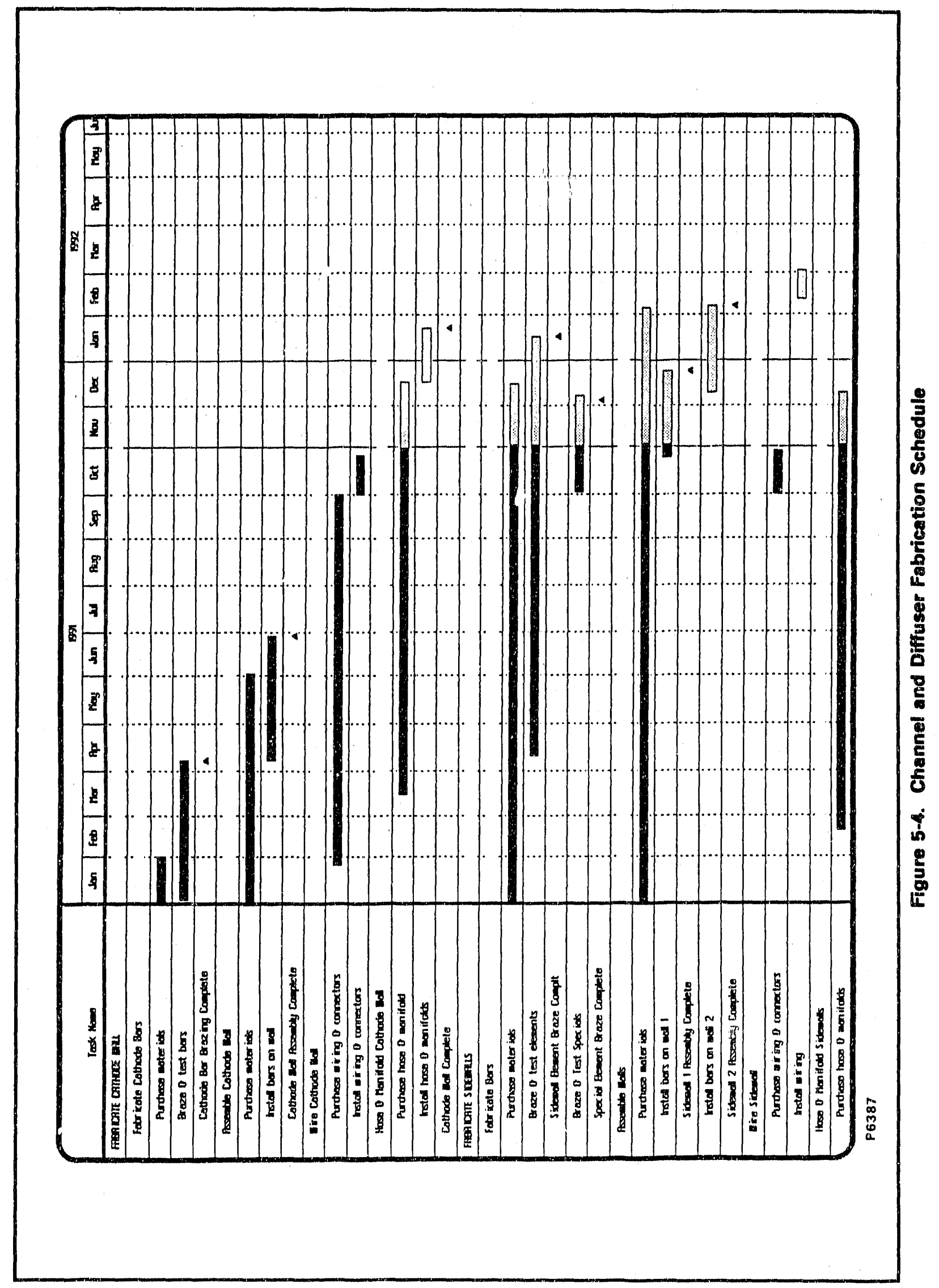




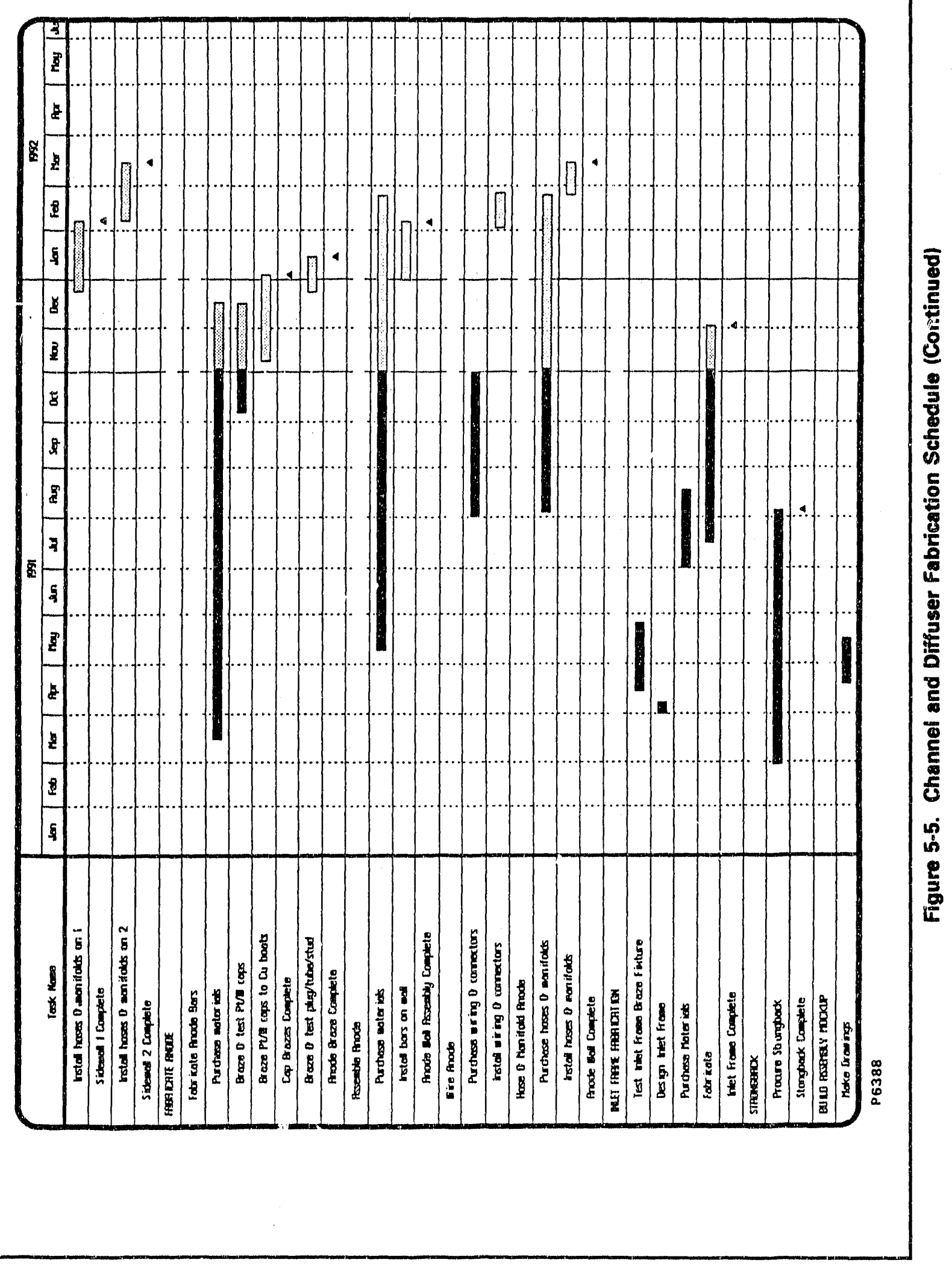




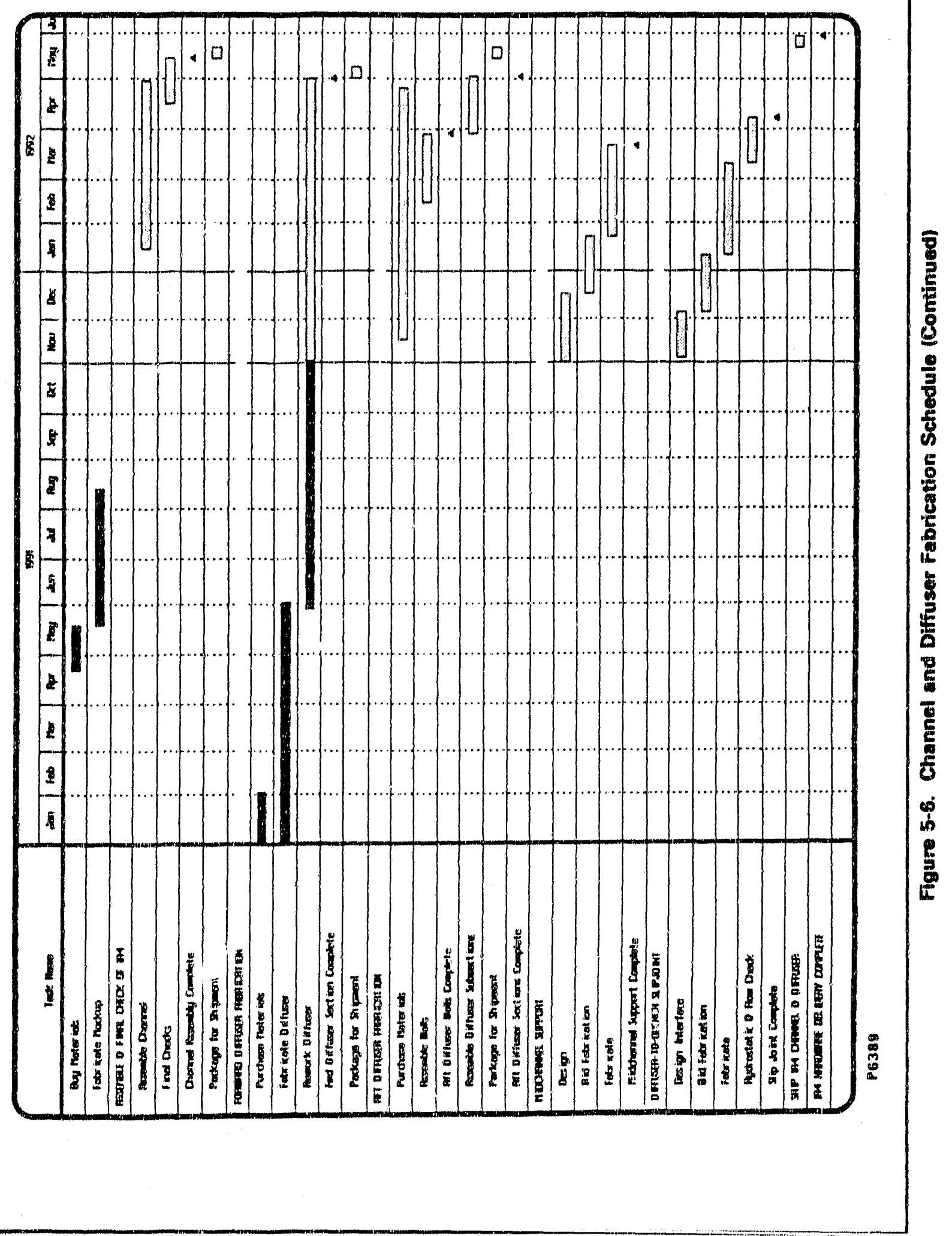




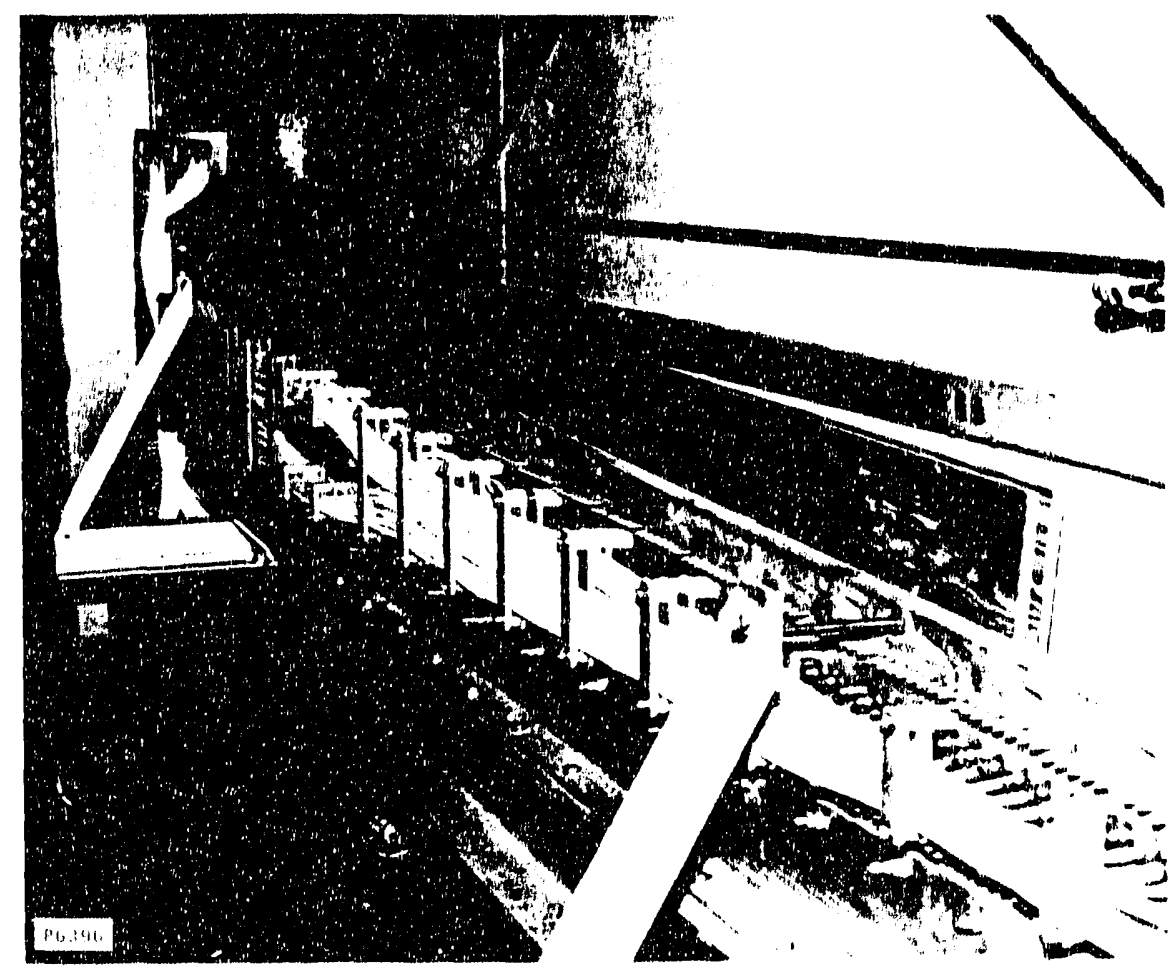

Figure 5-7. Cathode Wall Wiring

inspection results are shown in Figure 5-12. Images looking straight down (square images) and looking at an end view (rectangular images) are produced for each subassembly. Braze voids, which show up as white spots in the image, will cause a defective piece to be rejected. Exact record keeping for all components is maintained for quality control purposes.

\subsubsection{Manifolding and Supporting Brackets}

Cooling water manifolds and their supporting brackets have been designed and ordered. Figures $5-13$ and 5-14 are schematic representations of the manifolding/brackets.

\subsection{DIFFUSER DESIGN (TASK 4)}

\subsubsection{Summary}

The forward supersonic section in the 1A4 diffuser is a new component with transverse and axial segmentation designed to minimize current circulation. The other three diffuser sections (aft supersonic, forward subsonic, and aft subsonic) will be the standard copper design and will be constructed by modifying existing 1B2 diffuser sections. This eliminates the costly process of gun-drilling cooling water passages in new walls.

\subsubsection{Mectanical Design}

Figure 5-15(a) shows the gas-side dimensions of the $1 \mathrm{~A} 1$ diffuser and Figure 5-15(b) shows the dimensions of the 1 A4 diffuser.

The forward supersonic section is constructed using water-cooled copper elements mounted on four separable plastic walls. The copper bases will have explosion bonded stainless steel on the gas-side surface. There are 18 segments in the streamwise direction, and each segment on the sidewalls is divided into two electrically isolated elements. 


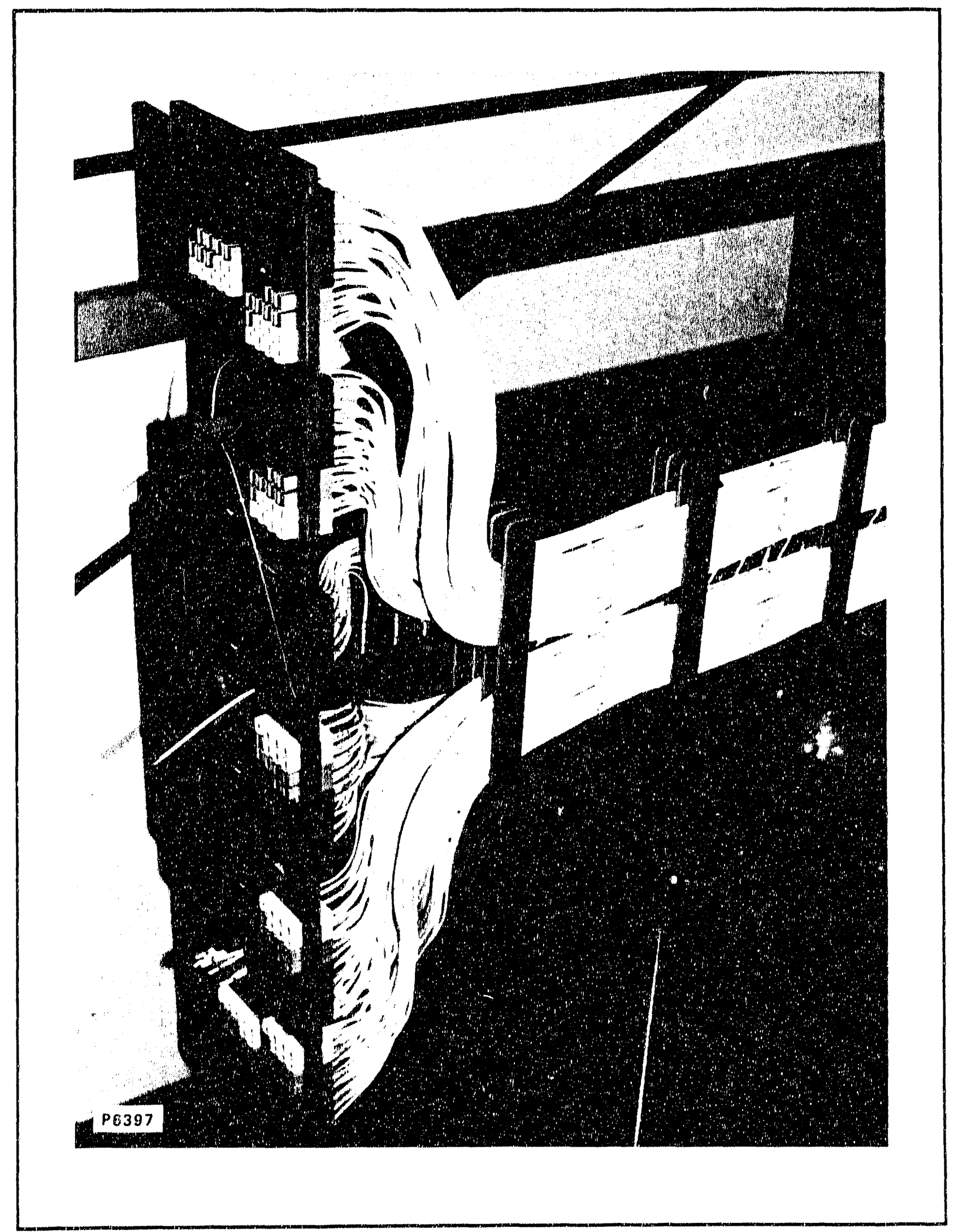

Figure 5-8. Cathode Wall Wiring Parel

围 


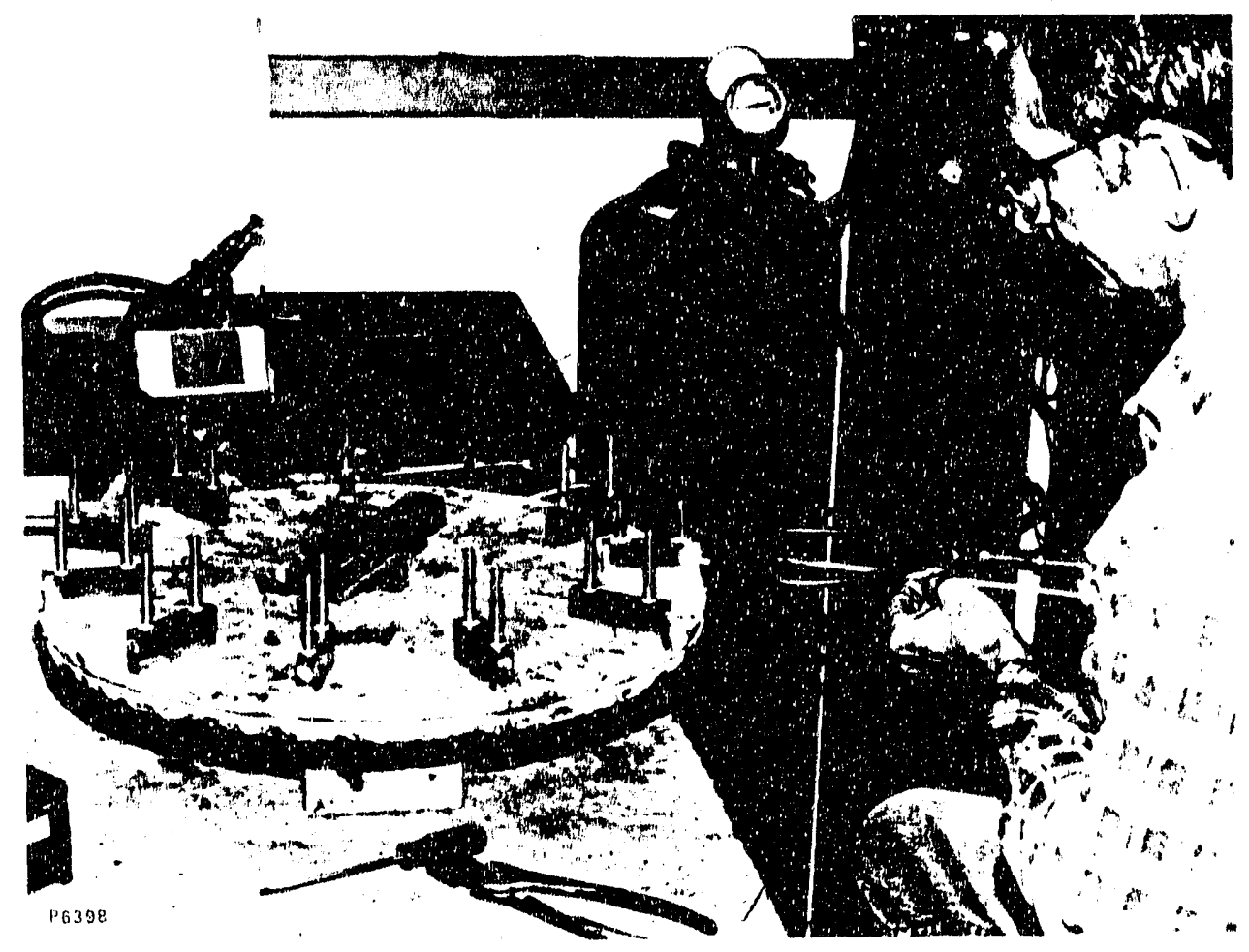

Figure 5-9. Sidewall Water Tube Brazing

In order to obtain the $1 \mathrm{~A} 4$ dimensions from the larger $1 \mathrm{~B} 2$ diffuser, the $1 \mathrm{~B} 2$ panels must be machined down, cutting across some of the existing cooling water holes which are therefore left unused. Finite element calculations were run to ensure that those edges were adequately cooled by the closest flowing passage. The results are discussed in Section 5.3.3.

There were no external coolant jumper hoses between sections on the $1 \mathrm{~B} 2$ diffuser. Instead, the integral manifolds on each section mated up with through holes and O-ring seals. Since these interfaces could potentially be the locations of water leaks during the POC testing, it was decided to machine the existing manifolds off and braze new ones on. The new manifolds would have fittings to allow exterior jumpering. Hosing of the three sections was designed to keep as neat a configuration as possible.

Investigations are currently underway to examine the possibility of coating the gas-side surfaces of the three aft sections with either nickel or ceramics using a plasma spray process. This would minimize gas" side erosion/corrosion of the bare copper surfaces.

\subsubsection{Cooling Water Design}

The forward supersonic section will be cooled independently because of the pressure drops associated with its segmentation. In addition, cooling this section is more critical because some of the elements will be used to carry current for the Westinghouse current consolidators. Each wall will be supplied with 15 GPM of cooling water and will have two passes using external jumper hoses.

The aft diffuser will be cooled in two separate sections: 1) the aft supersonic and forward subsonic sections will be cooled together, while 2) the aft subsonic will be manifolded independently. The interface to the facility, however, will be a single inlet and exit header supplying the total flow required. Each wall on all three sections will have two passes. This minimizes the number of inlet and exil hoses. The additional pressure drop from the extra passes and higher passage water velocity, as compared to the $1 \mathrm{Al}$ 


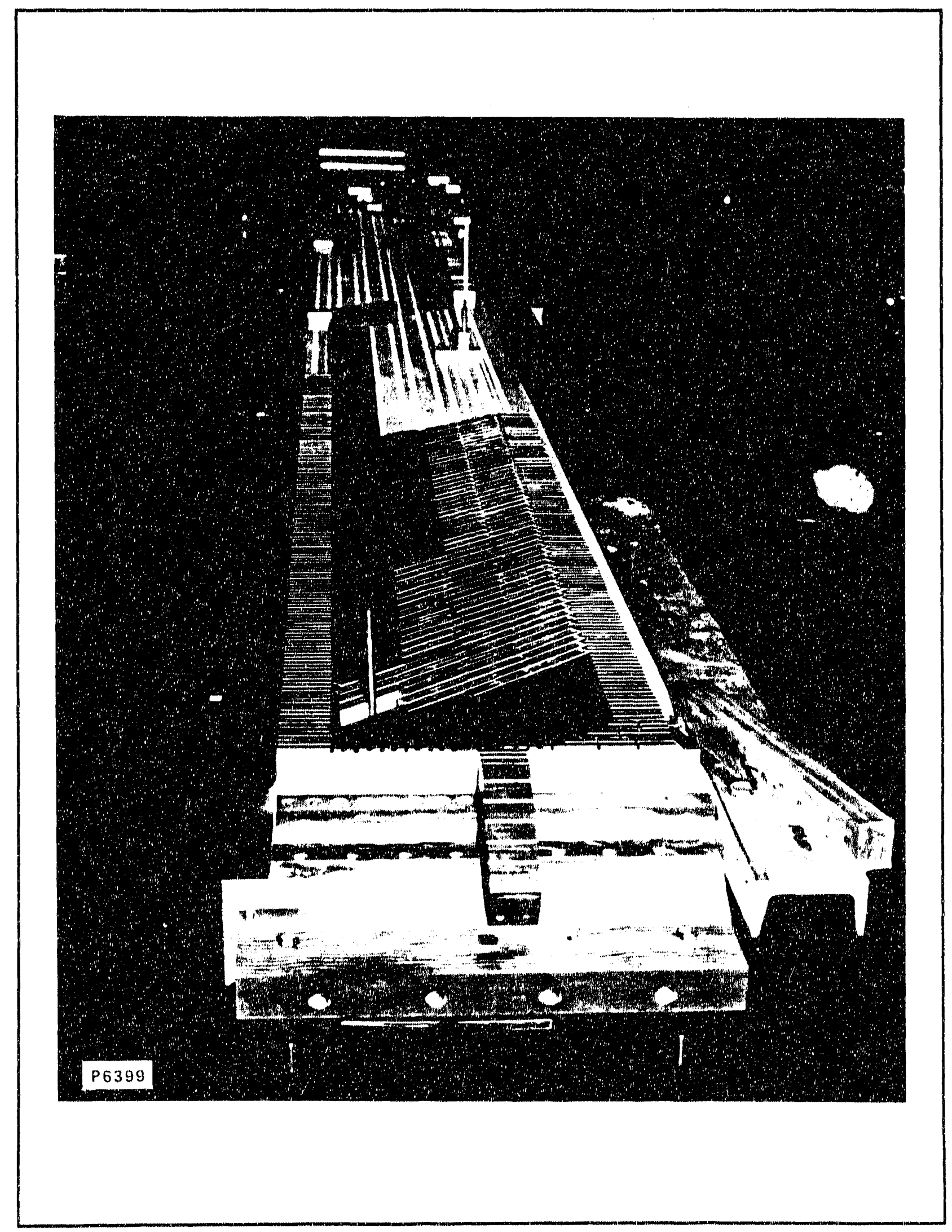

Figure 5-10. Partially Assembled Sidewall 


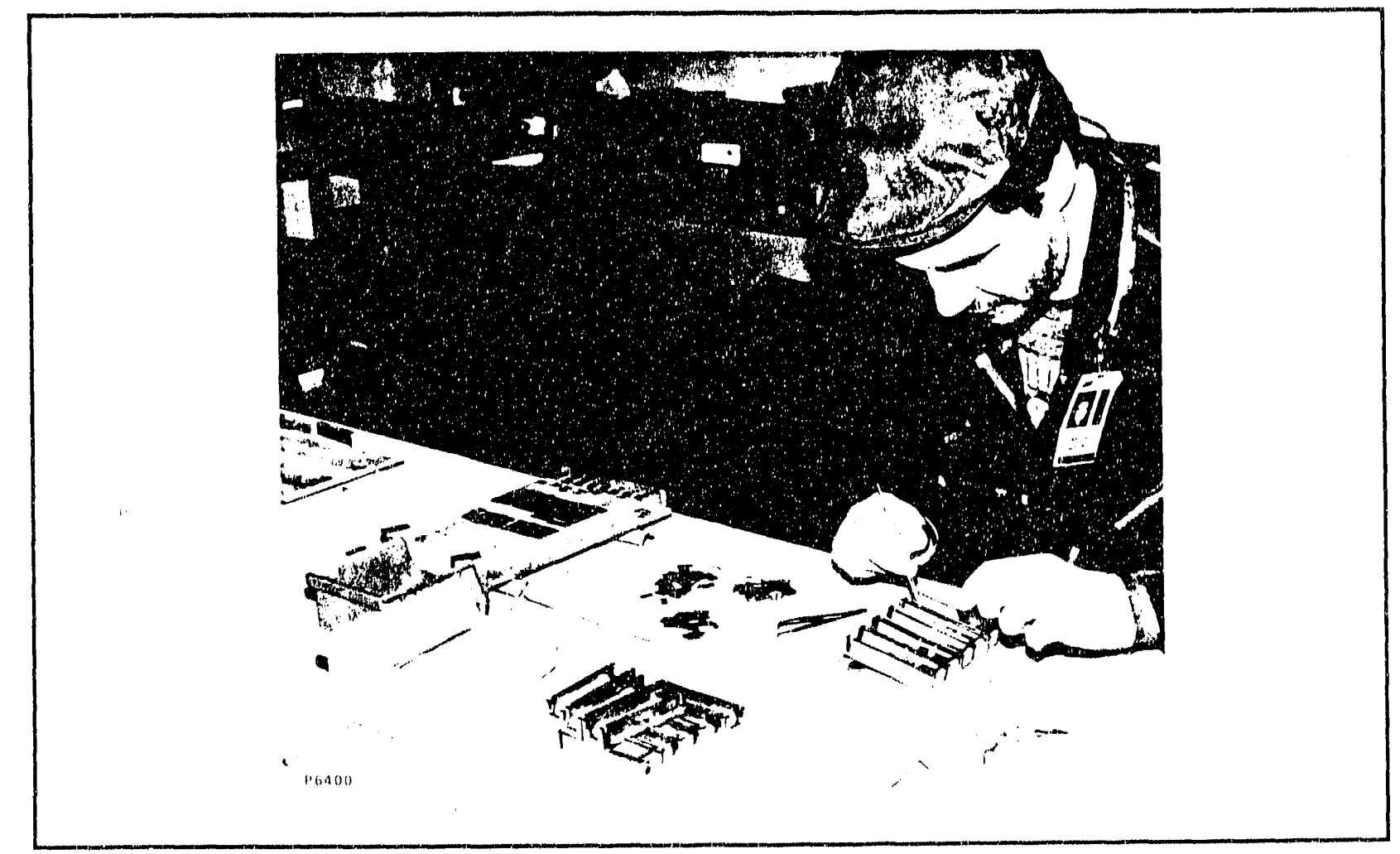

Figure 5-11. Anode Cap Subassembly Fixturing

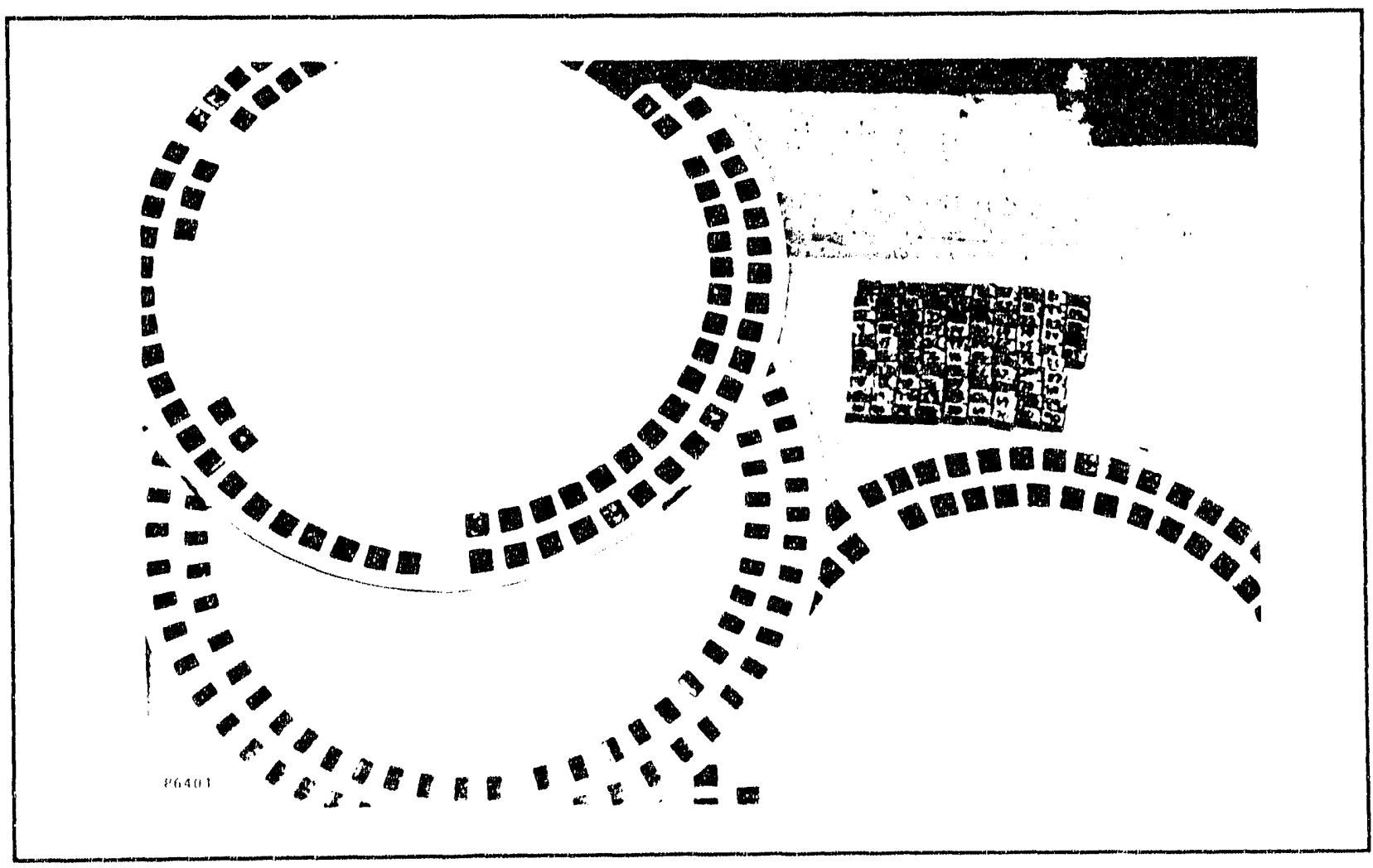

Figure 5-12. Anode Cap Subassembly Uitrasound Inspection Records 


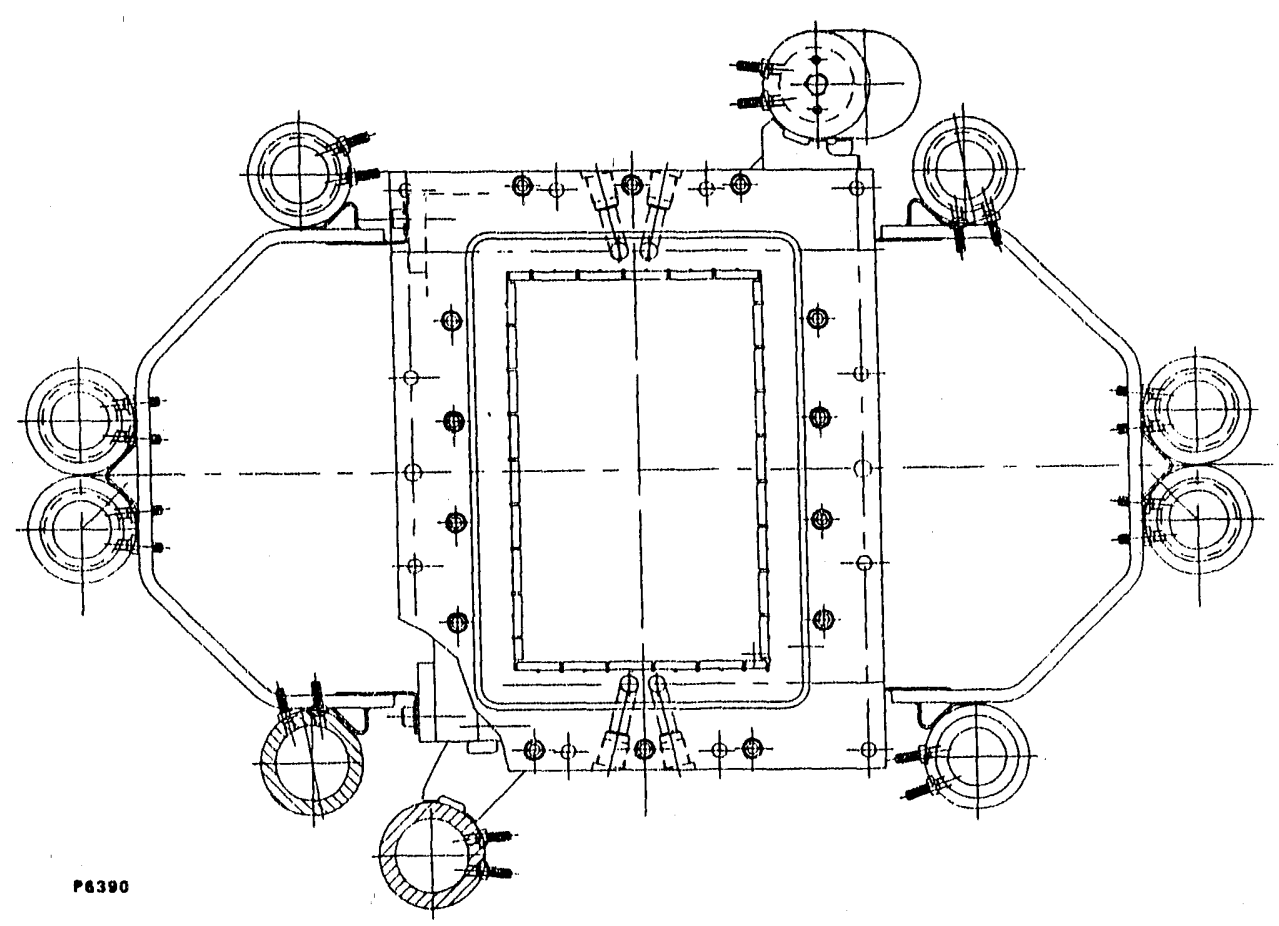

Figure 5-13. Water Manifolds and Brackets - End View

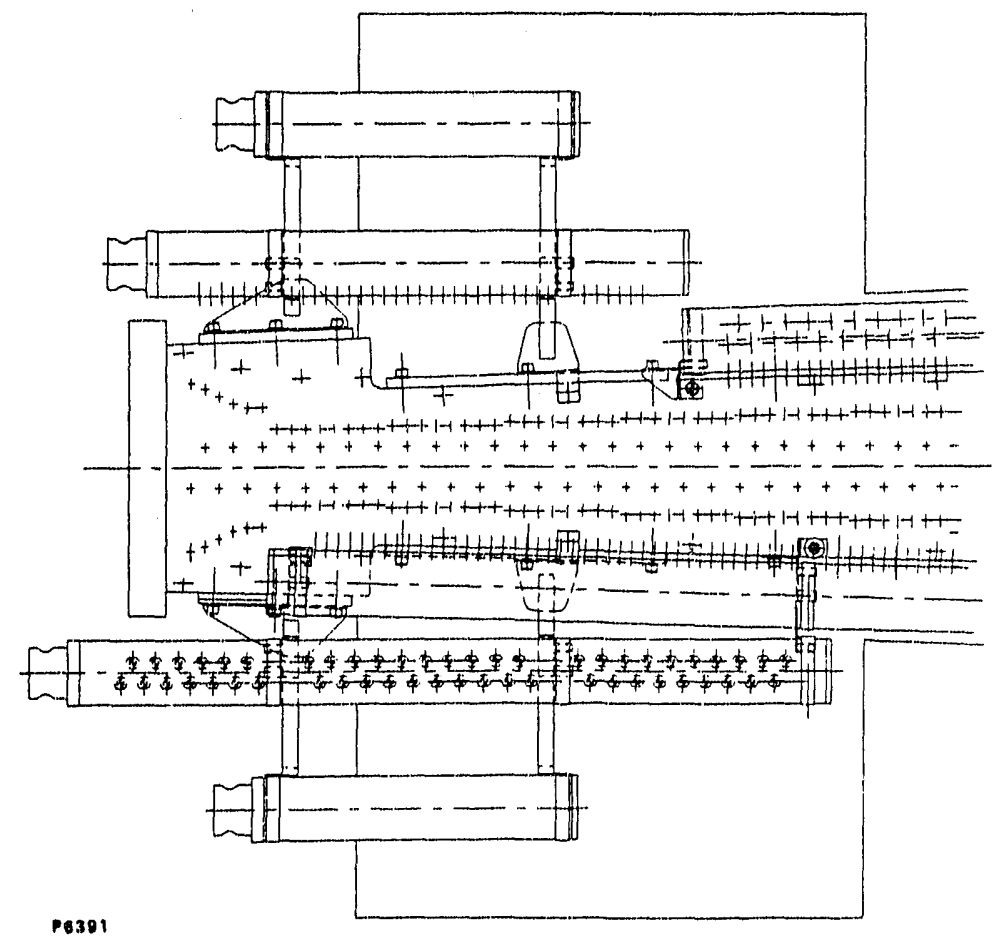

Figure 5-14. Water Manifolds and Brackets - Top View 


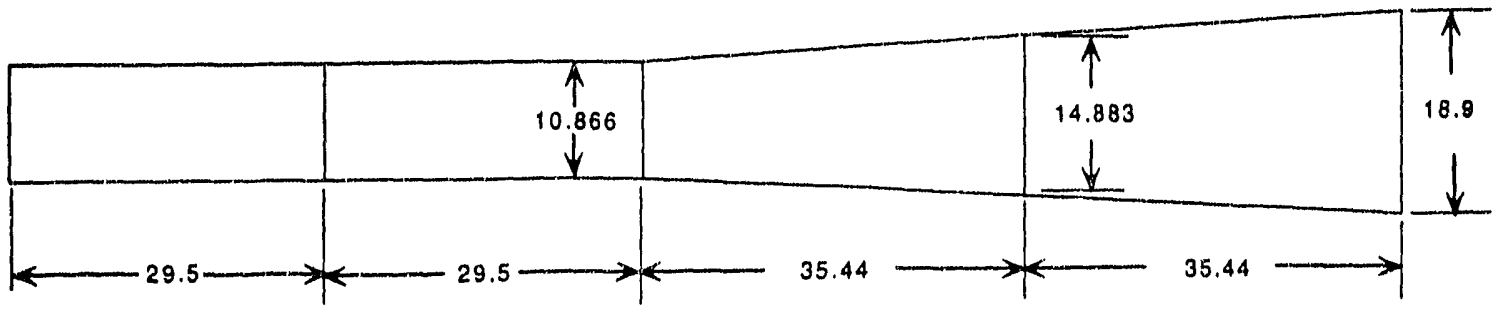

Electrode Wall

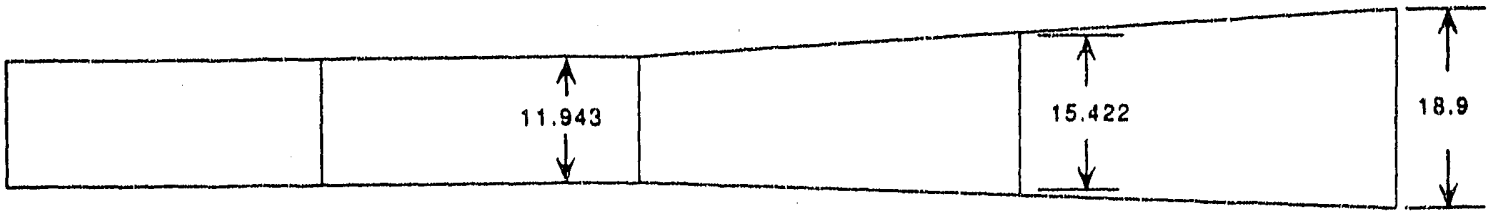

Sidewali

P6392

Figure 5-15(a). Diffuser Comparisons: CDIF 1A1

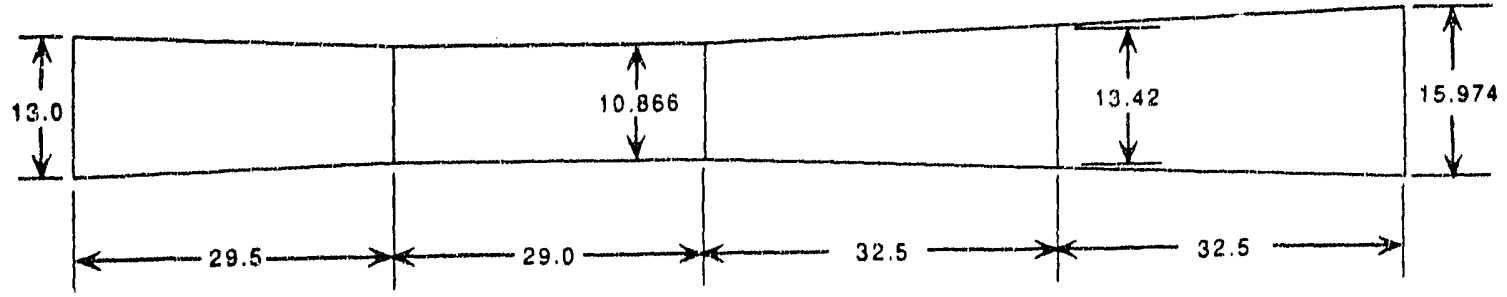

Electrode Wall

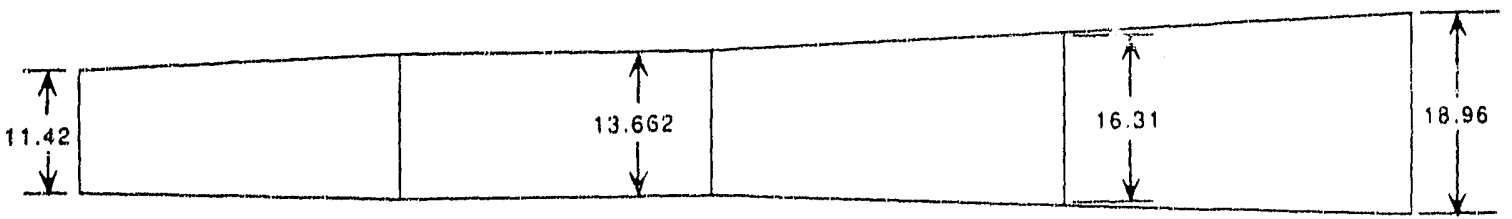

P6393

Sidewall

Figure 5-15(b). Diffuser Comparisons: CDIF 1A4 
diffuser, resulted in the last section being cooled separately. An added requirement of the aft subsonic section was that the hoses could not interfere with the slip joint and thus were to be kept as far forward as possible. Figure 5-16 shows a sketch of the manifolding scheme.

In calculating flow rates, it was assumed very conservatively that the heat flux throughout the diffuser is the same as at the channel exit. The resulting PCW flow requirements for each wall are shown in Table 5-1. This table also shows the calculated minimum safety factors for both nominal coolant flow conditions and the loss of an inlet hose. The worst case under normal conditions is the second pass of the aft subsonic section, where the velocity and available subcool are low, so that the safety factor is 5.3. In the event of a lost hose, the worst case condition becomes the loss of the inlet hose at the forward supersonic section where the pressure drop from the exit manifold back pressure is greatest and, therefore, the reverse water velocity would be lowest. This minimum safety factor was found to be 2.6, assuming the same heat flux as at the channel exit.

Calculations were then performed to determine whether the modified $1 \mathrm{~B} 2$ sections with unused water passages were adequately cooled. The worst case condition on the sidewalls would be at the second pass of the forward subsonic section where not only the cooling water temperature and surface heat flux are high, but where there are the greatest number of unused passages (three on each edge). A cross-section of one edge including four passages was analyzed, with the left-most passage being the only cooled one. The ambient heat flux was applied to the gas-side surface above that passage only, since the others would be sand wiching the top and bottom walls and therefore would not be exposed to the plasma. At a water temperature of $134^{\circ} \mathrm{F}$ in the cooled passage and a heat flux of $45 \mathrm{~W} / \mathrm{cm}^{2}$ on the sidewalls, the maximum copper temperature was found to be $210^{\circ} \mathrm{F}$ at the left comer of the heated surface. On the top and bottom walls, the maximum number of unused water passages is lower (one and a half in the aft supersonic section), but they are directly exposed to the plasma because these walls are sandwiched by the sidewalls.

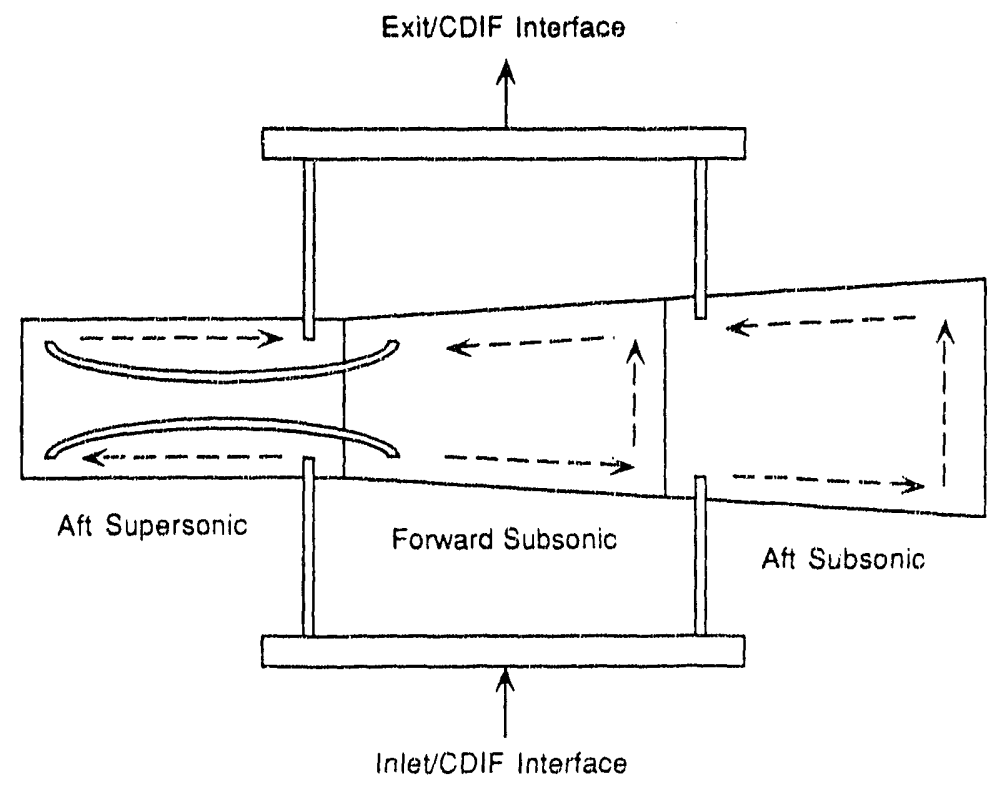

External Hosing

Figure 5-16. Typical Hosing Scherne for 1A4 Aft Diffuser Sections 
TABLE 5-1. COOLING WATER REQUIREMENTS

\begin{tabular}{|l|c|c|c|c|}
\hline \multicolumn{1}{|c|}{ Section } & $\begin{array}{c}\mathbf{Q} \\
\text { (W/cm }\end{array}$ & $\begin{array}{c}\text { Flow } \\
\text { (GPM) }\end{array}$ & $\begin{array}{c}\text { Safoty Factor } \\
\text { Nominal }\end{array}$ & $\begin{array}{c}\text { Safety Factor } \\
\text { Lost Hose }\end{array}$ \\
\hline Section 1. Top and Bottom & 60 & 15 & 5.7 & 4.0 \\
\hline Section 1, Sidewalls & 45 & 15 & 9.6 & 2.6 \\
\hline Sections 2-3, Top and Bottom & 60 & $40^{*}$ & 9.8 & 4.9 \\
\hline Sections 2-3, Sidewalls & 45 & $40^{*}$ & 10.9 & 8.5 \\
\hline Section 4, Top and Bottom & 60 & $20^{*}$ & 5.3 & 8.3 \\
\hline Section 4, Sidewalls & 45 & $20^{*}$ & 6.5 & 12.7 \\
\hline
\end{tabular}

* Each modified 182 wall will be supplied a total of 60 GPM of cooling water from an inlet header.

Here the heat flux was applied across the entire gas-side surface. At a water temperature of $137^{\circ} \mathrm{F}$ at the end of the second pass and a heat flux of $60 \mathrm{~W} / \mathrm{cm}^{2}$, the maximum temperature in this region was $375^{\circ} \mathrm{F}$ near the outer edge of the gas-side surface. Thus, neither uncooled region presents a problem.

\subsubsection{Diffuser Status}

The design of the forward supersonic section is complete and the section has been built. The drawings for the modification of the 1B2 diffuser sections have been completed and have been sent out for machine shop bids. The rework will primarily consist of the replacement of the manifolds and the machining of the edges. 


\section{CURRENT CONSOLIDATION SUBSYSTEM DESIGN AND FABRICATION}

\section{(TASK 5)}

Construction of the diode stack was completed during this reporting period. It was delivered to the CDIF site in September where it will be installed to support the fall test serier. Construction of the power cabinets continued this quarter with installation of shelving for the switch modules.

\subsection{CURRENT CONSOLIDATION DIODE STACK}

The diode stack is one of the components of the Westinghouse current consolidation subsystem. There are two diode stacks in the system, one for the channel anode side and one for the cathode side. The following sections describe the anode diode stack that was delivered to the CDIF during this reporting period.

\subsubsection{Diode Stack Overview and Principle of Operation}

The standard mode of operation of the current consolidation subsystem is to operate with an active consolidation circuit between the electrode and the consolidation bus in the PTO regions of the channel. The purpose of the diode stack is to transfer the electrode currents to the MSE resistive consolidation network. The diode stack contains an SCR switch to make the transfer. This transfer capability is provided so the channel would not have to be shutdown in the event of a failure in the active consolidation circuits. The system can be switched over to resistive consolidation by operator command at the central control rack, or by automatic transfer if all active current consolidation circuits are lost. The purpose of the diodes is to prevent currents from circulating between electrodes when the system is being operated with the active consolidation circuits.

Figure 6-1 shows the connection of the anode diode stack to the $1 \mathrm{~A} 1$ channel as it will be operated in the fall test series. Twenty-five of the 30 diodes (labeled D6 to D30) are shown connected to the MSE resistive consolidation network. The SRC switch for activating the diode network is shown connected between the inverter negative bus and one side of the diodes or resistors.

Figures 6-2 through 6-5 show a series of photographs of the diode stack. As shown in Figure 6-2, the diode stack sits on four high voltage insulators rated for $15 \mathrm{kV}$. Thus, the whole assembly floats at the channel potential during operation.

The diode stack consists of two major subassem slies. The lower portion of the stack contains 30 isolated diodes on individual heat sinks, as shown in Figure 6-3. Figure 6-4 shows a close-up of the diodes. The anode and cathode terminals of each diode are made available on two Weidmuller strips on the right and left sides of the cabinet. This enables flexible connections to the resistive consolidation network. The voltage isolation level between adjacent diode heat sinks has been tested to $2.5 \mathrm{kV}$. Thus, there are no restrictions as to where connections are made with respect to the channel PTO (maximum span voltage of 750 ).

The top portion of the diode stack contains the SCR switch and the associated gate drive circuitry, as shown in Figure 6-5. The top potion of the stack also contains a cooling fan which draws air from the bottom through the top of the assembly. When the SCR switch is turned on, the resistive consolidation network is activated. The switch is turned on by two means:

1) Automatic Activation: This mode automatically protects the channel from going open circuit in the unlikely event that all of the individual consolidator fuses are lost. Since the maximum output voltage range of the individual consolidators is 375 VDC, a voltage in excess of this value indicates that the channel is heading towards open circuit. The gate drive for the SCR in the diode stack contains a circuit that triggers the SCR on if 585 volts is detected between any electrode and the consolidation points. In this mode of operation, the gate drive operates on channel power only, and does not require an external AC source. 


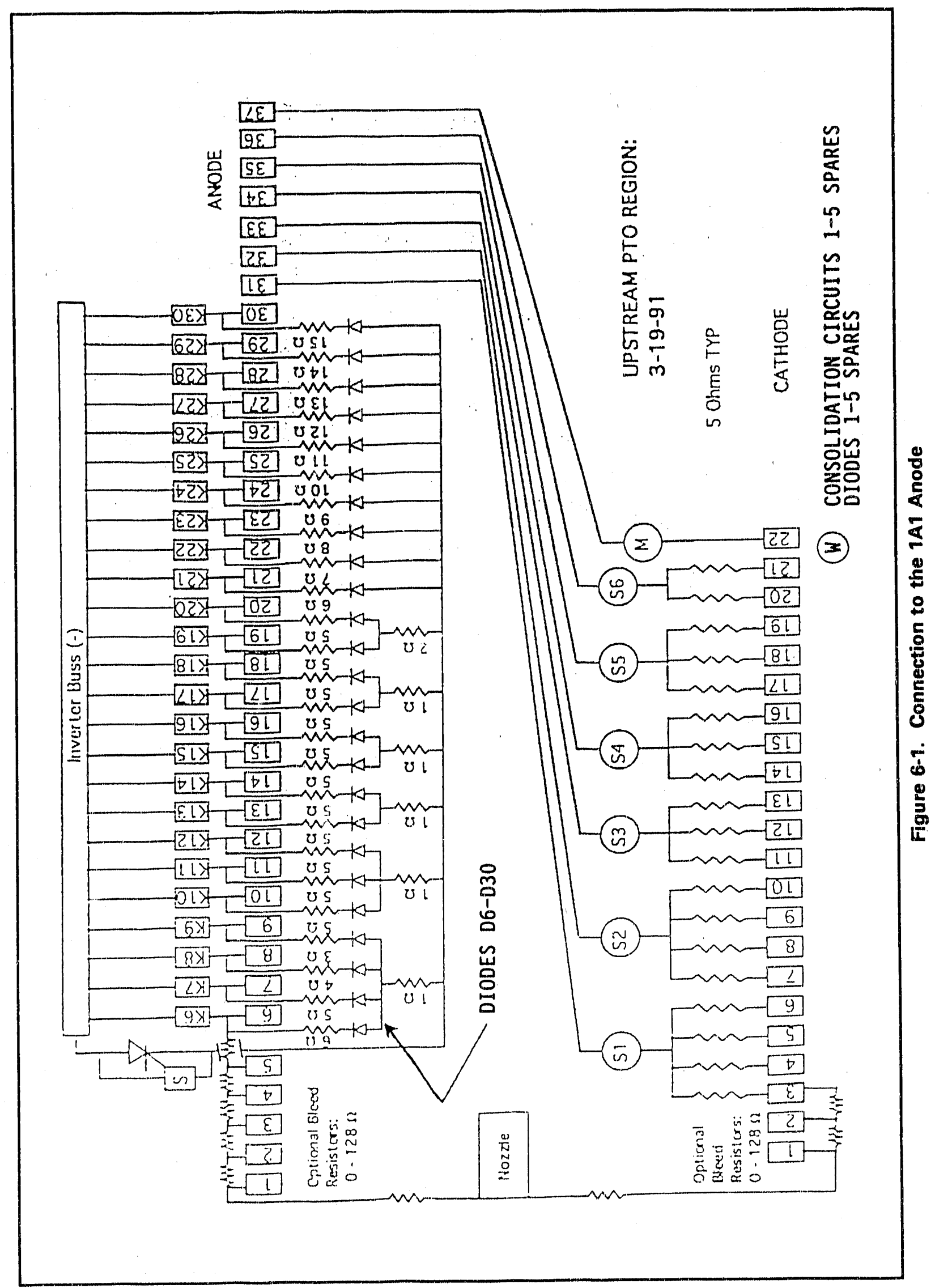




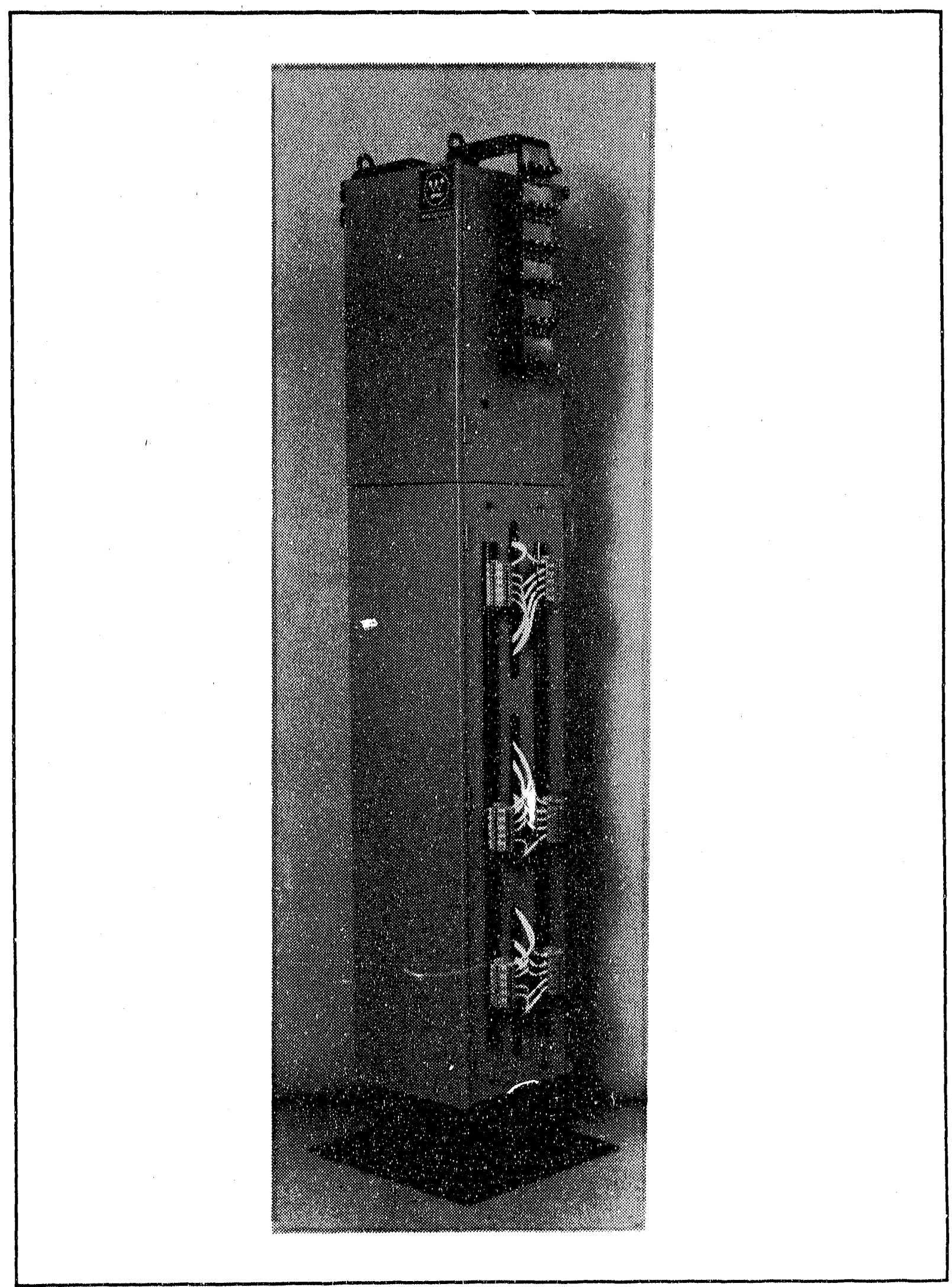

Figure 6-2. Diode Stack Right Side View 


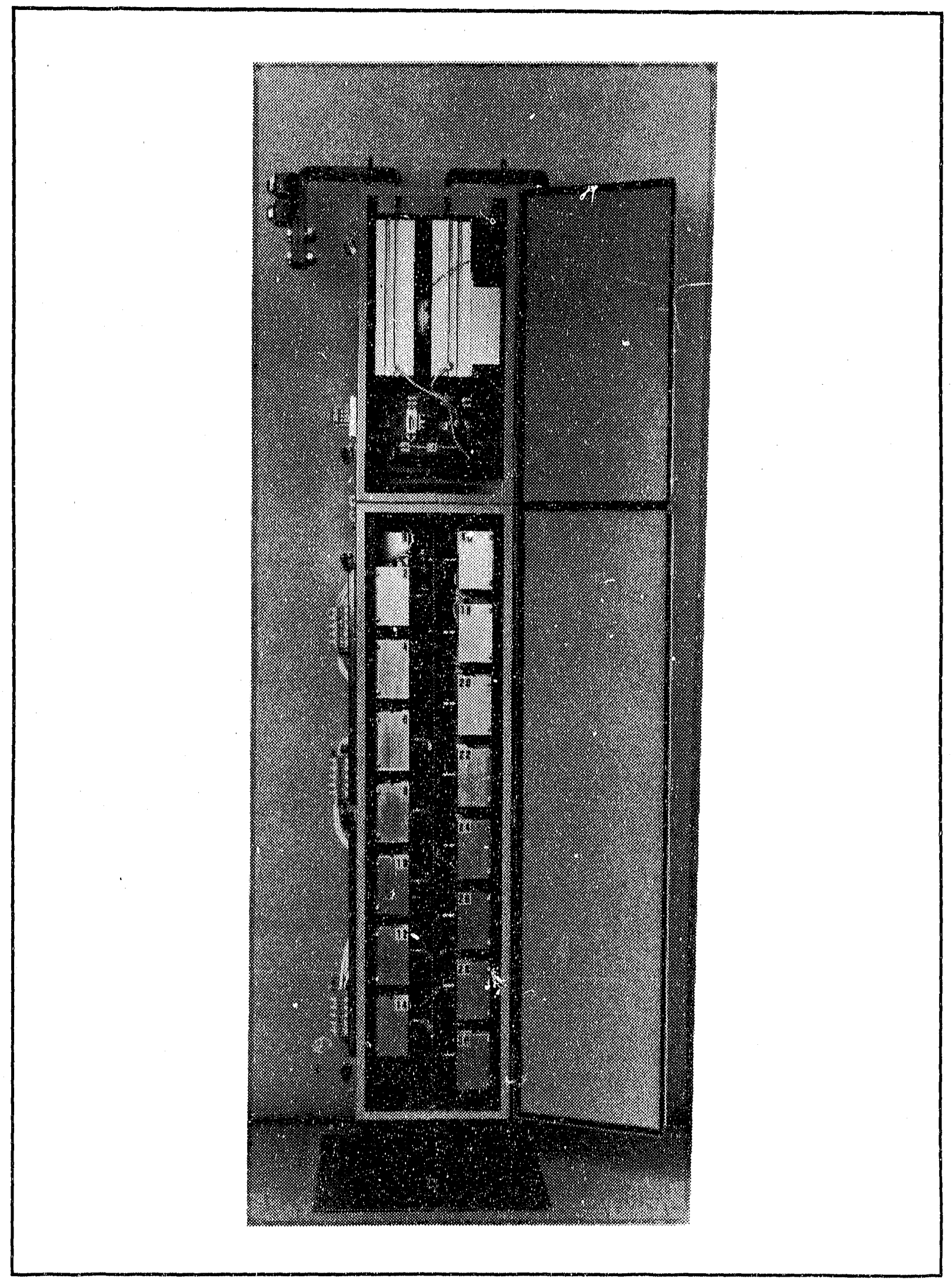

Figure 6-3. Diode Stack Internal View 

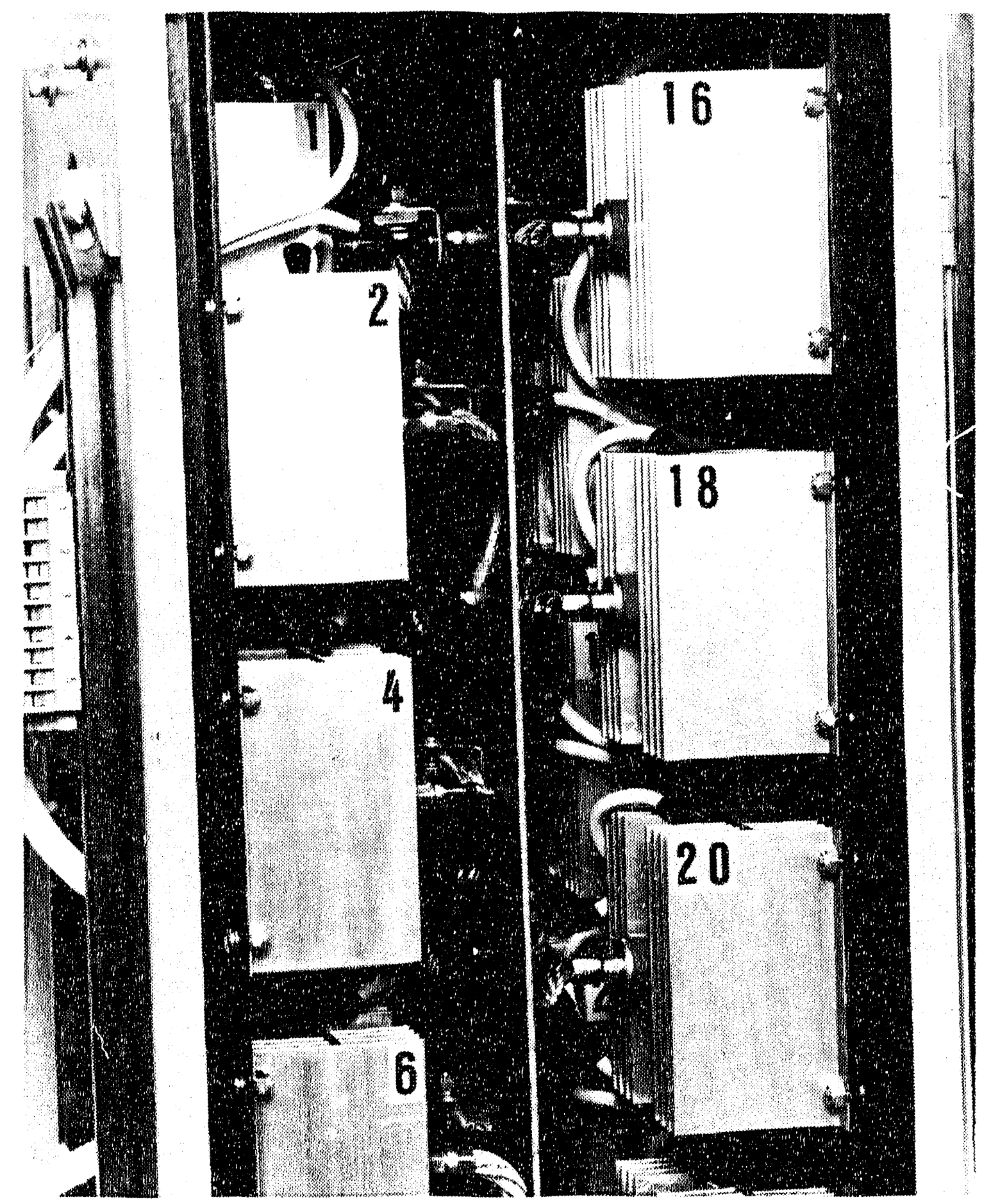

Figure 6-4. Diodes on Individual Hest Sinks 


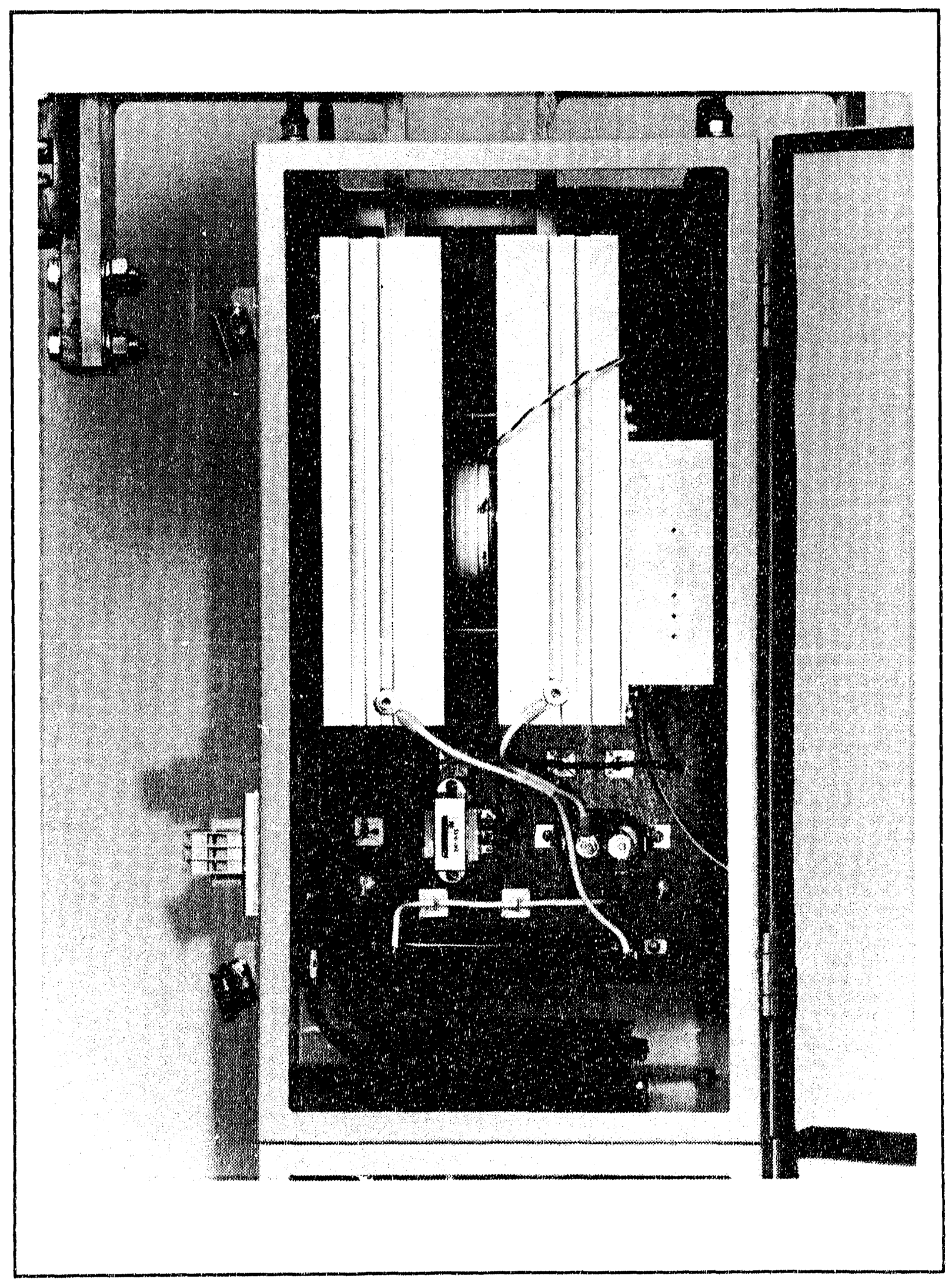

Figure 6-5. Diode Stack SCR Switch 
2) Operator-Initiated $\Delta$ ctivation: A fiber optic link runs from the anode local control system to the anode diode stack. This link is used to activate the SCR switch on an operator-initiated command at the central control. The SCR gate drive contains circuitry which fires the SCR switch based on the status of the fiber-optic link. This portion of circuitry requires an external source of $\mathrm{AC}$ power.

It is important to note that once the system has transferred to resistive consolidation on-line, transfer back to the active consolidation circuits is not possible. The channel must be brought down to zero current to tum the SCR device off once it has been activated.

\subsubsection{Diode Stack Construction}

Figure 6-6 shows a drawing of the diode stack and the associated assembly parts. The semiconductors used in the stack are as follow:

$$
\begin{aligned}
& \text { Individual Diodes - R601-18-25YB } \\
& \text { Voltage Rating - } 1800 \mathrm{~V} \\
& \text { Current Rating - } 250 \mathrm{~A}
\end{aligned}
$$

$$
\begin{aligned}
& \text { SCR - TA20221803DH } \\
& \text { Voltage Rating - 2200 V } \\
& \text { Current Rating - } 1800 \mathrm{~A}
\end{aligned}
$$

\subsubsection{Diode Stack Connections}

The details for connecting the stack to the CDIF system are summarized in the following sections.

\subsubsection{Connection to 115 VAC}

This provides fan power and SCR gate drive for the fiber-optic signal. The $115 \mathrm{VAC}$ power connection is made to the Weidmuller terminal at the top left side of the cabinet. Connection is made to the two outer ierminals, and the center terminal is left blank. Note that the source of 115 VAC power MUST be isolated to the maximum channel potential of $12 \mathrm{kV}$ with respect to ground. The Weidmuller terminals will accept the site standard No. 8 Rowe $15 \mathrm{kV}$ wire.

\subsubsection{Connection to Inverter Negative Bus}

The connection between the inverter negative bus and the anode side of the SCR switch is made via the bus bar at the top left of the cabinet. Connection is made to the bus bar with a Burndy type QQA44-4N lug, which accepts the $1000 \mathrm{MCM} 15 \mathrm{kV}$ cable form the inverter negative bus.

\subsubsection{Connection from SCR Cathode to MSE Resistors or Diode Anodes}

A series of 10 Bumdy type Q3A8C-2 lugs are attached to the bus bar connected to the SCR cathode. This provides 30 connections which can be made to either the MSE resistors or to the anode side of any of the diodes in the cabinet. The terminals accept No. 8 Rowe $15 \mathrm{kV}$ wire used by the site.

Note: As delivered to the site, Teledyne-Penn Union (TPU) type SLU-70 lugs were used in lieu of the Burndy Q3A8C-2 lugs. This provided 20 possible connections to the SCR cathode bus bar instead of 30 . This does not compromise the system, since 16 connections are required for the anticipated system connections. These terminals also accept the No. 8 Rowe $15 \mathrm{kV}$ wire. Westinghouse will replace the SLU70 terminals at a later date with the Burndy type connectors.

\subsubsection{Connection to Anodes and Cathodes of Diodes}

All 30 diode anode and cathode terminals are made available on Weidmuller strips on the left and right sides of the cabinet. The terminals are numbered 1 through 30 , which correspond to the diodes numbered 1 to 30 as labeled on the heat sinks inside the cabinet. The anodes are color-coded red, and the cathodes are white. The voltage isolation level between adjacent diodes has been verified to $2.5 \mathrm{kV}$, so there are no 

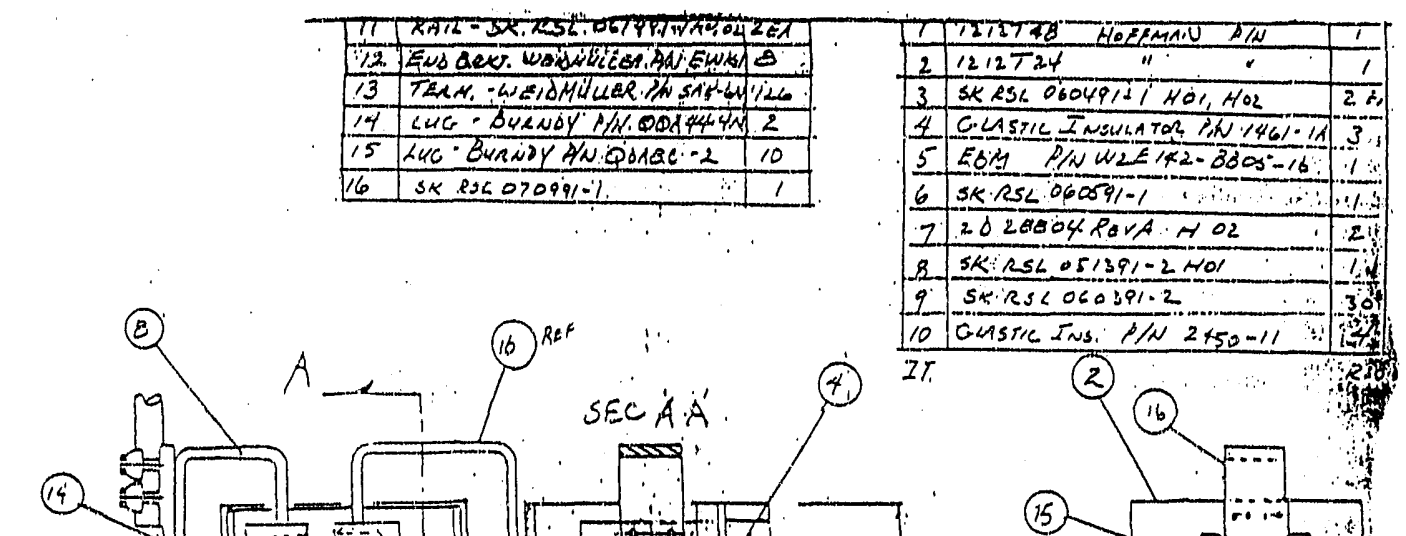

1

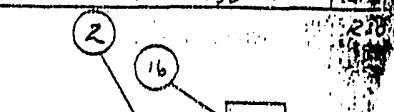

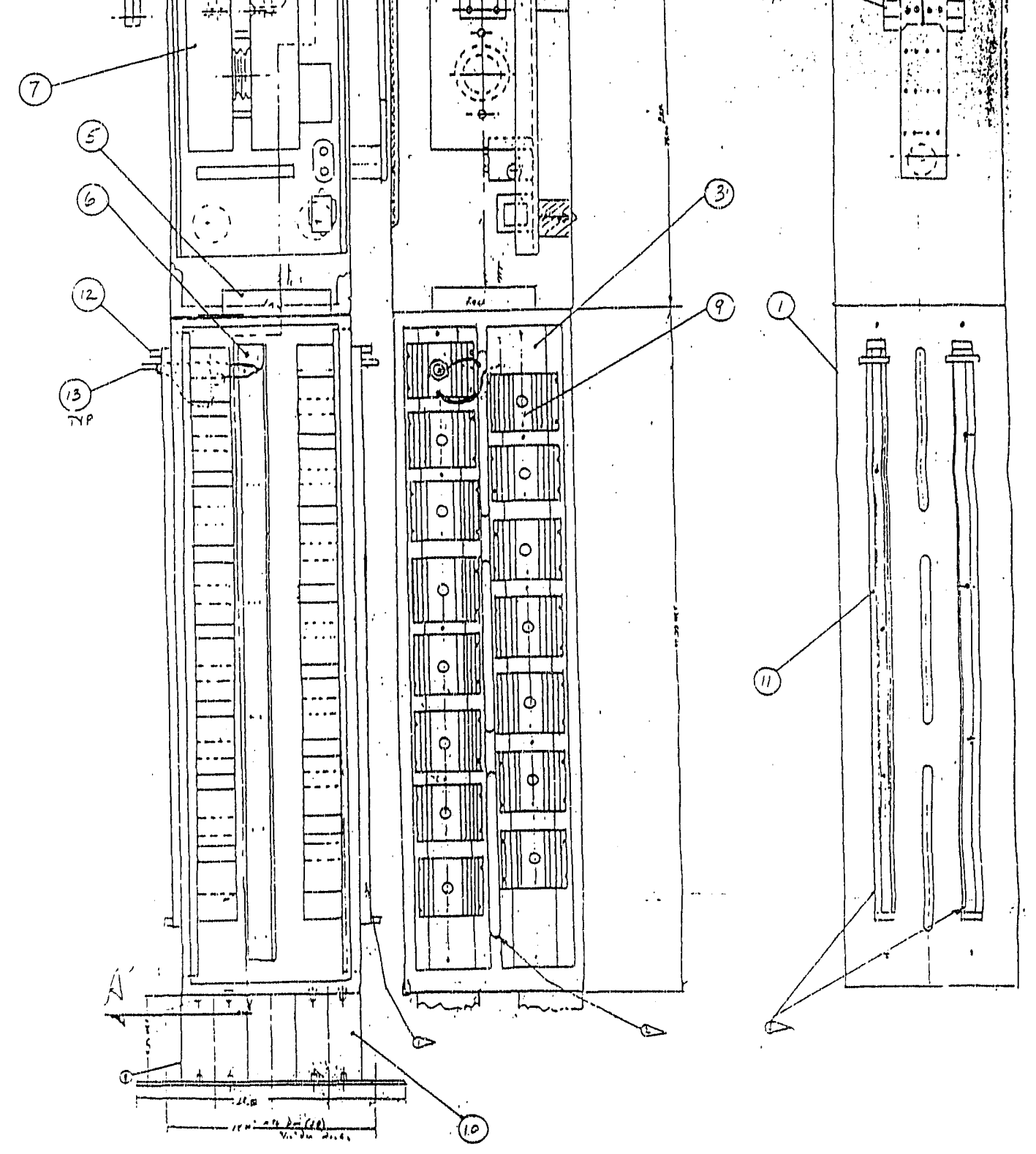

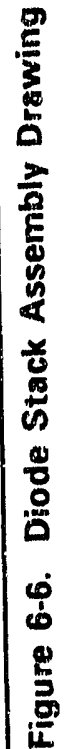


restrictions on how the diodes are connected to the system. The Weidmuller terminals accept the No. 8 Rowe $15 \mathrm{kV}$ wire.

\subsubsection{Connection to Anode Local Control}

A fiber-optic cable runs from the local anode control to the diode stack for the remote automatic trigger feature. The fiber-optic cable connector is passed into the opening on the upper right side of the diode stack and inserted into the opening on the SCR gate drive box. The Hewlett-Packard type HFBR-4501 connector on the cable snaps into place.

\subsubsection{Westinghouse Pre-Operation Tests}

The following tests were performed by authorized Westinghouse personnel to verify operation of the unit before shipment:

1) AC Power Test - 115 VAC was applied to the unit to check the fan operation.

2) Diode Test - All diodes were checked with a meter to verify that they conduct in the forward direction and block in the reverse direction.

3) SCR Test - The SCR gate drive box was tested on the bench to verify the correct waveform profiles for SCR turn-on and back porch. A load consisting of a resistor and power supply was placed across the switch SCR. The gate drive box was activated in both the automatic and manual modes to verify that the SCR iriggered on into the load.

4) Hi-Pot Test - The cabinet was hi-pot tested to $15 \mathrm{kV}$ from chassis to ground. Adjacent diodes were hi-pot tested to $2.5 \mathrm{kV}$.

\subsection{POWER CABINET CONSTRUCTION}

Figure 6-7 shows the structural members that have been installed in the power cabinets for mounting the switch modules. There are 3 tiers of shelves that hold 5 modules each, for a total of 15 modules per cabinet. Each tier has a copper bussing for connections to $\mathrm{AC}$ power and the consolidation point for each module in that tier. 


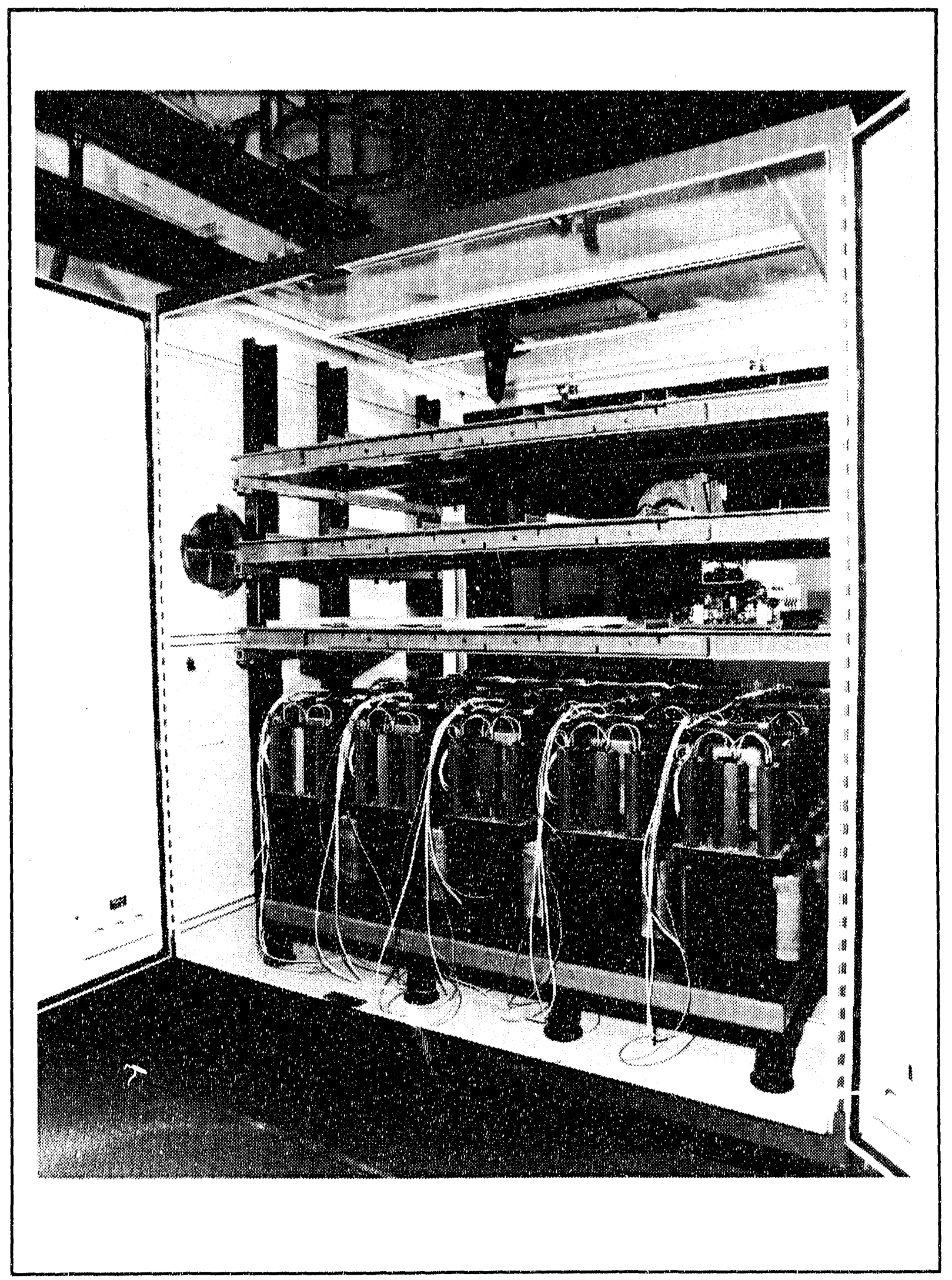

Figure 6-7. Installation of Shelving for Switch Modules 


\section{CDIF TESTING}

Workhorse power train testing at the CDIF is divided into two phases: 1) Design Verification Testing (DVT) of the coal-fired precombustor (CFPC) and 2) the Confirmation Test Series. During previous reporting periods, the precombustor DVT program was completed and the confirmation testing was initiated. The Confirmation Test Series is focused on confirming the design and performance characteristics of the individual prototypical power train components prior to installation of the entire prototypical power train.

Activities at the CDIF during the 17th quarter were focused on the installation of new power train components and on facility upgrades to support long duration testing. No testing of the power train was conducted during this reporting period.

The primary power train hardware activities performed at the CDIF during this reporting period included:

1) Installation of the rectangular cross-section, prototypical combustor second stage assembly.

2) Installation of new and refurbished prototypical channel elements in the workhorse $1 \mathrm{Al}$ channel. A discussion of these activities is contained in Section 7.2.

The key facility projects completed or nearing completion during the 17th quarter included:

1) Installation of the new Data Acquisition System (DAS)

2) Installation of expanded oxygen system storage capacity

3) Installation of the facility slag removal equipment

4) Repair and checkout of the magnet.

A discussion of the status of these and other facility projects is contained in Section 7.3.

Workhorse power train testing was originally scheduled to be re-initiated in September 1991. However, delays in the delivery of the refurbished prototypical channel elements for installation in the $1 \mathrm{~A} 1$ and delays in some of the facility projects have led to an overall delay in the startup of the workhorse test series. The test series is currently scheduled to begin in late November 1991 and will continue through January 1992. This will be the last workhorse power train test series conducted prior to the installation of the prototypical hardware. The total number of test hours (thermal) during this test series will be restricted in order to comply with an emission ceiling on carbon monoxide production ( 250 tons/year) at the CDIF. Test hours will remain restricted until a scheme (i.e. afterbumer) for reducing $\mathrm{CO}$ emissions at the CDIF is implemented. A discussion of the impact of stack emissions on test time and the plans for the upcoming test series are contained in Sections 7.3.10 and 7.4, respectively.

\subsection{WORKHORSE POWER TRAIN TESTING AT THE CDIF (SUBTASK 6.3)}

\subsubsection{Objectives of Workhorse Test Program}

The workhorse test program continues to have three main areas of emphasis at this time:

1) To provide operational and test data input to the POC component design such as:

- Combustor and slag rejector design

- Current consolidator design

- Channel design and material verification including loading of the power takeoff region

- "Simulated" segmented diffuser and nozzle

2) To develop long duration facility operational experience and to check out modified facility systems including:

- New DAS 
- Oxygen system expansion

- Slag removal system

- Magnet repair

3) To provide design verification testing of POC components as follows:

- Current controls as consolidators (aft PTO)

- Rectangular second stage

- Continuous slag rejection/removal system

- Current consolidation (forward PTO)

These items comprise the level of effort necessary to provide the ITC program with the confidence for a 2000-hour POC design.

\subsubsection{Approach}

The approach for the workhorse testing includes: 1) longer duration testing (16 to 24 hour electrical tests) to provide design data and longer duration facility experience, and 2) shorter duration testing (4 to 6 hour electrical tests). Short duration tests are geared for checkout and verification of the component designs and modifications such as the Phase III slag removal installation, and operational studies such as the power takeoff/configuration and simulated segmented diffuser/nozzle investigation, coal flow meter calibration, and rectangular second stage design verification.

\subsubsection{Test Summaries}

There were not any tests conducted at the CDIF during this reporting period. Test activities are presently scheduled to be re-initiated in November 1991. Test plans for the 18th quarter are outlined in Section 7.4.

\subsection{CDIF HARDWARE ACTIVITIES}

The primary power train hardware activities performed at the CDIF during this reporting period included:

1) Installation of the rectangular cross-section, prototypical combustor second stage assembly.

2) Installation of new and refurbisined prototypical channel elements in the workhorse $1 \mathrm{~A} 1$ channel.

These activities are discussed in detail in the following sections.

\subsubsection{Combustion Subsystem Activities - Rectangular Second Stage Installation}

The second stage of the prototypical combustor was delivered to the CDIF during this reporting period. The purpose of the early delivery (i.e. prior to delivery of the majority of the prototypical hardware) was to provide an opportunity to confirm the performance of the new flow cross-section of the second stage (rectangular vs. square) utilizing the workhorse $1 \mathrm{~A} 1$ channel. Transition sections were fabricated in order to mate the prototypical second stage to the workhorse combustor exit section and the workhorse $1 \mathrm{~A} 1$ channel. The configuration is illustrated in Figure 7-1.

Prior to delivery to the CDIF, the second stage components were non-reactive tested (leak proof and flow calibrated), assembled, mated to the $1 \mathrm{~A} 1$ nozzle assembly and pneumatically pressure tested at TRW. The assembly was installed on a steel shipping pallet and delivered to the CDIF prior to 1 September 1991. The rectangular second stage was subsequently installed at the CDIF, and cooling water flow balancing was performed in order to provide a minimum of 15 to 16 feet per second (fps) through the second stage frame coolant passages.

\subsubsection{Channel Subsystem Activities}

During this reporting period, several modified 1A4-style sidewall elements were fabricated for installation and design confirmation testing in the $1 \mathrm{~A} 1$ workhorse channel at the CDIF. These test coupons 
represent prototypical designs and incorporate modified designs to address cracking of the tungsten cap and cracking of the brass water tube. (See Section 5.3 of the 16th Quarterly Technical Progress Report for details on tungsten cap cracking and Section 5.1.1 of this report for details on water tube cracking.) Both issues relate to the use of a tungsten-copper base. In addition, the sidewalls are outfitted with advanced designs incorporating aluminum nitride ceramic capping. Previous testing completed on the Mark VII channel at TDS has shown aluminum nitride to resist electrochemical corrosion on the anodic surfaces of sidebar elements and to reduce the incidence of interbar arcing.

Two areas on the forward sidewalls of the $1 \mathrm{~A} 1$ channel have been modified for the installation of prototypical $1 \mathrm{~A} 4$ elements. New sidewail designs have been fabricated to address cracking of the tungsten cap when brazed to a tungsten-copper base and cracking of the naval brass water tube also when brazed to a tungsten-copper base.

The tungsten cap cracking issue has been addressed using a two-fold approach:

1) Reduce the width of the cap in the stress induced direction.

2) Provide a stress relieving compliant interface between the tungsten cap and the tungsten-copper base.

All 1A4-style end bar designs incorporate a split cap design, reducing the cap width from approximately 0.62 to 0.30 inches, and a 0.010 -inch thick compliant interface. The compliant interface is comprised of a nominally 0.010 -inch thick copper foil brazed on each side with a 0.002 -inch thick gold-nickel braze foil (Handy \& Harmon P13). All mid bar designs, their characteristic width being only 0.440 -inch, use only the nominal 0.010-inch compliant interface.

The brass water tube cracking issue has been addressed by the use of a bronze water tube. All 1A4style sidewall designs installed in the $1 \mathrm{~A} 1$ channel with a tungsten-copper base incorporate this change in the tube material.

In all, some 60 sidewall elements were fabricated for installation in the $1 \mathrm{~A} 1$ sidewall test sections. A map showing the relative location of the sidewall designs in the right and left forward sidewalls are shown in Figures 7-2 and 7-3, respectively. These coupons are scheduled for testing at the CDIF in the FY92 Fall/Winter test series.

\subsubsection{Slag Rejector Activities}

The installation of the continuous slag rejector and removal system was divided into 3 phases for installation at the CDIF. The slag rejection system schematic is shown in Figure 7-4 and the slag removal schematic is shown in Figure 7-5.

Phase I: Included the installation of the TRW supplied denseveyor, piping and collection tank. The equipment is placed only for operation of the equipment as a replacement for the existing slag tank extension pipe. Completed November 1990.

Phase II: This phase included the installation of controls necessary to operate the TRW supplied portion of the slag rejection system on a continuous basis. Completed April 1991.

Phase III: The final project phase includes the installation and startup of the CDIF portion of the slag removal equipment and interfacing into the integrated slag rejector/slag removal system. To be completed November 1991.

During this reporting period, Phase III of the system was installed. This phase provides the facility slag removal equipment required to transport the slag from the slag rejection system to a pad outside the test building. Testing of this equipment as well as the checkout of the Phase II installation during power operations will be conducted next quarter. 


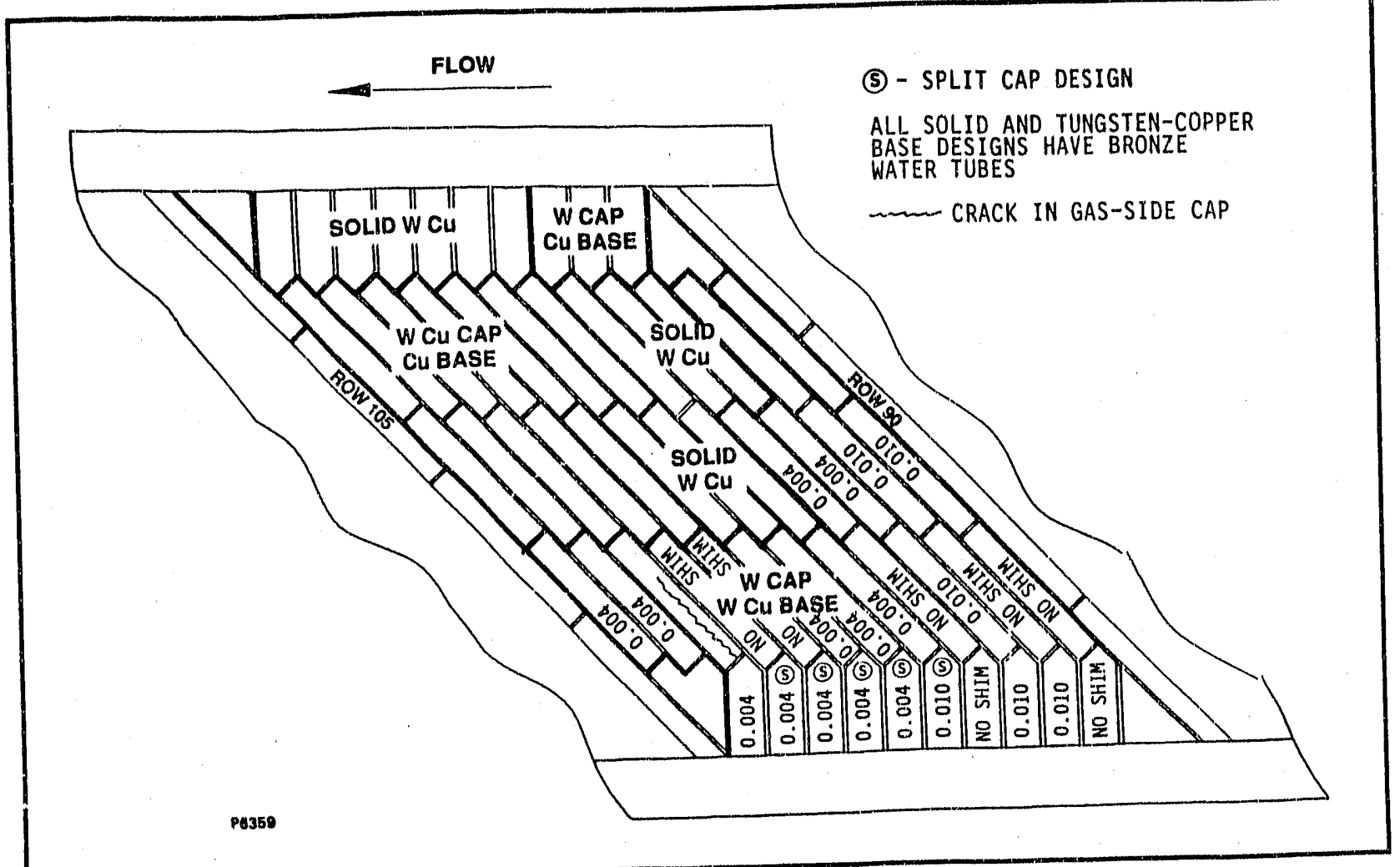

Figure 7-2. Location of 1A4 Test Coupons in 1A1 Right Forward Sidewall

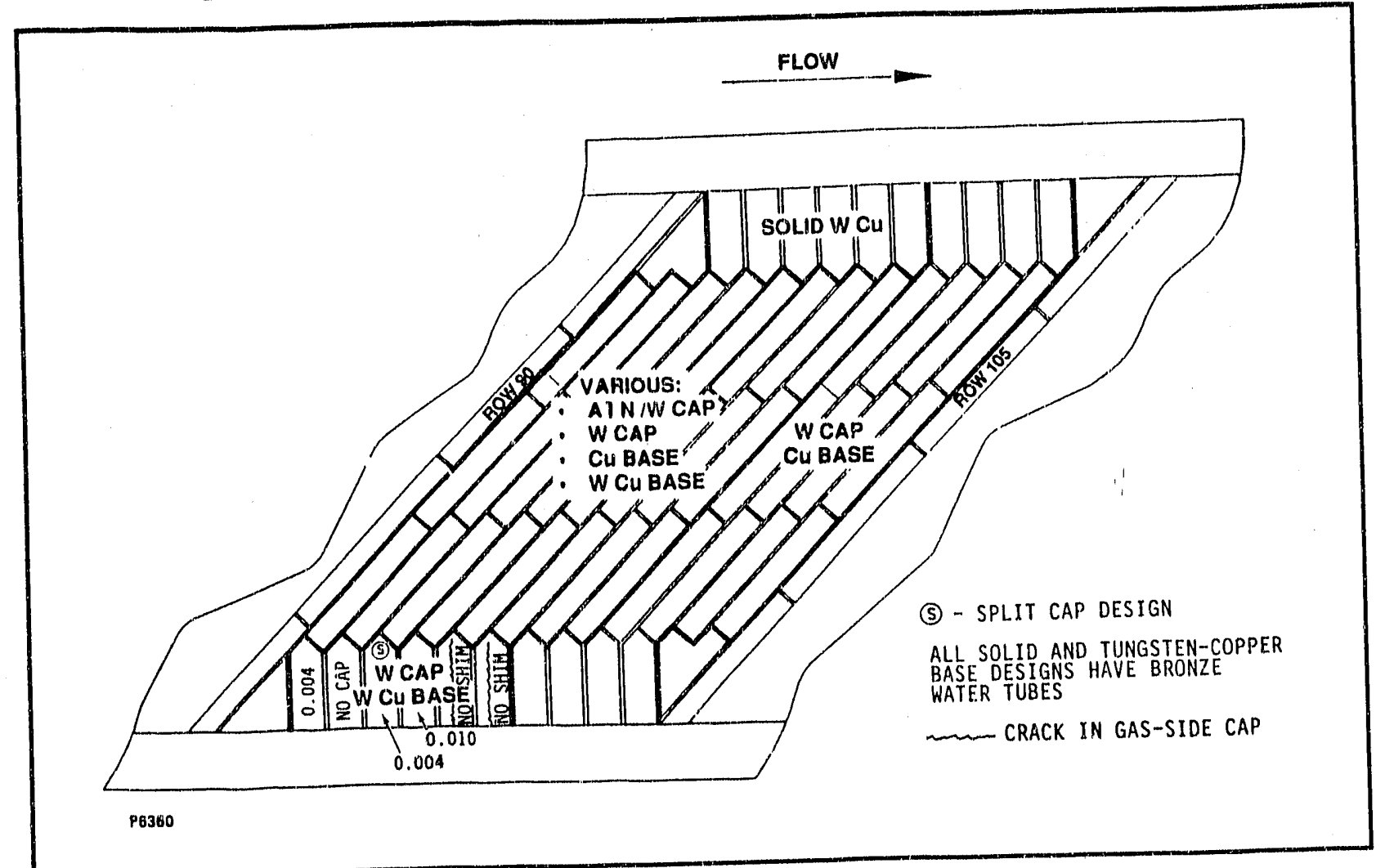

Figure 7-3. Location of 1A4 Test Coupons in 1A1 Left Forward Sidewall 


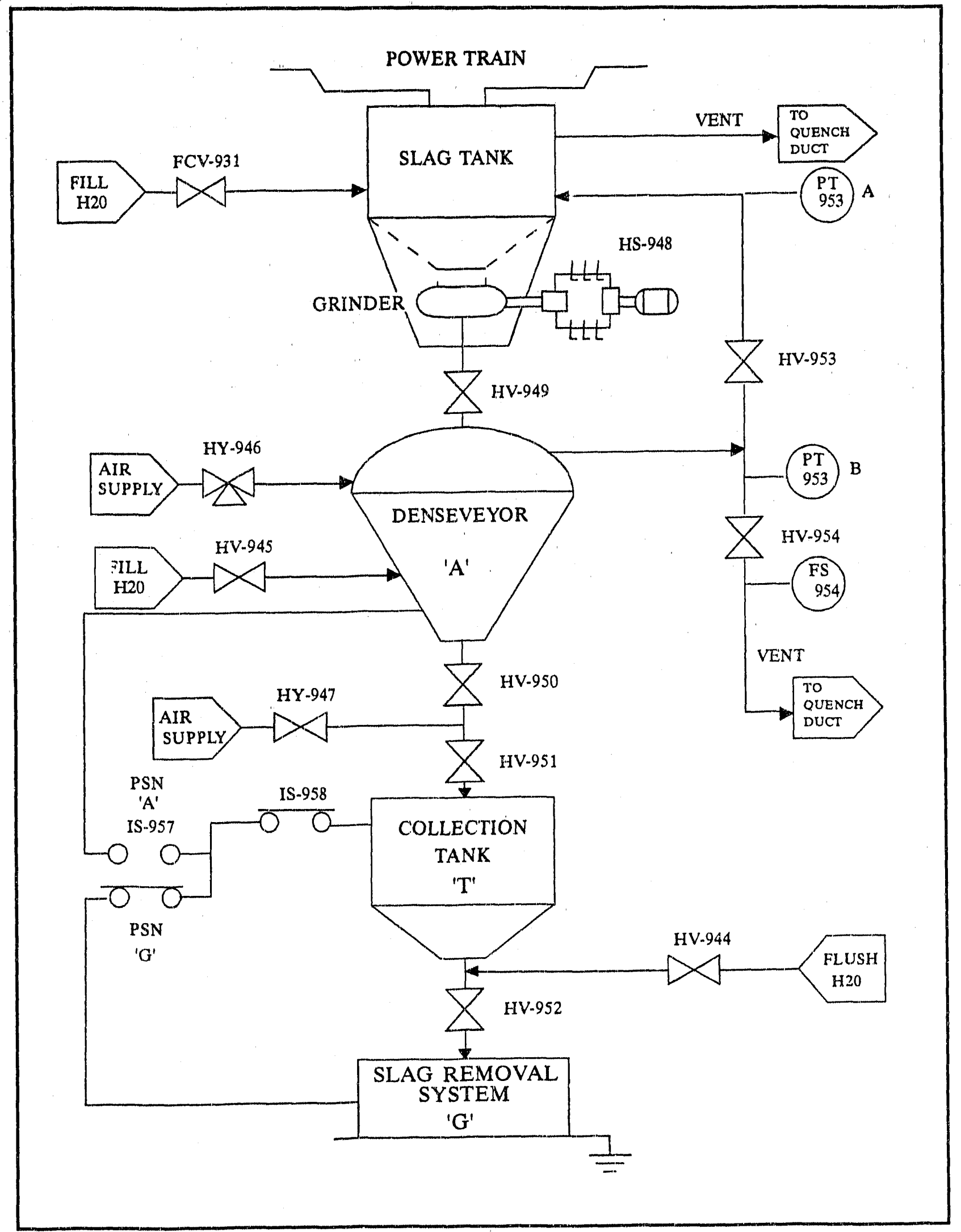

Figure 7-4. Slag Rejection System Schematic 


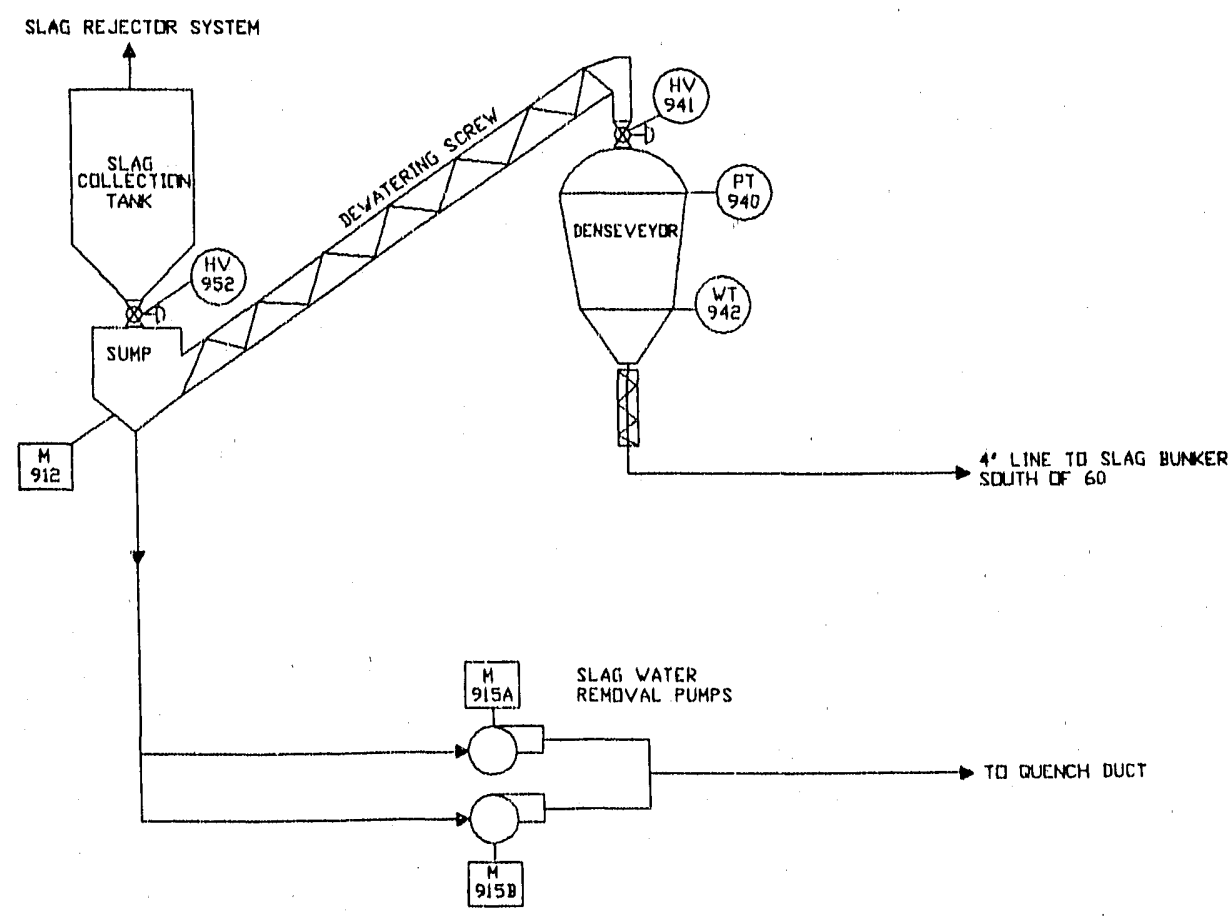

Figure 7-5. Slag Removal Schematic

\subsection{CDIF SYSTEM ACTIVITIES}

\subsubsection{Primary Cooling Water System (PCW)}

To ensure that the PCW system meets the prototypical channel requirements for $\mathrm{pH}(7.0 \pm 0.5)$, measurements of $\mathrm{pH}$ were made at the CDIF. Measurements of $\mathrm{pH}$ were taken at a location downstream of the mixed bed demineralizer unit. The readings did not consistently meet the $\mathrm{pH}$ requirements and, hence, a small pilot program was undertaken to investigate the cause of the variation in $\mathrm{pH}$ readings. Preliminary results indicated that the procedures for installing resins into the demineralizer tanks need to be modified, and activated carbon filters need to be installed upstream of the demineralizer tanks in order to remove chlorine (chloride increases the degradation of the resin and reduces the effectiveness of the regeneration process). The $\mathrm{pH}$ will continue to be monitored.

Dissolved oxygen measurements have also been made on the PCW water at the CDIF. The initial report indicates that the dissolved oxygen content in the PCW may be out of range (above $3.5 \mathrm{ppm}$ ). More measurements will be taken during the 18 th quarter to confirm this fact. If this is true, then the atmospheric vented tanks in the system will be blanketed with nitrogen.

\subsubsection{Iron Oxide System}

The requirement for iron oxide slurry ( 50 weight percent in hydraulic oil) addition into the prototypical MHD channel requires dedicated pumps supplying each of 4 injectors. A single circuit schematic of the iron oxide system is presented in Figure 7-6. Two injectors are located on the cathode wall while two are located on the anode wall. The required range of flow for each pump is 1 to 4 pounds of slurry per minute. Testing during the 15 th and 16th quarters indicated that, for this application, progressive cavity pumps 


\begin{tabular}{|c|c|c|c|c|c|}
\hline INUJECTOB & EUMP ND & $\begin{array}{l}\text { SUPPLY } \\
\text { ERESSURE }\end{array}$ & $\begin{array}{l}\text { FLDW } \\
\text { MEIER }\end{array}$ & $\begin{array}{l}\text { INJECTIIDN } \\
\text { PRESSULEE }\end{array}$ & NDMENGLATURE \\
\hline $\begin{array}{r}\text { CATHDDE - EAST } \\
\text { CATHDDE - WEST } \\
\text { ANDDE - EAST } \\
\text { ANDDE - WEST }\end{array}$ & $\begin{array}{l}51-1509 \\
51-1508 \\
51-1511 \\
51-1510\end{array}$ & $\begin{array}{l}P T-3814 \\
P T-3815 \\
P T-3816 \\
P T-3817\end{array}$ & $\begin{array}{l}\text { FIT }-3810 \\
\text { FIT-3E11 } \\
\text { FIT-3812 } \\
\text { FIT-3813 }\end{array}$ & $\begin{array}{l}\text { PT }-3802 \\
\text { PT }-3803 \\
\text { PT }-3808 \\
\text { PT-3809 }\end{array}$ & 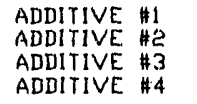 \\
\hline
\end{tabular}

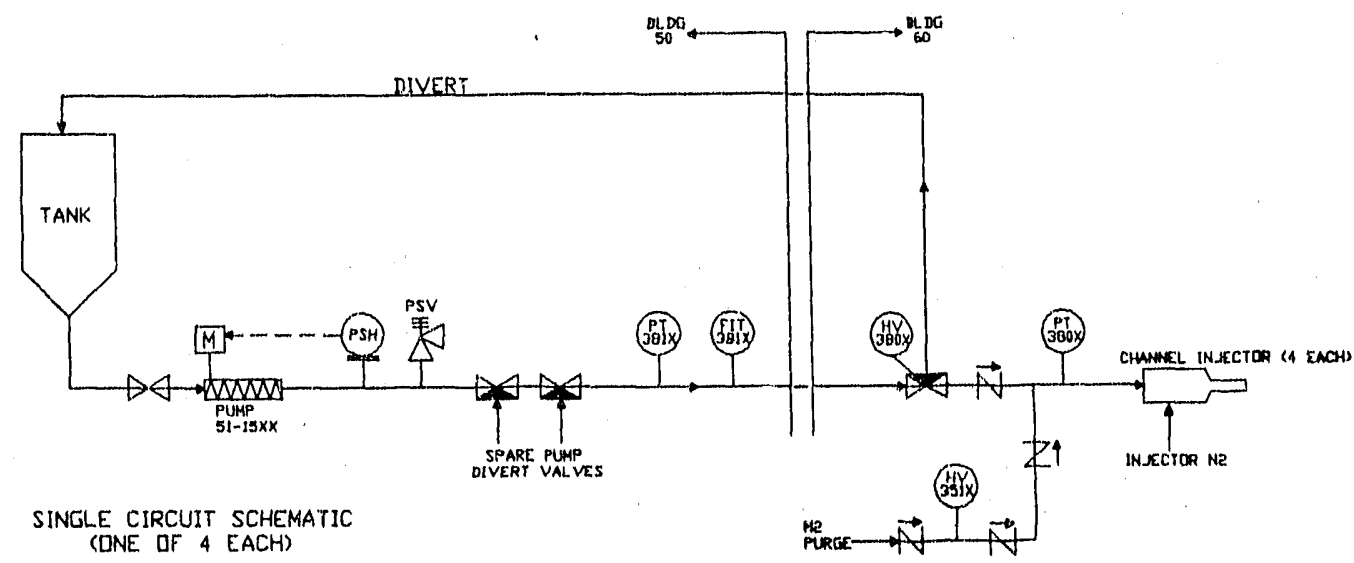

Figure 7-6. Iron Oxide Flow Circuit instrumentation

perform best; however, the lowest flow rate pump was supplying more than the minimum requirement of 1 pound/minute. The efforts during this reporting period were to rectify this problem.

During this quarter, one of the two 4-stage progressive cavity pumps installed during the 15 th quarter was fitted with a reduced speed motor modification. Testing of this modification has yielded low end flow rates of 1.1 pounds/minute of slurry. Since this is acceptabie, this modification will be made to on the other 4-stage pump. Two different 8-stage progressive cavity pumps were purchased and installed. These were purchased because the manufacturer indicated that the 8-stage design was more suitable to reduced flow rate longevity than the 4-stage design. Testing of the 8-stage pumps has not shown the ability to achieve flow in the 1 pound/minute range. The manufacturer is being consulted for input as to the method to reduce the total flow rate into the desired range.

Also during this quarter, gear-type flow meters were installed and checked out. Preliminary test results have indicated problems with this type of flow meter in this application.

\subsubsection{Coal System - Coal Mass Flow Meter Calibration}

No new work was accomplished on this system during the reporting period, except that the PVC piping that had temporarily connected the baghouse to the ash filter receiver for collection of coal fines was replaced with hard pipe. This modification will allow transfer of the coal fines collected in the baghouse into the ash storage hopper during coal processing in order to increase the amount of coal fines saved during coal processing. The coal fines will be reincorporated into the main test coal during two of the tests scheduled for next quarter in order to evaluate the impact of coal fines on power train performance.

During the 16th quarter, a calibration of the Endress + Hauser $(\mathrm{E}+\mathrm{H})$ coal system mass flow meters was attempted (see Section 7.2.5.4 of the 16th Quarterly Technical Progress Report). Analysis of the test 
setup and results has resuited in a decision to repeat this test. The recalibration of the Endress + Hauser meters will be performed during the 18th quarter.

Prior to the actual recalibration of the flow meters, the following tests will be performed off-line in order to improve the accuracy and reliability of the calibration test:

1) Configuration li: Coal feed system configured to run coal from primary injector vessel to Blue Vessel at nominal CFC coal rate $(210 \mathrm{lb} / \mathrm{min})$. CFC E+H meter installed in line. Filter receiver installed on Blue Vessel vent line.

$\begin{array}{cccc}\text { Condition } & \text { Coalflow Rate } & \text { Blue Vessel Back Pressure } & \text { Duration } \\ 1 & 210 \mathrm{jb} / \mathrm{min} & 85 \mathrm{psia} & 20 \mathrm{~min}\end{array}$

2) Configuration 2: Coal feed system configured to run coal from primary injector vessel to Blue Vessel at nominal CFPC coal rate $(30 \mathrm{lb} / \mathrm{min})$. CFPC E+H meter installed in line. Filter receiver installed on Blue Vessel vent line.

$\begin{array}{cccc}\text { Condition } & \text { Coal Elow Rate } & \text { Blue Vessel Back Pressure } & \text { Duration } \\ 2 & 30 \mathrm{lb} / \mathrm{min} & 85 \mathrm{psia} & 20 \mathrm{~min} \\ 3 & 30 \mathrm{lb} / \mathrm{min} & 45 \mathrm{psia} & 20 \mathrm{~min} \\ 4 & 30 \mathrm{lb} / \mathrm{min} & 65 \mathrm{psia} & 20 \mathrm{~min} \\ 5 & 30 \mathrm{lb} / \mathrm{min} & 85 \mathrm{psia} & 20 \mathrm{~min}\end{array}$

Notes:

1) Configuration 1 was proposed in order to perform a mass balance at the sarne mass flow as that expected for the calibration test, since the error between the load cell readings is likely to be a function of mass flow rate.

2) Configuration 2 will allow determination of how the relative error of the $\mathrm{E}+\mathrm{H}$ meter varies as a function of back pressure. Once this is known, the calibration test could be perfomed at a back pressure of 45 psia and the error corrected back to 85 psia.

3) All conditions should be run with the same batch of coal (with the same processing history) in order to minimize coal moisture variations from condition to condition.

4) If consistent readings are not oblained between conditions 2 and 5 above, then conditions 3 to 5 should be repeated.

\subsubsection{Seed System}

No new work was accomplished on this system at the CDIF during the reporting period. Modifications scheduled for this system for POC testing have been delayed so that the ash hopper can be used to store coal fines from the baghouse for coal fines testing during the 18 th quarter.

\subsubsection{Magnet}

The CDIF 3-Tesla iron core magnet developed an intemal cooling tube water leak in the Number 2 pancake of the West half early in the 15 th quarter. Repair methods were reviewed by the DOE and the CDIF operating contractor, including input from consultants from MIT, Oakridge National Laboratory, Innovation Services, and an English repair company. Test coupons were prepared by MSE to simulate the leak and given to both the English firm and Innovation Services.

Upor review of the "repaired" coupon, the decision was made to have the magnet West half repaired by stopping the leak with a thermosetting resin system. This was accomplished during this reporting period by the English repair firm. Leak testing was performed at temperature and showed that the leak had in fact becn repaired. Prinr to starting up the magnet, resistance checks (megger checks) were performed as required by the operation and maintenance manual. The East half of the magnet was found io have low 
resistance. Pressure drop tests were performed on the East half in the same manner as performed on the West half, but no leaks were found. The low resistance is believed to be due to water that is trapped in cracks of the epoxy. Efforts to "dry-out" the magnet have been unsuccessful. An atternpt was made to remove the endplate to see if the fault was occurring in that location; however, the endplate did not come off easily. It was not forced off fearing that more damage would be obtained by this effor than by leaving it alone. A decision was made to run the magnet "as-is" following the implementation of a MIT recommendation to install an improved interlock system to detect ground faults and initiate automatic magnet shutdown more reliably than the existing system. The magnet will be operated during the 18 th quarter just prior to MHD testing.

Another issue that was addressed during this reporting period, which arose as a result of the magnet failure, concems automatic shutdown of the magnet as a result of failure of other components. There are a few test train interlocks that force automatic shutdown of the magnet. These include failures in the current controls and slag rejection system, where the intent is to remove the power from the test train as rapidly as possible. Test data has shown that if the combustor trips, all power generation is stopped within 2 seconds from initiation of the shutdown. However, if the magnet is tripped and the combustor is left on, power generation stops in 11 seconds. Since there is great concem for the longevity of the magnet, and since it is felt that longevity will decrease as the magnet is stressed (e.g. fast shutdowns or trips), several of the interlocks that were originally assigned to the magnet have been removed and are now combustor trips. Since the implementation of these changes requires rewriting of the Safety Analysis Report (SAR) for Idaho DOE approval, the actual removal of the magnet trips from the interlocking scheme may not occur for several months. Efforts are underway to speed up the SAR process as quickly as possible to lessen the effects of magnet trips.

\subsubsection{Oxygen System Upgrade}

The oxygen storage and vaporization system at the CDIF was expanded to store 43 hours of oxygen for testing. This system will be checked out for operation during the 18th quarter.

\subsubsection{Westinghouse Current Consolidation Cabinet Installation}

During this reporting period, preparations for the installation of the Westinghouse anode current consolidator cabinet were made. A steel building was erected and the electrical wiring contract was let. Due to funding problems, the fabrication of the anode current consolidation cabinets was not completed on schedule. However, the companion diodes plus enclosure (diode stack) was delivered and installed at the CDIF. This installation will allow testing to proceed at the CDIF with resistive consolidation. The anode current consolidation cabinet is now scheduled to arrive at the CDIF early in the 19th quarter.

\subsubsection{Data Acquisition System (DAS) Installation and Checkout}

The new data acquisition system (DAS) was installed during the 16 th quarter. Standard of performance (SOP) testing was iniciated on October 20, 1991 and will proceed for 30 days. This test provides for continuous operation of the DAS for 30 days and must be completed without any failures of the system. Since DAS failures are more likely while power train testing is being conducted, it was originally planned for the SOP to be performed concurrent with power train testing. However, due to delays in the startup of the test program, no testing will be conducted during the SOP.

\subsubsection{High Voltage Room Modifications}

The CDIF High Voltage Room (HVR) is the nerve center of the MHD process. All wiring from the MHD channel to instrumentation, to the current controls/consolidators, and eventually to the inverter must pass through the HVR. Since the HVR must support TDS 1A1 and 1A4 testing (two different electrical pitches with different numbers/types of connections), a large amount of labor and effort has been and will be expended at the HVR. 
In May 1991, a testing configuration identifying electrical connections/requirements for the Fall/Winter test series was provided by the Power Management Task Force. The task force is comprised of TDS, TRW, MSE and Busek personnel. The HVR configuration engineering was initiated during the 16th quarter and consists of channel wiring configuration as well as instrumentation requirements.

\subsubsection{Stack Emissions Compliance}

During this reporting period, work was initiated on planning and implernentation of a scheme to reduce carbon monoxide emissions at the CDIF. The maximum allowable yearly emission of carbon monoxide is 250 tons. During power train operation at an overall equivalence ratio of 0.90 , the nominal carbon monoxide emission is 2.4 tons/hour. Therefore, the total test hours at the CDIF will be limited to a maximum of 104 hours in a 12-month time period until a scheme for reducing $\mathrm{CO}$ emissions is implemented.

\subsection{TEST PLANS}

The test plans for the next quarter (Table 7-1) have been modified in order to account for the following changes:

- The delay in delivery of the Westinghouse anode current consolidation equipment.

- The limitation on total test hours due to the carbon monoxide emissions restrictions.

The total thermal hours during the next quarter ("Fall/Winter") test series will be limited to 47 hours. Due to this restriction, the longer duration (24 to 50 hours) tests were eliminated and shorter duration tests were emphasized in order to gain as much information as possible within a short time period. Specifically the test series will evaluate the following:

1) Checkout of the new hardware/facility modifications; Baseline performance characterization.

2) Verify mechanical and electrical operation of the continuous slag rojection/slag removal system during power generation.

3) Evaluation performance of the "simulated" segmented nozzle and diffuser and TDS current controls as consolidation of the aft power takeoff region.

4) Evaluate the impact of coal fines on power train performance.

The test window available to perform the tests shown in Table 7-1 is late November 1991 through January 1992. The plant will be modified after testing is complete to install the prototypical combustion subsystem.

Additional details on these tests are contained in the following paragraphs.

\subsubsection{Baseline Power Takeoff Tests}

Experience with a segmented nozzle and diffuser will be gained with an "electrically shortened" $1 \mathrm{~A} 1$ channel during baseline characterization tests. The "unused" elements in the forward part of the channel will be used to simulate a segmented nozzle, while comparable elements in the aft region simulate a segmented diffuser. The channel will be configured with resistive consolidation in the front PTO, and TDS current controls will consolidate current in the aft PTO.

The test will commence with all bleed resistors open. Bleed resistor values and locations will be adjusted, as necessary, to provide "clean" voltage and current distributions. It is anticipated that several iterations will be required to obtain the best bleed resistor network configurations. Once these configurations are determined, they will remain in place for the balance of the test series. The cause of high speed current fluctuations will be investigated in the same test series.

\subsubsection{Anode Sidebar-to-Anode Middle Bar Shorting}

Anode sidebars in the prototypical Z-bar sidewall region have wires attached to them for: 1) connection to the high voltage room (HVR), and 2) connection to their neighboring anode middle bar. The former 


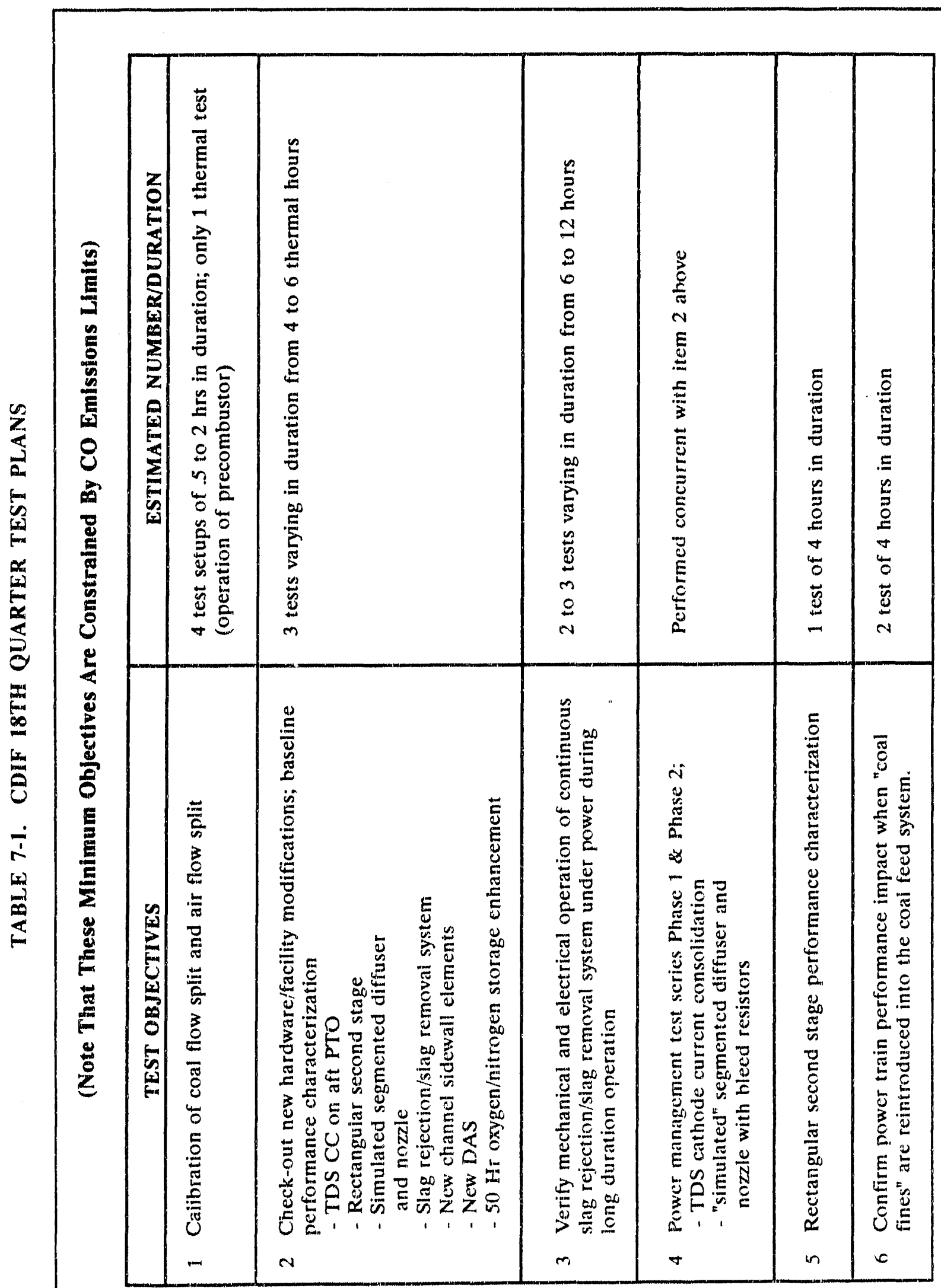


connection allows interelement instrumentation and the latter simulates a longer "Z-shaped" bar. Shorts will be in place (on the channel) at the beginning of the baseline characterization performance test. During this test, the viability of longer anode side/middle bars will be evaluated by noting voltage and current distributions in the sidewall. These results will be compared to distributions without the electrical short.

\subsubsection{Electrical Test}

The propensity of sidewall base materials to experience undercutting when exposed to high intercathode voltage gaps will be studied in the Fall/Winter test series. Also, the long duration effects of iron oxide injection on generator performance and material wear will be investigated.

Carbon monoxide emission limitations do not permit a long duration test series without iron oxide followed by a long duration series with iron oxide. Therefore, high voltage intercathode gaps typical of operation without iron oxide will be simulated with extemal shorts on the cathode wall (while iron oxide is on). When the baseline performance test commences, four cathodes will be shorted in the vicinity of copper-based sidewall elements and four cathodes (or fewer if, during preliminary performance characterization tests, too high an intercathode voltage or current appeared) will be shorted adjacent to $75 \mathrm{~W}$ $25 \mathrm{Cu}$ based sidewall elements. In this way long duration experience with iron oxide and sidewall undercutting tests can be conducted simultaneously. 


\section{MODELING AND PERFORMANCE ANALYSIS ACTIVITIES (SUBTASK 1.3)}

Subtask 1.3 of the ITC program, Power Train Performance Analysis, encompasses a broad range of activities aimed at: 1) understanding the fundamental chemical, electrical, and flow phenomena which occur in an MHD topping cycle power train, and 2) analyzing and interpreting the results of the many ongoing test programs to determine hardware performance. By thoroughly understanding the basic processes and knowing how the components and subsystems perform, information is obtained on ways to design better equipment and assess the risks of scaling up to the next level of development.

Modeling and performance analysis are ongoing parts of the ITC program. Two major efforts which are part of this subtask and which will continue throughout the contract are cold flow modeling of the combustion subsystem components and analysis of power train performance data obtained during testing at the CDIF. From time to time, other modeling and analysis activities arise from or are performed to support these major modeling and performance analysis efforts.

During the last quarter, power train modeling and performance analysis activities were focused on the following areas: analysis of seed utilization tests conducted in May 1991; evaluation of the combustor slag rejection requirement; improved modeling of the combustor slag rejection process; evaluation of coal and slag sampling procedures at the CDIF; and general test planning support for the fall 1991 test series at the CDIF. A summary of each of these activities is given below.

One of the objectives of the May 1991 test series at the CDIF was to investigate the effects of deswirl gas temperature and seed injection velocity on combustor seed utilization, particularly at the $1 \% \mathrm{~K}$ seeding level. Preliminary analysis of this data indicates that combustor seed utilization can be improved by increasing the amount of oxygen injected with the seed. This additional oxygen serves to both increase the seed injection velocity as well as increase the local temperature in the affected region. Combustor heat losses, however, were also found to increase with increased seed oxygen flow. Additional tests are planned during the fall 1991 test series to further investigate this trade-off and to deternine the best operating conditions at the $1 \% \mathrm{~K}$ seeding level.

A comprehensive evaluation of the combustor slag rejection requirement and the implications on combustor design and operation continued during the quarter. As part of this effort, improvernents were made to an existing analytical model of the slag rejection process which compares favorably with experimental data. The results of this study will be presented in a separate topical report. Included in this report will be a number of recommendations for future tests at the CDIF to improve the overall level of combustor slag rejection. The first series of tests involves combustor operational changes and is expected to be conducted during the fall 1991 test series. The remaining tests, which involve combustor design modifications, are expected to be conducted as part of POC design verification and duration testing.

A continuing effort is underway to improve the accuracy and repeatability of analyses of coal and slag samples taken at the CDIF. Accurate sampling of both coal and slag is critical to the evaluation of combustor performance in terms of combustion efficiency, slag rejection, and heat loss. As part of this effort. TRW has provided MSE with an updated list of recommended coal and slag sampling procedures to be evaluated during the fall 1991 test series.

Test planning support for the upcoming test series at the CDIF included: the formulation of a modified coal and air split calibration procedure to be performed prior to hot-fire testing; selection of operating conditions, test sequences, and data requirements for each individual test of the test series; and the recommendation of high speed data measurements to help isolate the cause of high frequency load current oscillations that have been previously observed during MHD power train testing at the CDIF. 


\section{TTIRC AND POC INTEGRATION TASK FORCE ACTIVITIES (TASK 8)}

The Task 8 activities of the ITC program relate to the operation of the MHD Technology Transfer, Integration and Review Committee (TTIRC) and TRW's mole in ensuring the integration of the three POC programs: Integrated Topping Cycle, Integrated Bottoming Cycle and Seed Regeneration Process. The integration function is the responsibility of the POC Integration Task Force.

The Power Management Working Group (an ad-hoc committee of the POC Task Force) activities continued during the reporting period. The working group is responsible for the integration of the subsystems which comprise channel power management. Meetings were held at TRW on 1 August and 12 October to re-evaluate the PTO configurations as a result of two new system level requirements:

- Protection of the consolidation circuity against reverse voltage.

- Distribution of excess current into the indirectly controlled electrode(s) resulting from high speed load current fluctuations.

As a result, a modified indirectly controlled electrode concept and additional PTO circuitry have been proposed.

The draft fifth and sixth semi-annual status reports have been approved for final distribution. Final distribution is expected early in the next reporting period.

Preparation of the draft seventh semi-annual status report is in progress. Distribution to the DOE and the TTIRC Executive Committee for review is expected in December. 


\section{PLANNED ACTIVITIES}

\section{Task 1}

- Maintain the detailed, integrated schedule for the manufacturing phase of the program.

- Release the CADM controlled version of the Interface Document.

- Complete the Test Plan for the POC testing.

- Continue to work the interface and integration issues related to the High Voltage Room (HVR) modifications required for the $1 \mathrm{~A} 4$ installation.

- Provide data analysis support for the upcoming test series, including evaluation of:

- Coal and air split calibration results

- Prototypical second stage operation

- Long duration slag rejector and removal system operation under power generating conditions

- High speed load current fluctuations

- Long duration precombustor operation

- Combustor slag rejection and seed utilization performance

- Effect of additional coal fines on power train performance

- Issue topical report on combustor slag rejection.

\section{Task 2}

- Complete manufacturing of LPCS.

- Complete manufacturing of all prototypical combustor components.

- Combustor assembly will be close to completion with most. of the panels welded in place.

\section{Task 3}

- Complete assembly of sidewall 1 and continue assembly of sidewall 2 .

- Initiate hosing and manifolding of sidewalls 1 and 2 .

- Complete fabrication of anode electrodes and initiate assembly of wall.

- Complete fabrication of channel inlet frame.

\section{Task 4}

- Complete design and procure materials for aft diffuser.

\section{Task 5}

- Complete construction of the current consolidation subsystem, in particular, the building of controls and system testing.

\section{Task 6}

- Complete the following facility upgrades:

- DAS (data acquisition system)

- Oxygen system

- Phase III slag removal installation 
- Magnet repair

- LPCS installation

- Perform the following required testing prior to prototypical component installation:

- Evaluate the channel power takeoff configuration including the TDS current controls as current consolidation and the simulated segmented diffuser and nozzle

- Slag rejector/removal system design verification testing

- Evaluate the impact on power train performance when coal fines from the baghouse are reincorporated into the main run coal

- Recalibration of the precombustor and main stage coal flow meters

- Rectangular second stage performance characterization

\section{Task 8}

- Complete final distribution of fifth and sixth semi-annual status reports of the MHD TTIRC activities.

- Prepare draft copy of seventh semi-annual status report for distribution to DOE and TTIRC Executive Committee. 


\section{SUMMARY}

Manufacturing of the prototypical combustor pressure shell and of forty-five cooling panels has been completed including checkout. All precombustor internal components (combustion can, baffle and swirl box) were received and checked, and integration of the components was initiated. Manufacturing of all other lead items is well in progress including the LPCS. Design of the servicing platforms and LPCS/combustor connecting piping was completed.

The assembly of the channel related prototypical hardware continued. The cathode wall electrical wiring is now complete. Sidewall assembly is well underway. A decision was made to utilize the copper-base sidewall elements as the primary design and the tungsten-copper base elements as the backup. Both primary and backup design elements will be included in the initial channel build for DVT testing. Anode cap subassemblies are presently undergoing braze attachment of the platinum top caps to the tungsten substrates.

The mechanical design of the diffuser has been completed. The forward supersonic diffuser section in the 1A4 channel is a new design and it features electrical segmentation to minimize current circulation. The three remaining diffuser sections (i.e., aft supersonic, forward subsonic, and aft subsonic) will be the standard copper design constructed by modifying the existing 1B2 diffuser.

Construction of the diode stack was completed, and the stack was delivered to the CDIF site where it will be installed to support the fall test series. Construction of the power cabinets continues with installation of shelving for the switch modules.

Activities at the CDIF focused on the installation of new power train components and on facility upgrades to support long duration testing. No testing of the power train was conducted. Workhorse power train testing is currently scheduled to begin in late November 1991 and will continue through January 1992. The total number of test hours (thermal) during this test series will be restricted in order to comply with an emission ceiling on carbon monoxide production (250 tons/year) at the CDIF.

Power train modeling and performance analysis activities were focused on the following areas: analysis of seed utilization tests conducted in May 1991; evaluation of the combustor slag rejection requirement; evaluation of coal and slag sampling procedures at the CDIF; and general test planning support for the fall 1991 test series at the CDIF.

The Power Management Working Group met to re-evaluate the PTO configurations as a result of new system level requirements. As a result, a modified indirectly controlled electrode concept and additional PTO circuitry have been proposed. 


\section{QUARTERLY REPORT DISTRIBUTION LIST \\ Required U.S. Department of Energy Distribution}

Dr. Harold Chambers

Technical Project Office

PM-40, MS 922-206

U.S. Department of Energy

Pittsburgh Energy Technology Center

P.O. Box 10940

Pittsburgh, PA 15236

Ms. Debra Ball

Contracting Officer

AD-22, MS 921-165

U.S. Department of Energ

Pittsburgh Energy Technology Center

P. O. Box 10940

Pittsburgh, PA 15236

Dr. Victor Der

U. S. Department of Energy

Office of Fossil Energy

FE-32

Washington, DC 20545

General Counsel for Patents

U.S. Department of Energy

Chicago Operations Office

9800 3outh Cass Avenue

Argonne, IL 60439

U.S. Department of Energy *

Office of Technology Transfer

P. O. Box 10940, MS 922

Pittsburgh, PA 15236

* First obtain clearance from Office of Patent Counsel, Chicago, then mail copies to OTT with statement, "Patents Cleared by Chicago Office of Patent Counsel on _(nsert Date) ". 


\section{Additional Distribution}

Dr. William Swift

Argonne National Laboratory

9700 South Cass Avenue

Argonne, IL 60439

Dr. R. Kessler

Avco Research Laboratory

2385 Revere Beach Parkway

Evereth, MA 02149

Mr. John Rackley

Babcock \& Wilcox

1562. Beeson Street

Alliance, $\mathrm{OH} 44601$

Dr. J. L. Bates

Battelle Pacific Northwest L.abs

PSL Building 3000 Area

Box 999

Richland, WA 99352

Dr. Bert Zauderer

Coal Tech Corporation

P. O. Box 154

Merion Station, PA 19066-0154

Mr. R. King

U.S. Department of Energy

Butte Project Office

P.O. Box 3462

Butte, MT 59702

Mr. G. Staats

U.S. Department of Energy

Pittsburgh Energy Technology Center

P.O. Box 10940, PM-20/MS 922-208

Pittsburgh, PA 15236

Dr. R. Rosa

Montana State University

Department of Mechanical Engineering

Bozeman, MT 59715

Mr. L. Farrar

Montec Associates

P.O. Box 4182

Butte, MT 59702
Mr. Norm Swift

U.S. Department of Energy

Chicago Operations Office

9800 South Cass Avenue

Argonne, IL 60439

Dr. R. A. Carabetta

U.S. Department of Energy

Pittsburgh Energy Technology Center

P.O. Box 10940

Pittsburgh, PA 15236

Mr. Leo Makovsky

U.S. Department of Energy

Pittsburgh Energy Technology Center

P. O. Box 10940, MS 922-206

Pittsburgh, PA 15236

Dr. A. Cohn

Electric Power Research Institute

P.O. Box 10412

3412 Hillview Avenue

Palo Alto, CA 94303

Mr. A. C. Dolbec

Electric Power Research Institute

P. O. Box 10412

3412 Hillview Avenue

Palo Alto, CA 94303

Dr. William Owens

Gilbert/Commonwealth, Inc.

19664 Club House Road, Suite 820

Gaithersburgh, MD 20879

Dr. Peter Marston

MIT/Plasma Fusion Center

175 Albany Street

NW17-207

Cambridge, MA 02139

Dr. W. S. Shepard

Mississippi State University

D.I.A.L.

P.O. Drawer MM

Mississippi State, MS 39762

Dr. C. Kruger

Stanford University

Terman Mech. Eng., Room 214

Stanford, CA 94305 
Mr. Stephen Myrick

TRW

P.O. Box 3767

Industrial Park

Butte, MT 59702

Mr. G. Funk

MSE, Inc.

P.O. Box 3767

Industrial Park

Butte, MT 59702

Mr. J. Sherick

MSE, Inc.

P.O. Box 3767

Industrial Park

Butte, MT 59702

MSE, Inc.

P.O. Box 3767

Industrial Park

Butte, MT 59702

Attn: Librarian

Dr. W. Thielbahr

U.S. Department of Energy

Idaho Operations Office

785 Doe Place

Idaho Falls, ID 83402

Mr. L. Kovalsky

Westinghouse Electric Corp.

Research and Development Center

1310 Beulah Road

Pittsburgh, PA 15235

Mr. M. Tuck

MSE, Inc.

P.O. Box 3767

Industrial Park

Butte, MT 59702

Dr. Bob Wright

U. S. Department of Energy

Office of Fossil Energy

FE-32

Washington, DC 20545

Dr. Joel Muehlhauser

Univ. of Tennessee

Space Institute

Tullahoma, TN 37388
Mr. S. Demetriades

STD Corporation

P.O. Box "C"

Arcadia, CA 91006

Mr. C. Maxwell

STD Corporation

P.O. Box "C"

Arcadia, CA 91006

Mr. N. Johanson

University of Tennessee Space

Institute

Tullahoma, TN 37388

Dr. Susan Wu

Engineering Research and

Consulting, Inc.

P. O. Box 417

Tullahoma, TN 37388

Mr. L. Van Bibber

Westinghouse Electric Corporation Advanced Energy Systems Division P.O. Box 10864

Pittsburgh, PA 15236

Mr. W. Irving

WMI, Inc.

236 N. Falmouth Highway

North Falmouth, MA 02556

Dr. Carl C. P. Pian

Avco Research Laboratory

2385 Revere Beach Parkway

Everett, MA 02149

Mr. J. M. Bauer

TRW Space and Technology Group

One Space Park, 01/1160

Redondo Beach, CA 90278 


\section{APPENDIX A. NOMENCLATURE}

\section{Abbreviations}

1. AIC - Ash Injected Combustor

2. CDIF - Component Development and Integration Facility

3. CDR - Critical Design Review

4. CFC - Coal-Fired Combustor

5. CFPC - Coal-Fired Precombustor

6. CTS - Capistrano Test Site (TRW)

7. DCT - Design Confirmation Test

8. DOE - Department of Energy

9. DVT - Design Verification Test

10. FETS - Fossil Energy Test Site (TRW)

11. GOX - Gaseous oxygen

12. ITC - Integrated Topping Cycle

13. MEF - Material Evaluation Fixture

14. OFV - Oil-Fired Vitiator

15. PDR - Preliminary Design Review

16. POC - Proof-of-Co ıcept

17. PRD - Project Requirements Document

18. PEM - Performance Evaluation Module

19. TTIRC - Technology Transfer, Integration and Review Committee

\section{Symbols}

20. $\beta$ - Beta - Hall parameter

21. $\delta$ - Boundary layer thickness (Meters)

22. $\sigma$ - Plasma Conductivity (Mhos/m) - There are several definitions for plasma conductivity, as follows:

1. Mid-channel conductivity - the conductivity at the channel mid-point determined experimentally from a plot of conductivity vs. channel axial length. This is the conductivity riost often used in presenting test results. Unless otherwise specified, $\sigma$ refers to this conductivity.

2. Inlet conductivity - the conductivity at the channel inlet. This parameter can be determined experimentally by extrapolating the conductivity vs. channel length curve to zero.

3. Bulk conductivity - the conductivity determined in the $1 \mathrm{~A} 1$ channel at CDIF by taking the voltage drop divided by the current. This parameter is available on-line and is used to spot conductivity changes during testing.

4. PEM conductivity - the conductivity measured at the Performance Evaluation Module at CrS at subsonic (stagnation) conditions.

23. $\phi_{01}$ - Precombustor Equivalence Ratio - Ratio of oxygen input to the coal-fired precombustor combustion chamber to stoichiometric oxygen required for complete combustion of fuels. 
24. 1 - First Stage Equivalence Ratio - Ratio of oxygen input to the first stage to stoichiometric oxygen required for complete combustion of fuels.

25. $\$ 2$ - Overall Equivalence Ratio - Ratio of total oxygen inputs to stoichiornetric oxygen required for complete combustion of fuels.

26. AR - Aspect Ratio - The height $H$ (anode to cathode distance) divided by the width $D$ (sidewall to sidewall distance) of the channel

27. B - Magnetic field (Tesla)

28. $E_{\mathrm{X}}$ - Axial electric field (volts/m)

29. Ie - Electric current (amps)

30. ISC - Short circuit current (amps)

31. Ix - Axial current (amps)

32. I leak - Constant current leakage that is proportional to the Hall voltage (relating to cathode wall nonunifonnities, plasma nonuniformities, and/or voltage drops) (amps).

33. Jy - Faraday current density (amps/cm²)

34. \%K - Amount of potassium injected as a percent of total mass flow through power train.

35. L/D - Length -to-hydraulic diameter ratio (second stage)

36. $M W_{e}-$ Electric megawatts (power output)

37. MWt - Thermal megawatts (heat input rate)

38. N/O - Molar ratio of nitrogen to oxygen inputs (all input streams).

39. Novlp - Number of overlapped electrodes in channel.

40. $\quad \mathrm{P}$ - electrode pitch (m)

41. $\mathrm{Pb}$ - bumer pressure (atm)

42. $P_{\text {diss }}$ - Power dissipated in ballast resistors (watts)

43. R-Resistance between shorted cathode gaps Johms/gap)

44. $R_{\text {ieak }}$ - An end-to-end resistance that is independent of Hall voltage (i.e., current transport through the liquid slag layer) (ohms/gap).

45. Rlink - Resistance value of link resistor (ohms)

46. T250 - Temperature at which slag viscosity equals 250 poise

47. $\mathrm{V}_{\boldsymbol{X}}$ - Open-circuit voltage (volts)

48. $\Delta \mathrm{V}$ - Transverse voltage drep (e.g., $\Delta \mathrm{V}_{\mathrm{bl}}$ - across boundary layer) (volts)

\section{Definitions}

49. Heat Flux - Heat loss per unit area (watts $/ \mathrm{cm}^{2}$ ).

50. Heat Loss - Sensible heat loss to cooling circuits, usually stated as a percent of total thermal input to the combustor.

51. Slag Recovery . Weight of dry slag collected in slag tank. as a percentage of dry, $\mathrm{SO}_{3}$-free ash fed to the combustor ( $\mathrm{SO}_{3}$ is volatile and is not found in the slag).

52. Weight Percent Oxygen in First Stage (wt. $\% \mathrm{O}_{2}$ ) - Weight percent of oxygen in vitiated gases entering combustor first stage. 

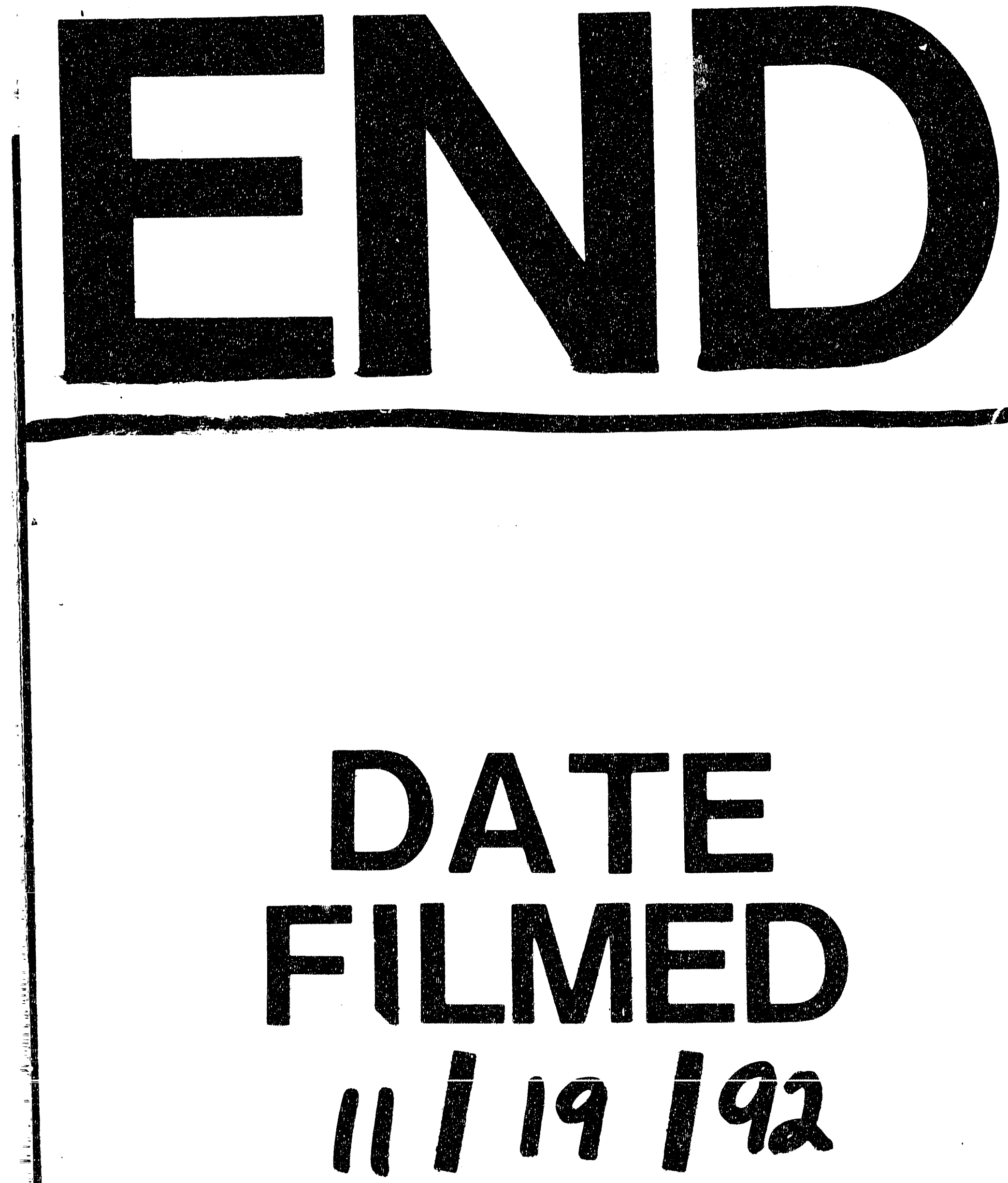


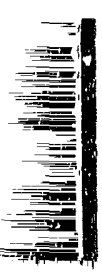

